\title{
INFLUÊNCIA DOS CUSTOS DE COMERCIALIZAÇÃO E DOS SUBPRODUTOS SOBRE A MARGEM DE COMERCIALIZAÇÃO DA CARNE BOVINA
}

JOSÉ LUIZ PARRÉ

Engenheiro Agrônomo

:

Orientador: Prof. Dr. GERALDO S. A. DE CAMARGO BARROS

Dissertação apresentada à Escola Superior de Agricultura "Luiz de Queiroz", da Universidade de São Paulo, para obtenção do título de Mestre em Agronomia, Área de Concentração: Economia Agrária.

PIRACICABA

Estado de São Paulo - Brasil

Novembro - 1995 
Dados internacionais de Catalogação na Publicação (CIP)

Divisão de Biblioteca e Documentação - CAMPUS "LUIZ DE QUEIROZ"/USP

Parré, José Luiz

Influência dos custos de comercialização e dos subprodutos sobre a margem de comercialização da carne bovina. Piracicaba, 1995.

$86 p$.

Diss. (Mestre) - ESALQ

Bibliografia.

1. Carne bovina - Comercialização - Margem 2. Carne bovina - Custos São Paulo (Estado) 3. Carne bovina - subproduto - Preço 4. Modelo econôni co 1. Escola Superior de Agricultura Luiz de Queiroz, Piracicaba 


\title{
INFLUÊNCIA DOS CUSTOS DE COMERCIALIZAÇÃO E DOS SUBPRODUTOS SOBRE A MARGEM DE COMERCIALIZAÇÃO DA CARNE BOVINA
}

\author{
JOSÉ LUIZ PARRÉ
}

Aprovada em 10.11.1995

Comissão julgadora:

Prof. Dr. Geraldo S. A. de Camargo Barros

ESALQ/USP

Prof. Dr. Joaquim Bento de S. Ferreira F ESALQ/USP

Dr. Flávio Condé de Carvalho

IEA/SAASP

Prof. Dr. Geraldo S

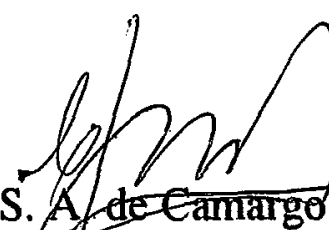


À memória de meu pai

JOSÉ PARRÉ

DEDICO

À minha mãe

LEONOR E. PARRÉ OFEREÇO 


\section{AGRADECIMENTOS}

Sou grato ao Professor Geraldo S. A. de Camargo Barros, pela dedicada e eficiente orientação oferecida.

Aos Professores Joaquim Bento de Souza Ferreira Fº Mírian Rumenos Piedade Bacchi, e ao pesquisador Dr. Flávio Condé de Carvalho, pelas inúmeras sugestões.

Agradeço ao Departamento de Economia e Sociologia Rural da ESALQ/USP, que me possibilitou frequentar o curso de Pós-graduação em Economia Agrária.

Aos professores e funcionários do DESR, que direta e indiretamente colaboraram com esta pesquisa.

Aos colegas do curso pelo estímulo e apoio na realização deste trabalho.

Ao CNPq, pela Bolsa de Estudos que possibilitou minha participação no curso de mestrado.

Agradeço a Rosana pela paciência e carinho em todos os momentos. 


\section{SUMÁRIO}

Página

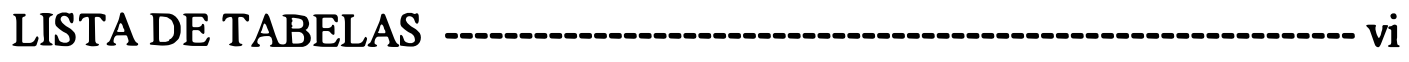

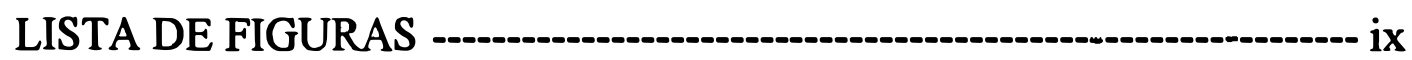

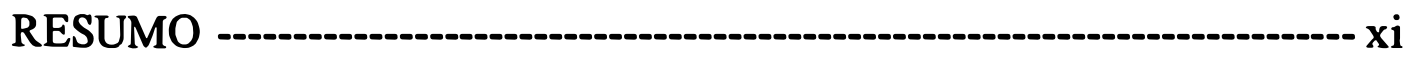

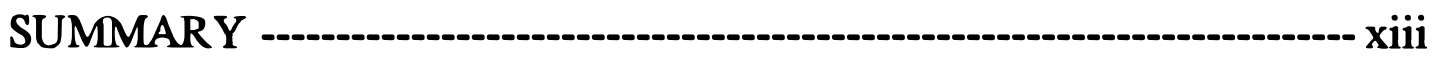

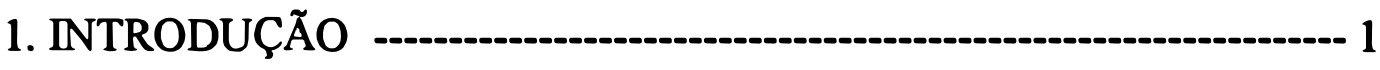

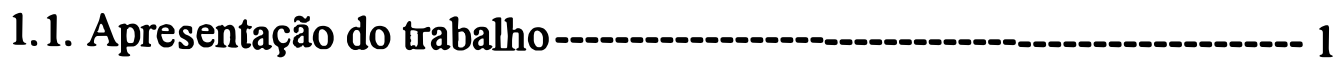

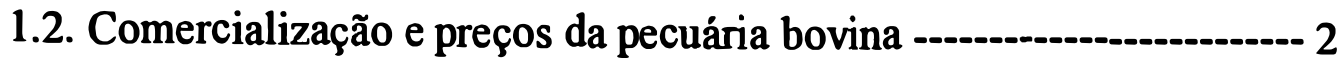

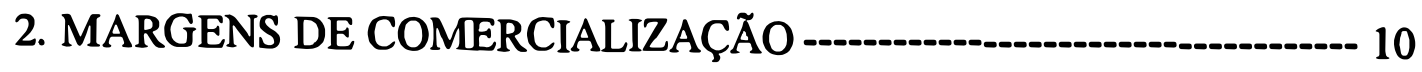

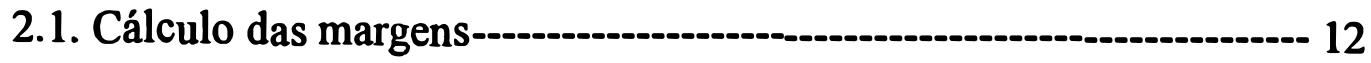

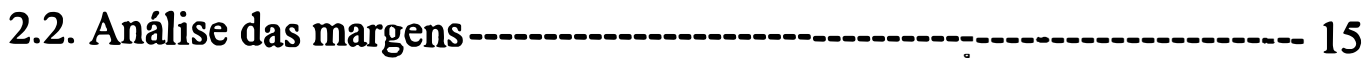

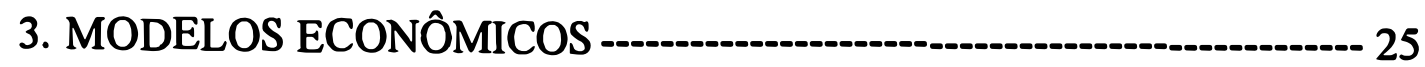

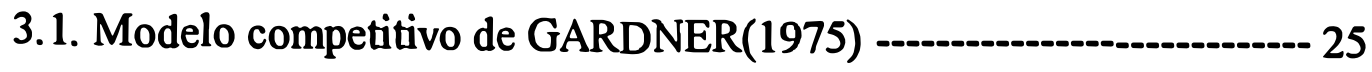

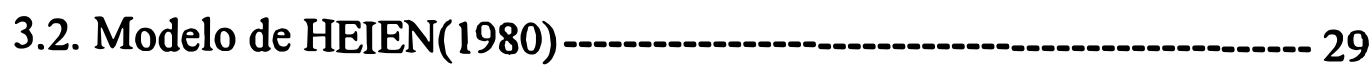

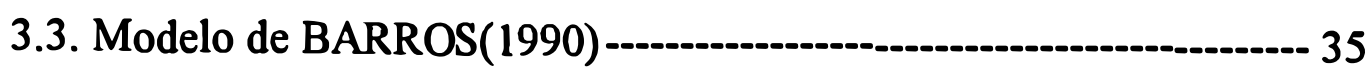

4. MODELO PROPOSTO

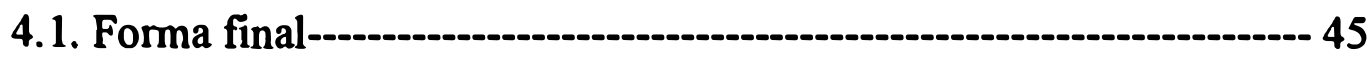




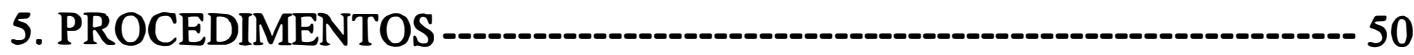

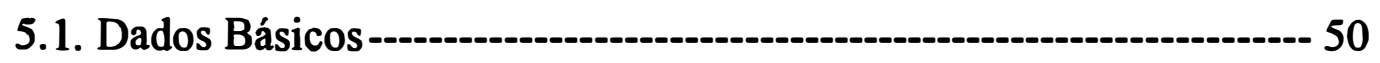

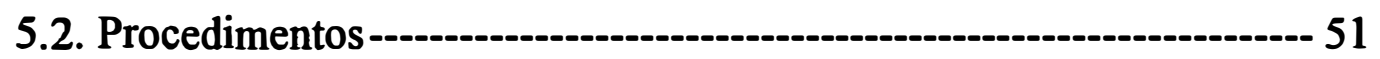

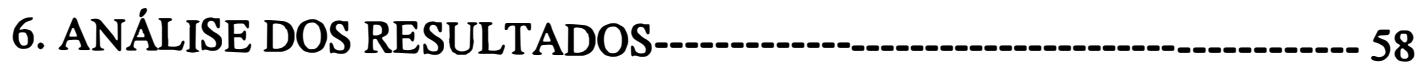

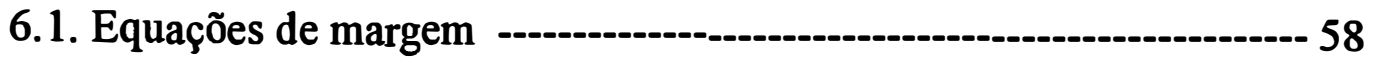

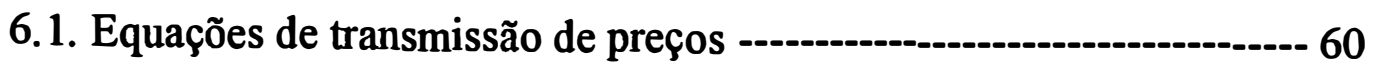

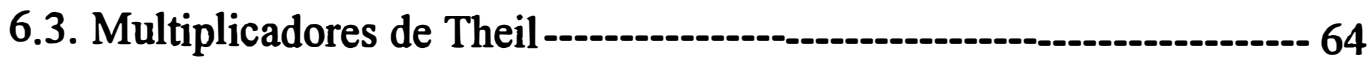

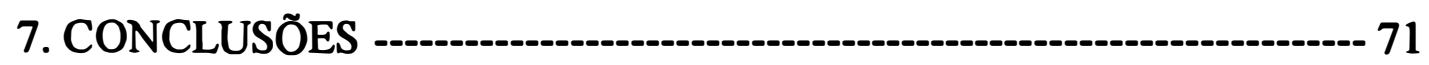

BIBLIOGRAFIA -------------------------------------------------------------------- 75

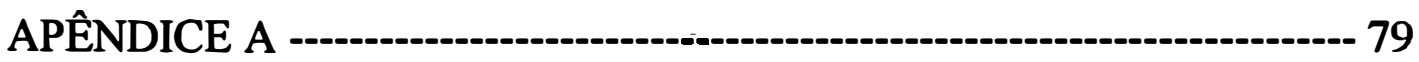

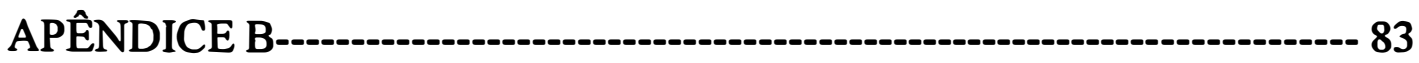




\section{LISTA DE TABELAS}

Tabela $\mathbf{n}^{\circ}$

Página

1. Número de estabelecimentos que possuem bovinos e a área ocupada, estado de São Paulo, 1985

2 Brasil: Distribuição regional dos matadouros e frigoríficos e razão de concentração da capacidade instalada de abate, $1983 / 1994$

3 Distribuição percentual entre os locais de compra das carnes, cidade de São Paulo, 1987

4 Estrutura utilizada no cálculo das margens de comercialização de carne bovina, sendo que os preços correspondem a valores médios, ao nível de atacado, para o mês de janeiro de 1986 a 1993

5 Participação da carcaça, dos subprodutos comestíveis, dos subprodutos não comestiveis e dos subprodutos totais; em porcentagem, na constituição do valor do boi comercializado ao atacado. Março de 1986 a dezembro de 1993

6 Parcelas e margens porcentuais de comercialização de carne bovina. Médias mensais (1986/1993), em \%

7 Estimativas dos modelos estruturais de margem de 
comercialização total, do varejo e do atacado; da carne bovina no estado de São Paulo; dados mensais de 1986 a 19993

8 Estimativas do ajustamento em dois estágios das equações simultâneas dos preços aos níveis de produtor, atacado e varejo; no mercado de carne bovina no estado de São Paulo;dados mensais de 1986 a 1993 63

9 Estimativas das equações reduzidas da margem total e dos preços aos níveis de produtor, atacado e varejo; utilizando método SUR; no mercado da carne bovina no estado de São Paulo; dados mensais de 1986 a 1993 65

10 Efeito dos choques nas variáveis exógenas sobre a margem total de comercialização da carne bovina multiplicadores de THEIL $-69$

11 Efeito dos choques nas variáveis exógenas sobre os preços ao varejo da carne bovina - multiplicadores de THEIL

12 Efeito dos choques nas variáveis exógenas sobre os preços ao produtor da carne bovina - multiplicadores de THEIL 
13 Efeito dos choques nas variáveis exógenas sobre os preços ao atacado da carne bovina - multiplicadores de THEIL 70

B.1 Parcelas e margens porcentuais de comercialização de carne bovina. Dados mensais de março de 1986 a dezembro de 1993, em \% -..-...- 84 


\section{LISTA DE FIGURAS}

Figura $\mathbf{n}^{\circ}$

Página

1 Subprodutos para o cálculo de margens de comercialização

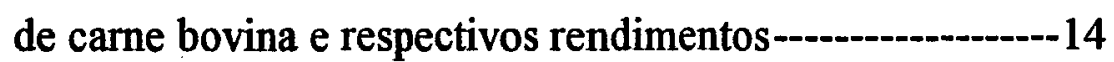

2 Parcela porcentual do atacado e margem porcentual do atacado de carne bovina para o Estado de São Paulo. Médias mensais (1986/1993) $-20$

3 Parcela total e margem total de comercialização de carne bovina para o Estado de São Paulo. Em porcentagem. Médias mensais (1986/1993) $-20$

4 Parcela porcentual do atacado (atac/sem) e margem porcentual do atacado (atac/com) de carne bovina para o Estado de São Paulo. Valores mensais de 1986 a1993

5 Índices da participação da carcaça, dos subprodutos comestiveis e dos subprodutos não comestiveis no valor do boi ao atacado. Mês base: março de 1986 $-21$

6 Preços médios mensais de carne bovina recebidos pelos produtores do Estado de São Paulo; atacadistas e varejistas da cidade de São Paulo, em R\$/kg, 1986/1993 
7 Preços médios anuais da carne bovina recebidos pelos produtores do Estado de São Paulo; atacadistas e varejistas da cidade de São Paulo, em R\$/kg, 1986/1994. Obs: Os preços de 1994 são a média até julho---------------22

8 Preços médios mensais do varejo da cidade de São Paulo e margem total absoluta (médias mensais) do Estado de São Paulo, em R\$/kg, 1986/1993 - -

9 Preços médios anuais do varejo da cidade de São Paulo e margem total absoluta (médias anuais) do Estado de São Paulo, em R\$/kg, 1986/1993

10 Preços médios mensais dos subprodutos comestiveis, dos subprodutos não comestíveis e do preço ao varejo da carne bovina, em R\$/kg, 1986/1993 -

11 Preços médios anuais dos subprodutos comestíveis, dos subprodutos não comestíveis e do preço ao varejo da carne bovina, em R\$/kg, 1986/1993 - 


\title{
INFLUÊNCIA DOS CUSTOS DE COMERCIALIZAÇÃO E DOS SUBPRODUTOS SOBRE A MARGEM DE COMERCIALIZAÇÃO DA CARNE BOVINA
}

\author{
autor: JOSÉ LUIZ PARRÉ \\ orientador: PROF. DR. GERALDO S.A. CAMARGO BARROS
}

RESUMO:

O objetivo central deste trabalho foi examinar o impacto dos preços dos subprodutos obtidos ao atacado e dos custos de comercialização na formação da margem de comercialização no mercado de carne bovina no Estado de São Paulo. Foram utilizados dados mensais de preços da carne aos níveis de produtor,atacado e varejo; preços dos subprodutos obtidos ao atacado; preços do óleo diesel, saláriomínimo e taxa de juros. O período considerado foi março de 1986 a junho de 1994.

Primeiramente, caracterizou-se o processo de comercialização da carne bovina e também as oscilações de preços que ocorrem neste mercado. Além disso, realizou-se uma análise dos comportamentos dos preços e das margens de comercialização nos diversos níveis do mercado. Observou-se que, quando se considera os subprodutos, a participação do setor atacadista na margem de comercialização aumenta consideravelmente. Também percebe-se uma tendência de queda dos preços reais durante o período analisado.

As margens mensais totais de comercialização da carne bovina foram calculadas em valores absolutos (em valores de junho de 1994) e porcentualmente (em relação ao preço de varejo). O valor médio obtido para a margem total absoluta foi de $\mathrm{R} \$ 1,47 / \mathrm{kg}$ e para a margem total relativa foi obtido $49,95 \%$ (quando não se considera os subprodutos esses valores são $\mathrm{R} \$ 1,24 / \mathrm{kg}$ e $42,10 \%$, respectivamente). 
O modelo teórico desenvolvido neste trabalho foi baseado no modelo de BARROS (1990), sendo que a principal mudança foi a consideração no modelo dos subprodutos obtidos ao nível de atacado. A partir desse modelo estrutural foram desenvolvidas todas as equações de preços e de margens utilizadas no estudo.

As equações de margem total, ao atacado e ao varejo foram estimadas por mínimos quadrados ordinários; as equações de preços foram estimadas por minimos quadrados em dois estágios e as equações de preços e margem total foram estimadas pelo método SUR. A análise dinâmica foi realizada por meio dos multiplicadores de Theil.

Os resultados das estimações mostram que os impactos causados pelos preços dos diferentes níveis de mercado sobre as margens de comercialização predominam sobre os impactos causados pelos insumos de comercialização. Também foi constatada a importância da consideração dos subprodutos nos estudos de margem de comercialização. 


\title{
EFFECTS OF MARKETING COSTS AND BYPRODUCTS ON BEEF MARKETING MARGINS
}

\author{
author: JOSÉ LUIZ PARRÉ \\ adviser: PROF. DR. GERALDO S.A. CAMARGO BARROS
}

\section{ABSTRACT:}

The main objective of this study is to determine the impact of marketing costs and byproducts at the wholesale level on the marketing margin formation in the São Paulo beef market. Monthly data on producer, wholesale and retail beef prices, as well as prices of byproducts at the wholesale level, diesel fuel prices, minimum wage and interest rates were used. The time period considered in the study goes from march 1986 to june 1994.

First, the beef marketing process and the price variations in the São Paulo beef market were characterised. In addition, an analysis of price and marketing margins behavior at different market levels was carried out. It was observed that when byproducts are considered into analysis, participation of wholesale in the marketing margin increases significatively. A diminishing trend in real beef prices was also noted during the study time period.

The monthly total marketing margins were estimated in absolute terms (at constant june 1994 prices) as well as in the relative terms (in relation to retail prices). The mean estimated value for the absolute total margin is $\mathrm{R} \$ 1,47 / \mathrm{kg}$ and for 
the total relative margin it is $49,95 \%$ (when byproducts are not considered into calculations, those values drop to $\mathrm{R} \$ 1,24 / \mathrm{kg}$ and $42,10 \%$, respectively).

The teoric model developed in this study is based on the BARROS(1990) model, the inclusion of byproducts at the wholesale level beeing the main model modification. From that structural model, all the price and margin equations used in the study were developed.

The total wholesale and retail margin equations were estimated using ordinary least squares procedures. The price equations were obtained using two stage least squares and the price and total margin equations were estimated using the SUR method. The dinamyc analysis was performed using the Theil's multiplicators method.

The results show that the impacts caused by different market level prices on marketing margins are higher than the impacts caused by the marketing inputs. The importance of considering byproduct effects in marketing margin studies was also verified. 


\section{INTRODUÇÃO}

\subsection{Apresentação do Trabalho}

O objetivo principal dessa pesquisa é estudar as margens de comercialização no mercado de carne bovina, levando em conta os valores dos subprodutos obtidos no processamento e comercialização da mesma.

A relevância do estudo decorre da importância econômica representada pelos subprodutos do processamento do boi, os quais são em geral desconsiderados nos estudos da margem. Como consequência, não é raro encontrar estudos - BLISKA , 1989 , por exemplo - em que, por dificuldade na obtenção de dados necessários, se detectam margens muito pequenas e, as vezes, negativas ao atacado, sugerindo que tal segmento chega a operar com prejuizo em certas ocasiões. De qualquer forma, a omissão do valor de subprodutos pode levar a resultados enganosos. Além disso, como atualmente existe disponibilidade satisfatória de dados sobre subprodutos, não se justifica mais a desconsideração dos mesmos em análises da comercialização do boi e seus derivados.

Especificamente, pretende-se realizar um estudo detalhado da obtenção e comercialização dos subprodutos gerados ao nível de atacado e também avaliar a importância desses subprodutos na formação das margens de comercialização no 
mercado de carne bovina, ao lado de outros fatores ligados à oferta e à demanda desse produto.

A obtenção da carne é o objetivo principal do abate de bovinos. Entretanto, são obtidos outros produtos além da carne, sendo estes, denominados de subprodutos. Segundo ENSMINGER (1973), no início da indústria frigorífica, os únicos subprodutos que se aproveitavam eram o couro, a lã ${ }^{1}$, o sebo e a língua. Os outros subprodutos eram jogados em rios, queimados ou enterrados. Com o passar do tempo, apareceram nas imediações dos frigorificos fábricas que elaboravam cola, fertilizantes, sabão, botões e outros subprodutos.

Alguns destes estabelecimentos estavam integrados com o frigorífico; outros eram indústrias independentes. Então, grande parte do que antes era considerado desperdício, se converteu em produtos valiosos.

Atualmente, além dos subprodutos que se obtinha no início da indústria frigorífica, o abate de bovinos produz cerca de 80 subprodutos que têm grande variedade de aplicações.

Este trabalho utiliza e analisa os preços dos principais subprodutos bovinos aproveitados no Brasil. A caracterização destes subprodutos é feita no apêndice $\mathrm{A}$.

\subsection{Comercialização e preços da pecuária bovina}

Os produtos agrícolas podem apresentar mercados competitivos, no caso de existir um grande número de vendedores e de compradores com informações

\footnotetext{
1 ENSMINGER se refere à indústria frigorifica em geral, incluindo bovinos, suinos e ovinos. Neste caso, a lä é subproduto dos ovinos.
} 
sobre o mercado, negociando mercadorias razoavelmente homogêneas. No caso do produto agrícola ser matéria prima de uma agroindústria, pode ocorrer que um grande número de produtores agrícolas se defrontem com um número reduzido de compradores. A pulverização da produção agrícola faz com que os produtores do setor sejam, de maneira geral, passivos à formação dos preços, sujeitando-se ao. preço estabelecido no mercado (KASSOUF, 1988).

O setor de bovinocultura é formado por empresas na sua maioria tradicionais em termos tecnológicos. FERNANDES (1988) citando Prodiat ${ }^{2}$ afirma que o rebanho brasileiro não tem obtido resultados tecnológicos expressivos e a absorção de tecnologia não tem sido uniforme para as diferentes zonas criatórias, cujas desigualdades se acentuam à medida que os preços relativos na agricultura vão se modificando. No entanto, nas áreas de influência dos frigoríficos ligados aos grandes centros urbanos, pode-se detectar certo grau de mudança tecnológica, mormente no que diz respeito ao melhoramento de pastagens e à especialização do rebanho.

O sistema de comercialização da carne bovina inicia-se a nível de produtor com a venda do boi gordo ao frigorifico, diretamente ou através dos "escritórios compradores" que são firmas especializadas em comprar bois gordos e que realizam esta atividade para vários frigoríficos ao mesmo tempo. Os agentes atacadistas são os frigoríficos, entrepostos e distribuidores. Os agentes varejistas são os açougues/casas de carne, supermercados e clientes institucionais (rede de hotéis e restaurantes, hospitais, etc.). As compras a nivel de atacado correspondem principalmente aos quartos de carcaça bovina (dianteiros e traseiros), sendo os cortes exigidos ao nível de consumidor realizados no próprio estabelecimento varejista (BLISKA, 1989).

2 PRODIAT. Estudo do mercado de carne bovina. Brasilia, 1985, 89 p. (Série Estudos e Pesquisas, 10). 
O mercado atacadista é constituído por pequeno número de agentes econômicos, opera com produtos considerados bons substitutos entre si e cuja diferenciação geralmente está ligada aos serviços e facilidades de venda que cada empresa oferece. Especializando-se no comércio de um número limitado de produtos, o setor aparenta deter volume maior e melhor de informações, ao contrário dos setores de produção e varejo, normalmente não especializados e/ou operando em pequena escala (BLISKA, 1989).

Em virtude disso, alguns autores têm apontado a existência de um sistema oligopsonista dos frigoríficos em relação aos produtores e oligopolista em relação aos varejistas (Mascolo e Adabo citados por BLISKA, 1989)³ .

Essa discussão sobre o comportamento do sistema de comercialização da carne bovina é importante visto que, a partir da observação deste comportamento serão elaboradas as hipóteses que definem como ocorrem as variações de preços nos diferentes níveis de mercado. E essas hipóteses fundamentarão o modelo teórico que será desenvolvido neste trabalho.

Em virtude disso serão apresentados alguns dados que caracterizam os segmentos do mercado. Iniciando-se pela tabela 1 , que apresenta o número dos estabelecimentos que possuem bovinos, pode-se observar o elevado número de propridades que praticam atividade pecuária e a grande área ocupada por estas propriedades, apenas no estado de São Paulo.

Através da tabela 2, que apresenta a distribuição regional dos frigoríficos e matadouros e a concentração da capacidade instalada de abate; pode-se observar a importância da região Sudeste no abate de bovinos no país. Segundo Moricochi et al. (1995), cerca de 90\% dos abates inspecionados em 1994 estão

\footnotetext{
3 ADABO, J. H. Análise dos preços de atacado e varejo da carne bovina na cidade de São Paulo. São Paulo, 1980, 145 p. (Mestrado - Escola de Sociologia e Politica de Sðo Paulo/USP).

MASCOLO, J.L. Um estudo econométrico da pecuária de corte no Brasil. Revista Brasileira de Economia. Rio de Janeiro, 33 (1): 65-105, jan./mar. 1979.
} 
concentrados nas regiões Sudeste, Sul e Centro-Oeste, sendo que a região Sudeste representa $44 \%$ dos abates do país e o estado de São Paulo responde por $25 \%$ da capacidade nacional.

Tabela 1: Número de estabelecimentos que possuem bovinos e a área ocupada, estado de São Paulo, 1985.

\begin{tabular}{c|c|c}
\hline Grupos de cabeças de bovinos & número de estabelecimentos & Área (ha) $^{*}$ \\
\hline menos de 10 & 36.094 & 765.061 \\
10 a menos de 20 & 24.961 & 816.058 \\
20 a menos de 50 & 35.746 & 1.781 .526 \\
50 a menos de 100 & 21.513 & 1.928 .659 \\
100 a menos de 200 & 13.427 & 2.239 .545 \\
200 a menos de 500 & 8.470 & 2.828 .862 \\
500 a menos de 1000 & 2.513 & 1.854 .241 \\
1000 a menos de 2000 & 1.047 & 1.391 .345 \\
2000 e mais & 446 & 1.445 .750 \\
\hline
\end{tabular}

Fonte: Censo Agropecuário - São Paulo (1985).

* Inclusive terras inaproveitáveis e outras atividades agropecuárias.

Tabela 2: Brasil: Distribuição regional dos matadouros e frigorificos e razão de concentração da capacidade instalada de abate, 1983/1994.

\begin{tabular}{l|c|c|c|c}
\hline \multirow{2}{*}{ Região } & \multicolumn{2}{|c|}{ Unidades Industriais } & \multicolumn{2}{c}{ Concentração (\%) } \\
\cline { 2 - 5 } & 1983 & 1994 & 1983 & 1994 \\
\hline Norte & 5 & 10 & 2 & 3 \\
Nordeste & 16 & 20 & 7 & 6 \\
Sudeste & 118 & 139 & 51 & 44 \\
Sul & 54 & 85 & 23 & 27 \\
Centro-Oeste & 40 & 63 & 17 & 20 \\
\hline Total & 233 & 317 & 100 & 100 \\
\hline
\end{tabular}

Fonte: Moricochi et al. (1995).

A tabela 3 mostra os locais onde os consumidores da cidade de São

Paulo adquirem a carne; baseado na despesa média mensal familiar, por locais de compra. Sendo que os estabelecimentos especializados são representados por açougues tradicionais. Vale ressaltar que os dados originais da tabela são baseados na pesquisa de orçamento familiar de 1987 e desde então pode ter havido alterações na composição, com aumento da participação dos supermercados. 
Tabela 3: Distribuição percentual entre os locais de compra das carnes.

\begin{tabular}{c|c|c|c|c|c}
\hline $\begin{array}{c}\text { Locais de } \\
\text { compra }\end{array}$ & $\begin{array}{c}\text { Bovina de } \\
\text { primeira }\end{array}$ & $\begin{array}{c}\text { Bovina de } \\
\text { segunda }\end{array}$ & $\begin{array}{c}\text { Suína } \\
\text { Armazém }\end{array}$ & $\begin{array}{c}\text { Carnes e pei } \\
\text { xes industr. }\end{array}$ & Frangos \\
\hline Est.especializado & 70,56 & 1,91 & 2,44 & 12,61 & 4,91 \\
Feira & 0,52 & 75,60 & 63,41 & 22,61 & 41,75 \\
Mercado & 1,57 & 1,44 & 4,88 & 4,35 & 14,74 \\
Supermercado & 24,22 & 1,44 & 1,22 & 3,04 & 2,81 \\
Vend. ambulante & 0,52 & - & 23,17 & 55,65 & 20,00 \\
Outros & 0,52 & - & 4,88 & 1,30 & 1,40 \\
\hline
\end{tabular}

Fonte: De Zen (1994).

Observando-se as tabelas de 1 a 3 nota-se que o setor atacadista é mais concentrado que os setores de produção e de varejo, possuindo assim mais facilidade de acesso a informações sobre os preços e elevada frequência de transações, o que dá condições ao setor de ajustar mais rapidamente os seus preços; enquanto que os outros setores ajustam seus preços com certa defasagem em relação ao atacado.

HADDAD (1993) demonstra que o conjunto dos índices zootécnicos do rebanho brasileiro é bastante desfavorável, levando a um baixo desempenho da pecuária de corte do país. Pode-se citar a nutrição inadequada, sanidade precária, baixa natalidade e elevada mortalidade como características notáveis quando se examinam os índices zootécnicos do Brasil.

Analisando a influência desse baixo desempenho no mercado de carne bovina nacional, observamos que este desempenho contribui, junto com outros fatores, para que o mercado apresente um caráter cíclico, com períodos de alta e de baixa dos preços, com correspondentes variações nas margens.

Existem dois tipos de oscilações na oferta de carne bovina; oscilações estacionais e oscilações plurianuais. As estacionais são decorrência do fenômeno da passagem da safra para a entressafra e as plurianuais são causadas pelo ciclo pecuário.

Essas oscilações têm sido descritas por diversos autores, entre eles: IGREJA (1987), KASSOUF (1988), BLISKA (1989) e MARQUES \& AGULAR (1993). Os ciclos plurianuais decorrem basicamente das expectativas das cotações 
do boi gordo no futuro. Se a tendência do preço do boi gordo for declinante e 0 pecuarista projetá-la para o futuro, não haverá estímulo para a produção e retenção de matrizes. Os produtores, necessitando cobrir seus custos e estando os preços baixos, levarão um maior número de animais ao abate, incluindo matrizes, o que acentuará a tendência de baixa nos preços pelo excesso de oferta. Contudo, esta matança indiscriminada de animais acarretará em algum tempo escassez de boi gordo, o que fará reverter a tendência, com alta nos preços. Havendo uma expectativa futura desta alta, a produção é estimulada e matrizes e bezerros serão retidos, reduzindo ainda mais a oferta de animais para abate, acentuando a tendência altista dos preços. Entretanto, futuramente esta retenção de animais ocasionará excesso de oferta e consequente declínio nos preços, dando início a nova fase de queda nos preços, e assim sucessivamente.

Em relação aos ciclos plurianuais, $\operatorname{HADDAD(1994)}$ recomenda as seguintes medidas: programas que visem estimular a precocidade dos animais, pois quanto maior a precocidade menor será a duração do ciclo pecuário; programas de incentivo à retenção de matrizes, procurando evitar o abate descontrolado de ventres e, em consequência, a futura escassez de boi gordo.

Outro tipo de variação que ocorre nos preços da pecuária de corte é a variação sazonal ou estacional, que se dá dentro de um mesmo ano. A sazonalidade ocorre devido a efeitos climáticos que provocam variações na capacidade de suporte das pastagens, originando dois períodos distintos, um de oferta abundante de animais e preços baixos, chamado safra, e outro de oferta reduzida e altos preços, conhecido como entressafra.

A partir de abril, com a diminuição das chuvas e da temperatura, a produção das pastagens cai significativamente na região Centro-Sul (responsável por quase $80 \%$ do rebanho nacional, segundo o censo agropecuário de 1985), o que provoca perda de peso dos animais criados em regime de pastos (maioria no Brasil), 
com consequente diminuição da quantidade oferecida para abate. Por outro lado, o período que vai de outubro a abril é caracterizado por chuvas e temperaturas elevadas na região Centro-Sul, fatores que favorecem o crescimento das pastagens nessa região. Com isso, a oferta de animais gordos deve crescer significativamente a partir de dezembro, já que cerca de dois meses são necessários para que os pastos se recuperem e os animais atinjam o peso necessário para o abate (acima de 15 arrobas de peso de carcaça) (MARQUES \& AGUIAR, 1993).

Algumas formas de se diminuir o efeito sazonal têm surgido mais recentemente, como a prática do confinamento dos animais durante a entressafra. Além disso, o governo procura, em alguns anos, comprar carne durante o período de safra para manter um estoque regulador, que seria desovado no pico da entressafra (setembro a novembro) (MARQUES \& AGUIAR, 1993).

Esses dois efeitos (cíclico e sazonal) fazem com que os preços do setor apresentem grandes flutuações. Grande esforço tem sido feito no campo de pesquisa científica no sentido de explicar e medir essas variações de preços. Se, por exemplo, essas variaçõ̀es de preços apresentarem intensidades diversas em níveis diferentes de mercado (varejo, atacado e produtor), ocorrerão mudanças nas margens de comercialização com consequentes variações na renda agrícola e no nível de consumo da população.

A formação dos preços agropecuários se passa num contexto do qual participam produtores, intermediários e consumidores. Compondo este cenário está um número considerável de mercados de produtos agrícolas ou industrializados, incluindo os mercados de insumos utilizados na produção e comercialização.

MARTINES $F^{\circ}$ (1988), citando Barros \& Xavier ${ }^{4}$, observa que o mecanismo de formação e determinação de preço opera sob a dependência de uma

\footnotetext{
4 BARROS, G.S.C. \& XAVIER, L.E. Aspectos da comercialização e seus efeitos sobre os preços e rendas agricolas. Revista de Economia Rural, Brasilia, 17 (3): 25-50, 1979.
} 
superestrutura institucional. Esta superestrutura é definida, principalmente, pelo grau de competitividade do mercado e pelo grau de intervenção governamental no mesmo, condicionando um mecanismo de transmissão de preços do consumidor ao produtor e vice-versa, através do setor de intermediação, o qual apropria-se de uma margem como contrapartida pela prestação de serviços.

Dessa forma, a análise de preços agrícolas envolve três aspectos básicos:

a) por um lado, o processo pelo qual os preços se transmitem de um nível para o outro de mercado - produtor, atacado e varejo - associa-se intimamente aos procedimentos de apropriação dos intermediários. Ou seja, ao mesmo tempo em que os intermediários cobram certa margem pelos seus serviços, concretiza-se um processo de transmissão de preços, cuja intensidade necessita ser conhecida;

b) por outro lado, torna-se relevante determinar a origem das oscilações de preços que serão transmitidas simultaneamente à apropriação das margens, $\mathrm{e}$

c) por fim, as magnitudes apropriadas no processo de comercialização e sua tendência precisam ser conhecidas.

Não se pode esquecer, no entanto, que os preços da carne dependem do comportamento dos preços dos subprodutos, podendo haver redução ou aumento de margens conforme as tendências nos mercados de subprodutos. Neste sentido, este trabalho procura responder a 2 perguntas: (a) que relação tem havido entre preços de subprodutos e os preços do boi e seus derivados no varejo? ; (b) as oscilações de preço de subprodutos têm tido reflexos estabilizadores ou desestabilizadores sobre os preços ao produtor e ao consumidor? 


\section{MARGENS DE COMERCIALIZAÇÃO}

A margem corresponde às despesas cobradas ao consumidor pela realização das atividades de comercialização, sendo utilizada principalmente para avaliar o desempenho dos mercados, através do acompanhamento de sua evolução (BARROS, 1987).

O cálculo da margem se dá pela diferença entre o preço pelo qual um conjunto de intermediários vende uma unidade de produto e o pagamento que faz pela quantidade equivalente que precisa comprar para vender essa unidade. Essa quantidade equivalente pode ser maior do que a quantidade vendida, devido à perdas ocorridas tanto por amassamento como por podridão ou processamento. Quando algum subproduto é obtido na industrialização, o pagamento pela quantidade equivalente é ajustado pela subtração do valor imputado a esses subprodutos (JUNQUEIRA \& CANTO,1971).

As margens de comercialização podem ser absolutas ou relativas (totais ou específicas para cada nível de mercado): Essas margens podem ser alteradas em função de fatores ligados à oferta e demanda pelos serviços de comercialização adicionados à matéria-prima.

Vários são os trabalhos que calcularam as margens de comercialização para alguns produtos agrícolas, sendo um dos primeiros no Brasil realizado por JUNQUEIRA \& CANTO (1971). Estes autores calcularam margens totais de comercialização, utilizando a Cesta de mercado para a cidade de São Paulo. Verificou-se que a margem de comercialização é tanto maior quanto maior for a 
exigência de processamento da matéria-prima agrícola. Os produtos farináceos apresentaram a maior margem de comercialização, ao redor de $82 \%$ do preço do varejo, enquanto que no grupo de aves e ovos a margem gira ao redor de $32 \%$. No grupo das carnes, a margem de comercialização foi em média de $19,5 \%$.

BLISKA (1989) analisou a natureza das relações de transmissão de preços entre os níveis de mercado de carne bovina (produtor, atacado e consumidor), estudando os mecanismos através dos quais se propagam os choques nesses preços, determinando a intensidade e duração desses choques e calculando margens de comercialização.

Naquele estudo, foi estimado um modelo de auto-regressão vetorial, com 12 meses de defasagem, constituído das variáveis preços do boi gordo a nível de produtor, preços da carcaça no atacado e preços da carne bovina no varejo.

Utilizou-se, nos testes de causalidade, séries de preços médios mensais reais recebidos pelos mercados atacadista paulista, varejista da cidade de São Paulo e produtores de boi gordo dos estados de São Paulo, Minas Gerais, Goiás, Mato Grosso e Rio Grande do Sul, no período de janeiro de 1971 a dezembro de 1987. Os testes mostraram os seguintes resultados:

a) Identificou-se efeito causal no sentido dos preços recebidos pelo mercado produtor de boi gordo paulista para os mercados varejista e atacadista e do mercado varejista para os mercados atacadista e produtor paulista.

b) Identificou-se efeito causal no sentido dos niveis de atacado e varejo para os mercados produtores de boi gordo de Minas Gerais, Goiás e Mato Grosso.

c) Não foi observado efeito causal no sentido dos produtores de boi gordo de Minas Gerais, Goiás, Mato Grosso e Rio Grande do Sul para os mercados atacadista e varejista de São Paulo.

d) Passividade do atacado em relação aos demais niveis do mercado paulista de carne bovina. 
e) Ausência de variável essencialmente exógena.

As margens de comercialização foram denominadas parcelas, pois não se computaram em seu cálculo os valores dos subprodutos bovinos. As parcelas interanuais do produtor e do atacado apresentaram comportamentos opostos. Nas fases ascendentes do ciclo de preços reais do boi gordo, a parcela do produtor cresceu, enquanto a do atacado decresceu; nas fases descendentes do ciclo a parcela do produtor caiu a do atacado elevou-se.

Quanto às parcelas intra-anuais, a do produtor mostrou-se mais elevada na entressafra, quando os preços reais do boi gordo recebidos pelos produtores são mais elevados; a parcela do atacado, ao contrário, foi menor nesse período.

As parcelas dos supermercados foram sempre inferiores às dos açougues, tanto em termos de carne de segunda como de primeira, embora tenham apresentado comportamentos semelhantes ao longo do período analisado, inter e intra-anualmente.

\subsection{Cálculo das Margens}

O cálculo das margens será feito utilizando-se as seguintes expressões:

\begin{tabular}{|c|c|c|}
\hline $\mathrm{MT}=\mathrm{PV}-\mathrm{PP}$ & \multicolumn{2}{|c|}{$\mathrm{MT}^{\prime}=(\mathrm{PV}-\mathrm{PP}) / \mathrm{PV}$} \\
\hline $\mathrm{MA}=\mathrm{PA}-\mathrm{PP}$ & \multicolumn{2}{|c|}{$\mathrm{MA}^{\prime}=(\mathrm{PA}-\mathrm{PP}) / \mathrm{PA}$} \\
\hline $\mathrm{MV}=\mathrm{PV}-\mathrm{PA}$ & \multicolumn{2}{|c|}{$M V^{\prime}=(P V-P A) / P V$} \\
\hline $\mathrm{MT}^{\prime \prime}=\frac{\mathrm{PV}-\mathrm{PP}}{\mathrm{PV}} * 100$ & $\mathrm{MA}^{\prime \prime}=\frac{\mathrm{PA}-\mathrm{PP}}{\mathrm{PA}} * 100$ & $M V^{\prime \prime}=\frac{P V-P A}{P V} * 100$ \\
\hline
\end{tabular}


MT = Margem absoluta total de comercialização, que é a diferença entre os preços pagos pelos consumidores e os valores recebidos pelos produtores pela quantidade equivalente na fazenda.

MA = Margem absoluta do atacado.

MV = Margem absoluta do varejista.

$\mathrm{MT}^{\prime}$ = Margem total relativa, expressa como proporção do preço no varejo.

$\mathrm{MA}^{\prime}=$ Margem relativa do atacado.

$\mathrm{MV}^{\prime}=$ Margem relativa do varejo.

MT" = Margem porcentual total de comercialização.

$\mathrm{MA}^{\prime}=$ Margem porcentual do atacado.

MV" = Margem porcentual do varejo.

PV = Preço real ao nível do varejo.

$\mathrm{PP}=$ Preço real ao nível de produtor.

PA = Preço real ao nível de atacado.

Quando os produtos são processados durante a cadeia de comercialização e são obtidos subprodutos, deve-se transformar o preço recebido pelo produtor em quantidade equivalente na fazenda, para separar o valor recebido pelo produtor pela venda de sua produção em duas partes, uma devido ao produto comercializado no varejo e outra devido aos subprodutos, ou seja, os preços são corrigidos para que todos os produtos se refiram à mesma unidade no varejo.

BARROS (1987) e MARQUES (1993) demonstram que o preço ao produtor deve ser corrigido de forma que possa ser comparado com a unidade vendida ao varejo, ou seja, calcula-se a porcentagem que os subprodutos representam no valor total obtido na venda no nivel mais alto de mercado e se desconta do preço de custo (preço ao produtor).

CANTO et al. (1986) apresentam os coeficientes técnicos de processamento de um bovino, ou seja, todos os subprodutos que devem ser considerados no cálculo de margens de comercialização de carne bovina e respectivos rendimentos. Estes subprodutos podem ser observados na figura 1. 


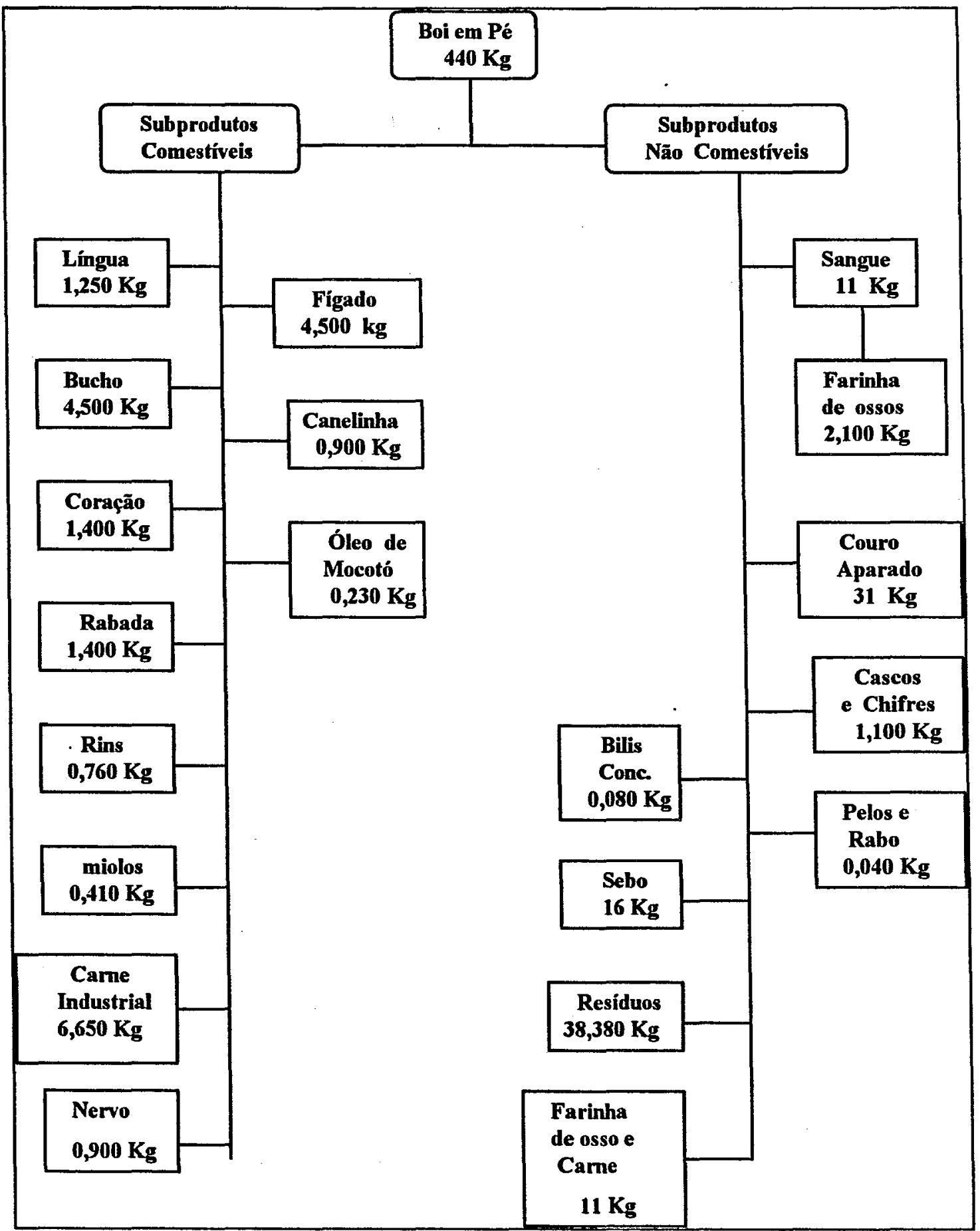

Figura 1:Subprodutos para o cálculo de margens de comercialização de carne bovina e respectivos rendimentos.

Fonte: CANTO (1986). 


\subsection{Análise das Margens de Comercialização}

Um dos objetivos deste trabalho é calcular as margens de comercialização da carne bovina verificando o impacto dos subprodutos nas margens dos diferentes níveis do mercado, utilizando os preços equivalentes na fazenda. Serão obtidas, então, margens sem a inclusão dos preços dos subprodutos e margens com a inclusão destes valores. Os dados utilizados são comentados no capítulo 5 (ítem 5.1).

As margens calculadas sem a obtenção de preços equivalentes devido aos subprodutos serão denominadas parcelas de comercialização da carne bovina (total, do varejo e do atacado) e as margens calculadas usando os preços equivalentes dos subprodutos serão denominadas margens de comercialização da carne bovina.

Vale lembrar que a consideração dos subprodutos causa alteração nas margens total e do atacado; não alterando a margem do varejo. Isto ocorre pelo fato dos subprodutos serem obtidos apenas ao nível de atacado. Portanto, espera-se que, considerando os subprodutos, a margem ao atacado aumente, aumentando assim a margem total e consequentemente a participação do produtor diminua.

O mecanismo de incorporação do efeito dos subprodutos foi baseado em CANTO (1986). Para exemplificá-lo será apresentada a tabela 4 que representa a média para o mês de janeiro. Como podemos observar, a carcaça correspondeu em média a $87,83 \%$ do valor total obtido pelos atacadistas pelo boi, os $12,17 \%$ restantes correspondem ao valor dos subprodutos. Torna-se necessário, então, para se fazer um cálculo mais realista da margem para o mês de janeiro, descontar o valor correspondente a esta porcentagem do valor recebido pelo produtor. 
Tabela 4: Estrutura utilizada no cálculo das margens de comercialização de carne bovina, sendo que os preços correspondem a valores médios, ao nível de atacado, para o mês de janeiro de 1987 a 1993.

\begin{tabular}{|c|c|c|c|c|c|c|}
\hline & & \multicolumn{2}{|c|}{ Nivel de Atacado } & & \multirow[b]{2}{*}{$\begin{array}{l}\% \text { das } \\
\text { partes no } \\
\text { valor total }\end{array}$} & \multirow[b]{2}{*}{$\begin{array}{l}\% \text { dos } \\
\text { grupos no } \\
\text { valor total }\end{array}$} \\
\hline & $\begin{array}{l}\text { Partes no } \\
\text { Frigorffico }\end{array}$ & $\begin{array}{l}\text { Peso médio } \\
\text { (kg) ou peças }\end{array}$ & $\begin{array}{l}\text { Preço } \\
\text { R\$ } / \mathrm{kg}\end{array}$ & $\begin{array}{l}\text { Valor das } \\
\text { partes }\end{array}$ & & \\
\hline \multirow{3}{*}{ carcaça } & 2 Traseiros & 115,250 & 2,52 & 290,43 & 54,21 & \multirow{3}{*}{87,83} \\
\hline & 2 Ponta Agulha & 29,400 & 1,26 & 37,04 & 6,91 & \\
\hline & 2 Dianteiros & 90,550 & 1,58 & 143,07 & 26,70 & \\
\hline \multirow{9}{*}{$\begin{array}{l}\text { Sub-produtos } \\
\text { Comestíveis }\end{array}$} & Fígado & 4,500 & 1,39 & 6,26 & 1,17 & \multirow{9}{*}{3,40} \\
\hline & Lingua & 1 peça & 1,66 & 1,66 & 0,31 & \\
\hline & Bucho & 4,500 & 0,67 & 3,02 & 0,56 & \\
\hline & Coração & 1,400 & 0,66 & 0,92 & 0.17 & \\
\hline & Rabada & 1,400 & 1,99 & 2,79 & 0,52 & \\
\hline & Rins & 0,760 & 0,19 & 0,14 & 0,03 & \\
\hline & Mocotó & 1 peça & 0,72 & 0.72 & 0,13 & \\
\hline & Miolos & 0,420 & 0,17 & 0,07 & 0,01 & \\
\hline & Carne Industrial & 6,650 & 0,40 & 2,66 & 0,50 & \\
\hline \multirow{8}{*}{$\begin{array}{c}\text { Sub-produtos } \\
\text { Não } \\
\text { Comestíveis }\end{array}$} & Farinha de carne & 11,000 & 0,51 & 5,61 & 1,05 & \multirow{7}{*}{8,77} \\
\hline & Farinha de sang. & 2,100 & 0,38 & 0,80 & 0,15 & \\
\hline & Couro Aparado & 31,000 & 0,99 & 30,69 & 5,73 & \\
\hline & Cascos e Chifres & 1,100 & 0,07 & 0,08 & 0,01 & \\
\hline & Pelos e rabo & 0,040 & 1,39 & 0,06 & 0,01 & \\
\hline & Bnlis & 0,080 & _- & 0,00 & 0,00 & \\
\hline & Sebo & 16,000 & 0,61 & 9,76 & 1,82 & \\
\hline & Totais & & & 535,77 & 100,00 & \\
\hline
\end{tabular}

Fonte: CANTO (1986), IEA e INTERCARNES; elaboração do autor.

A tabela 5 mostra, mês a mês, a participação da carcaça e dos subprodutos na constituição do valor do boi comercializado ao atacado (como exemplificado na tabela 4 ).

A seguir são apresentados alguns resultados que realçam a importância da consideração dos preços dos subprodutos no cálculo das margens dos diferentes niveis do mercado. 
Tabela 5: Participação da carcaça, dos subprodutos comestíveis, dos subprodutos não comestiveis e dos subprodutos totais; em porcentagem, na constituição do valor do boi comercializado ao atacado.Março de 86 a Dezembro de 93.

\begin{tabular}{|c|c|c|c|c|c|c|c|c|c|}
\hline meses & carcaça & $\begin{array}{c}\text { subprod. } \\
\text { comestiv. }\end{array}$ & $\begin{array}{l}\text { subpr. não } \\
\text { comestív. }\end{array}$ & $\begin{array}{c}\text { subprod. } \\
\text { total }\end{array}$ & meses & carcaça & $\begin{array}{l}\text { subprod. } \\
\text { comestiv. }\end{array}$ & $\begin{array}{l}\text { subpr. não } \\
\text { comestiv. }\end{array}$ & $\begin{array}{c}\text { subprod. } \\
\text { total }\end{array}$ \\
\hline 86/Jan. & - & - & - & - & 90/Jan. & 90,57 & 3,12 & 6,31 & 9,43 \\
\hline fev. & - & . & - & - & fev. & 85,48 & 4,93 & 9,59 & 14,52 \\
\hline mar. & 87,87 & 3,29 & 8,84 & 12,13 & mar. & 86,40 & 4,88 & 8,72 & 13,60 \\
\hline abr. & 89,09 & 3,35 & 7,57 & 10,91 & abr. & 90,65 & 4,24 & 5,11 & 9,35 \\
\hline maio & 87,88 & 3,40 & 8,72 & 12,12 & maio & 86,48 & 5,10 & 8,42 & 13,52 \\
\hline jun. & 85,48 & 3,52 & 11,00 & 14,52 & jun. & 84,17 & 5,59 & 10,24 & 15,83 \\
\hline jul. & 85,64 & 3,36 & 11,00 & 14,36 & jul. & 85,98 & 5,92 & 8,10 & 14,02 \\
\hline ago. & 84,26 & 3,74 & 12,01 & 15,74 & ago. & 87,16 & 5,52 & 7,33 & 12,84 \\
\hline set. & 88,44 & 0,00 & 11,56 & 11,56 & set. & 89,10 & 5,13 & 5,77 & 10,90 \\
\hline out. & 81.17 & 4,87 & 13,96 & 18,83 & out. & 89,17 & 4,85 & 5,98 & 10,83 \\
\hline nov. & 82,09 & 4,53 & 13,38 & 17,91 & nov. & 89,98 & 4,33 & 5,69 & 10,02 \\
\hline dez. & 86,85 & 2,96 & 10,19 & 13,15 & dez. & 90,91 & 3,37 & 5,72 & 9,09 \\
\hline 87/Jan. & 86,78 & 3,10 & 10,12 & 13,22 & 91/Jan. & 91,43 & 2,75 & 5,82 & 8,57 \\
\hline fev. & 86,81 & 3,63 & 9,56 & 13,19 & fev. & 90,71 & 3,22 & 6,07 & 9,29 \\
\hline mar. & 89,23 & 3,62 & 7,15 & 10,77 & mar. & 89,14 & 3,94 & 6,92 & 10,86 \\
\hline abr. & 90,09 & 3,17 & 6,74 & 9,91 & abr. & 87,95 & 3,57 & 8,48 & 12,05 \\
\hline maio & 90,20 & 2,77 & 7,03 & 9,80 & maio & 87,01 & 4,34 & 8,65 & 12,99 \\
\hline jun. & 89,47 & 3,15 & 7,38 & 10,53 & jun. & 88,07 & 4,41 & 7,53 & 11,93 \\
\hline jul. & 90,42 & 2,92 & 6,66 & 9,58 & jul. & 87,93 & 4,86 & 7,21 & 12,07 \\
\hline ago. & 89,96 & 2,96 & 7,09 & 10,04 & ago. & 88,36 & 4,85 & 6,79 & 11,64 \\
\hline set. & 88,73 & 3,56 & 7,71 & 11,27 & set. & 88,92 & 4,31 & 6,77 & 11,08 \\
\hline out. & 89,79 & 3,62 & 6,59 & 10,21 & out. & 90,08 & 3,66 & 6,26 & 9,92 \\
\hline nov. & 89,92 & 3,42 & 6,66 & 10,08 & nov. & 90,42 & 3,40 & 6.18 & 9,58 \\
\hline dez. & 89,04 & 3,47 & 7,49 & 10,96 & dez. & 90,51 & 3,06 & 6,43 & 9,49 \\
\hline 88/Jan. & 88,33 & 4,05 & 7,62 & 11,67 & 92/Jan. & 90,73 & 2,61 & 6,66 & 9,27 \\
\hline fev. & 86,87 & 3,37 & 9,75 & 13,13 & fev. & 87,73 & 3,40 & 8,87 & 12,27 \\
\hline mar. & 85,60 & 3,16 & 11,24 & 14,40 & mar. & 85,40 & 4,13 & 10,48 & 14,60 \\
\hline abr. & 83,68 & 3,40 & 12,92 & 16,32 & abr. & 85,06 & 4,74 & 10,20 & 14,94 \\
\hline maio & 83,48 & 3,87 & 12,66 & 16,52 & maio & 84,41 & 5,14 & 10,46 & 15,59 \\
\hline jun. & 83,48 & 4,41 & 12,12 & 16,52 & jun. & 84,25 & 4,82 & 10,93 & 15,75 \\
\hline jul. & 82,31 & 5,01 & 12,68 & 17,69 & jul. & 84,20 & 5,42 & 10,38 & 15,80 \\
\hline ago. & 83,81 & 4,09 & 12,10 & 16,19 & ago. & 86,10 & 4,86 & 9,04 & 13,90 \\
\hline set. & 84,90 & 4,35 & 10,75 & 15,10 & set. & 87,06 & 4,46 & 8,48 & 12,94 \\
\hline out. & 83,38 & 4,41 & 12,21 & 16,62 & out. & 86,81 & 4,16 & 9,03 & 13,19 \\
\hline nov. & 84,12 & 4,92 & 10,96 & 15,88 & nov. & 85,30 & 4,16 & 10,53 & 14,70 \\
\hline dez. & 85,57 & 4,67 & 9,77 & 14,43 & dez. & 86,99 & 3,26 & 9.75 & 13.01 \\
\hline $89 / J a n$. & 84,91 & 4,27 & 10,83 & 15,09 & 93/Jan. & 87,67 & 3,08 & 9,25 & 12,33 \\
\hline fev. & 85,14 & 4,25 & 10,61 & 14,86 & fev. & 85,80 & 3,29 & 10,92 & 14,20 \\
\hline mar. & 85,93 & 4,35 & 9,72 & 14,07 & mar. & 82,65 & 4,70 & 12,65 & 17,35 \\
\hline abr. & 83,28 & 4,41 & 12,32 & 16,72 & $a b r$. & 81,12 & 5,65 & 13,23 & 18,88 \\
\hline maio & 82,62 & 5,16 & 12,22 & 17,38 & maio & 81,22 & 5,41 & 13,37 & 18.78 \\
\hline jun. & 79,67 & 6,87 & 13,46 & 20,33 & jun. & 82,30 & 5,19 & 12,51 & 17,70 \\
\hline jul. & 80,70 & 7,76 & 11,54 & 19,30 & jul. & 84,42 & 4,89 & 10,69 & 15,58 \\
\hline ago. & 84,04 & 6,42 & 9,55 & 15,96 & ago. & 86,60 & 3,90 & 9,50 & 13,40 \\
\hline set. & 85,01 & 5,26 & 9,73 & 14,99 & set. & 86,30 & 3,62 & 10,08 & 13.70 \\
\hline out. & 85,80 & 4,44 & 9,76 & 14,20 & out. & 86,30 & 3,54 & 10,17 & 13.70 \\
\hline nov. & 88,89 & 3,45 & 7,66 & 11.11 & nov. & 85,22 & 3,78 & 11,00 & 14,78 \\
\hline dez. & 91,02 & 2,98 & 6,00 & 8,98 & dez. & 87,18 & 2,90 & 9,92 & 12,82 \\
\hline
\end{tabular}

Fonte: CANTO (1986), IEA e INTERCARNES; elaboração do autor. 
As parcelas e margens porcentuais médias mensais de comercialização de carne bovina de 1986 a 1993 são representadas na tabela 6 e figuras 2 a 4 . $\mathrm{Na}$ tabela B.1 (Apêndice B), tem-se a representação mensal destes dados.

O primeiro aspecto que se observa é o comportamento bastante semelhante das parcelas e das margens, apesar de apresentarem valores reais significativamente diferentes.

As tabelas 6 e B.1 e figura 2 mostram que quando se considera os subprodutos a participação do atacado aumenta consideravelmente. Este aumento fica em torno de $8 \%$. Também se observa que a tendência dessa margem é a mesma com ou sem os subprodutos, atingindo valor máximo no mês de julho. Na figura 4, que apresenta valores mensais das parcelas e margens do atacado, este aumento também pode ser observado sendo que em alguns meses a parcela do atacado apresenta valores negativos como em abril de 93 (- 2,94\%), entretanto, a margem apresenta valor positivo $(8,70 \%)$.

A figura 3 apresenta valores mensais das parcelas e margens totais de comercialização. Pode-se observar que, com o aumento da margem do atacado, a margem total aumenta proporcionalmente e, consequentemente, a participação do produtor diminui.

As figuras 5 a 11 tratam basicamente das oscilações dos preços nos diferentes mercados e períodos estudados.

A figura 5 apresenta índices da participação da carcaça e dos subprodutos comestíveis e não comestíveis no valor total do boi ao atacado.

$\mathrm{Na}$ figura 6 estão representados os preços médios mensais reais recebidos pelos produtores paulistas e mercados varejista e atacadista da cidade de São Paulo, respectivamente. Na figura 7 estão representados os preços médios anuais reais recebidos pelos produtores paulistas e mercados varejista e atacadista. Verifica-se que os preços, tanto anuais quanto mensais, apresentam comportamento 
semelhante nos três níveis de mercado e que os preços médios anuais apresentam tendência a diminuir.

A relação que existe entre o preço no varejo e a margem total absoluta, em $R \$ / k g$, é apresentada nas figuras 8 e 9 , sendo que a figura 8 representa as médias mensais e a figura 9 as médias anuais.

Nas figuras 10 e 11 os subprodutos foram separados em subprodutos comestíveis e subprodutos não comestíveis, de acordo com a figura 1 . A soma dos valores dos dois grupos foi então relacionada com o preço do kg de carne ao varejo, para verificar qual dos grupos apresenta preços relacionados com o preço da carne ao varejo. Pela figura 10 se observa que as médias mensais apresentam muito pouca relação para ambos os grupos e a figura 11 mostra que os dois grupos apresentam tendência de queda nos preços maior que a apresentada pela carne ao varejo.

Tabela 6: Parcelas e margens porcentuais de comercialização de carne bovina. Médias mensais (1986-1993), em \% ${ }^{5}$.

\begin{tabular}{|c|c|c|c|c|c|c|}
\hline \multirow[t]{2}{*}{ Meses } & \multicolumn{3}{|c|}{ Parcelas de comercializaçăo } & \multicolumn{3}{|c|}{ Margens de comercializaçăo } \\
\hline & Total & Varejo & Atacado & Total & Varejo & Atacado \\
\hline $\begin{array}{l}\text { Jan. } \\
\text { Fev. } \\
\text { Mar. } \\
\text { Abr. } \\
\text { Maio } \\
\text { Jun. } \\
\text { Jul. } \\
\text { Ago. } \\
\text { Set. } \\
\text { Out. } \\
\text { Nov. } \\
\text { Dez. }\end{array}$ & $\begin{array}{l}45,38 \\
43,27 \\
44,43 \\
43,44 \\
43,70 \\
41,14 \\
40,68 \\
38,61 \\
39,07 \\
42,09 \\
40,75 \\
41,80\end{array}$ & $\begin{array}{l}37.80 \\
35.52 \\
34.53 \\
34,94 \\
37.64 \\
35.77 \\
30.91 \\
31.05 \\
31.80 \\
34.03 \\
34.58 \\
35.09\end{array}$ & $\begin{array}{l}7,58 \\
7,75 \\
9,90 \\
8,50 \\
6,07 \\
5,37 \\
9,77 \\
7,56 \\
7,27 \\
8,06 \\
6,17 \\
6,71\end{array}$ & $\begin{array}{l}52,03 \\
51,03 \\
52,23 \\
51,56 \\
52,36 \\
50,91 \\
49,91 \\
47,48 \\
47,15 \\
50,11 \\
48,71 \\
49,01\end{array}$ & $\begin{array}{l}37,80 \\
35,52 \\
34,53 \\
34,94 \\
37,64 \\
35,77 \\
30,91 \\
31,05 \\
31,80 \\
34,03 \\
34,58 \\
35,09\end{array}$ & $\begin{array}{r}14,23 \\
15,51 \\
17,70 \\
16,62 \\
14,72 \\
15,14 \\
19,00 \\
16,43 \\
15,34 \\
16,09 \\
14,13 \\
13,93\end{array}$ \\
\hline
\end{tabular}

Fonte: CANTO (1986), IEA e INTERCARNES; elaboração do autor.

S tabela B.I (ApêndiceB) apresenta estes dados mês a mès. 


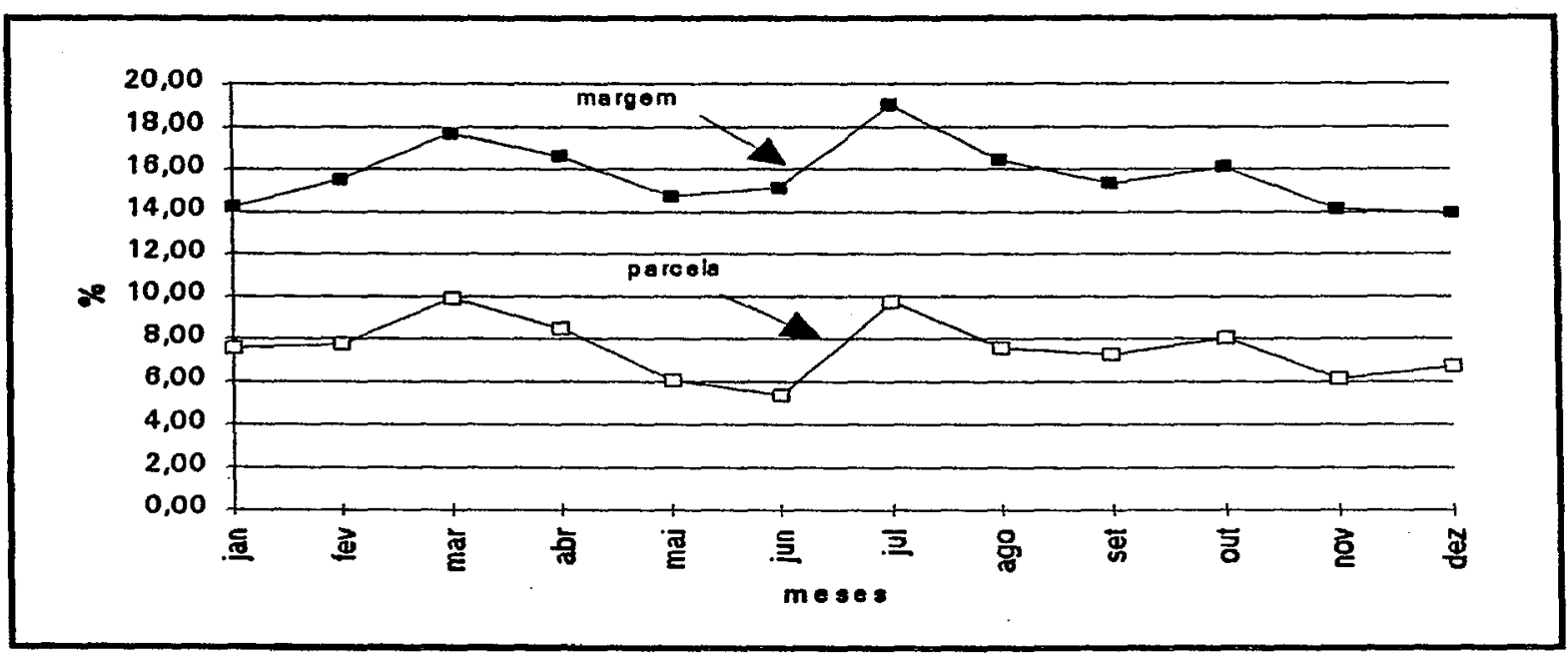

Figura 2: Parcela porcentual do atacado e margem porcentual do atacado de carne bovina para o Estado de São Paulo. Médias mensais (1986/1993).

Fonte: CANTO (1986), IEA e INTERCARNES; elaboração do autor.

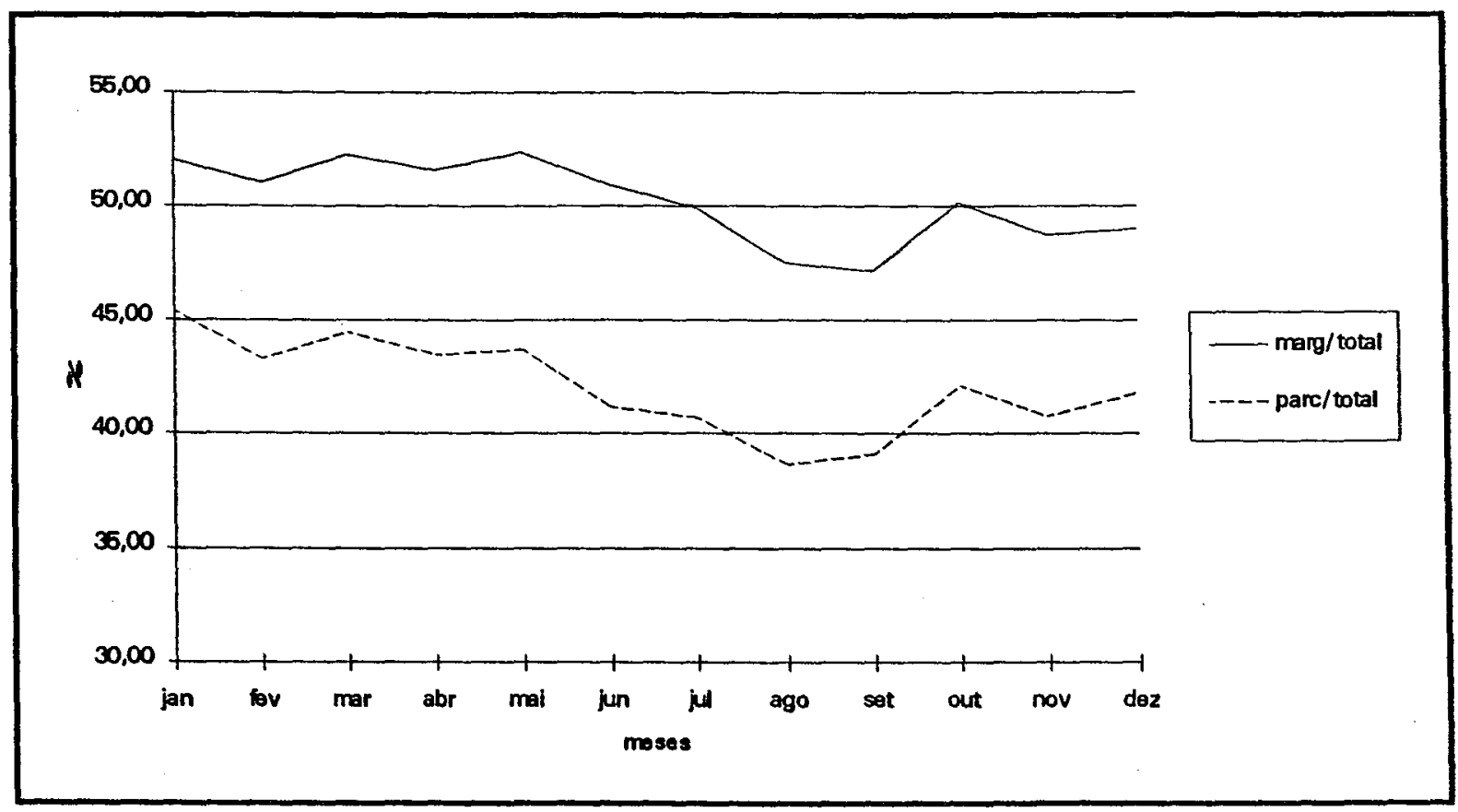

Figura 3: Parcela total e margem total de comercialização de carne bovina para 0 Estado de Sãp Paulo.Em porcentagem. Médias mensais 1986/1993. Fonte: CANTO (1986), IEA e INTERCARNES; elaboração do autor. 


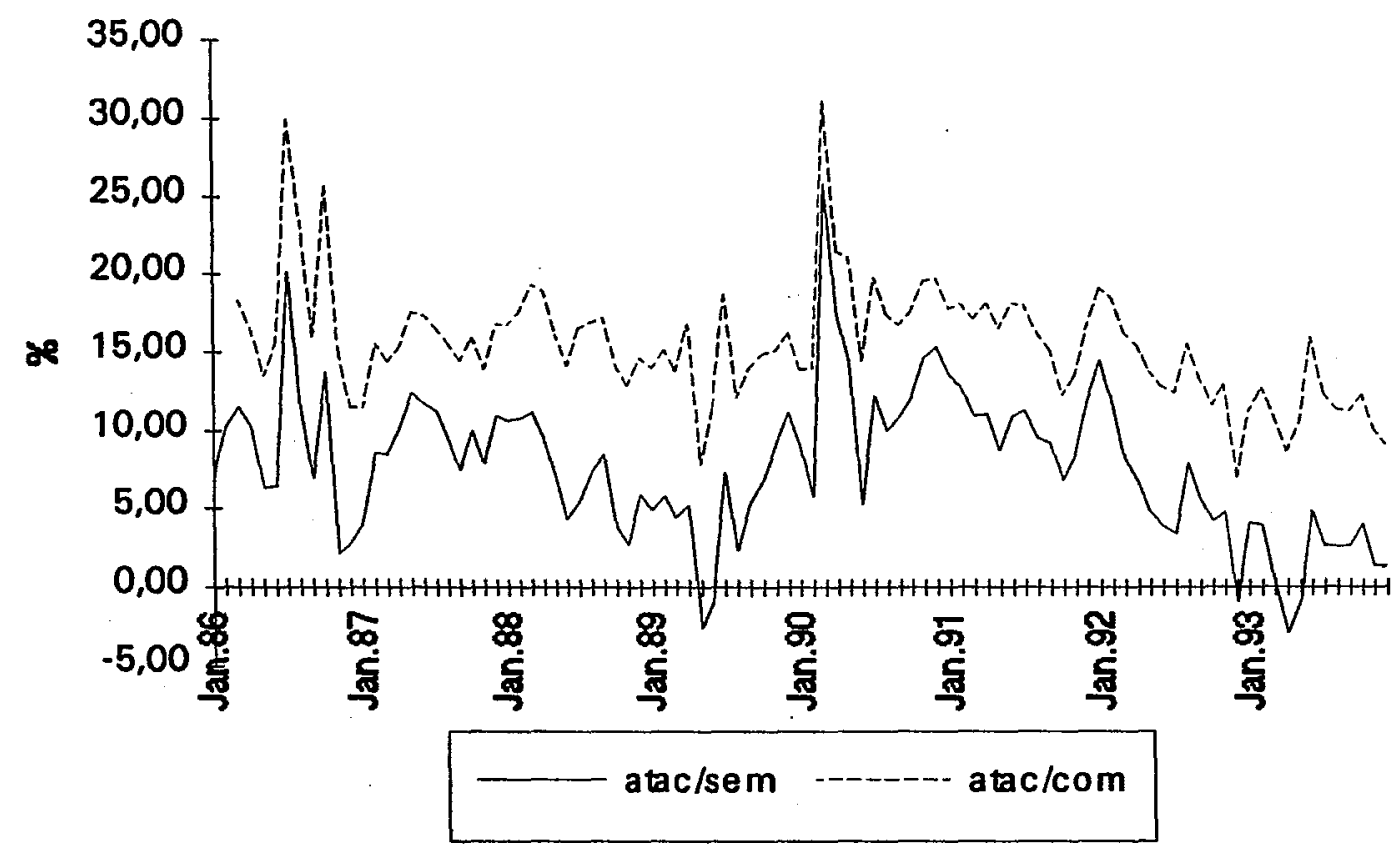

Figura 4: Parcela porcentual do atacado (atac/sem) e Margem porcentual do atacado (atac/com) de carne bovina para o Estado de São Paulo. Valores mensais de 1986 a 1993.

Fonte: CANTO (1986), IEA e INTERCARNES; elaboração do autor.

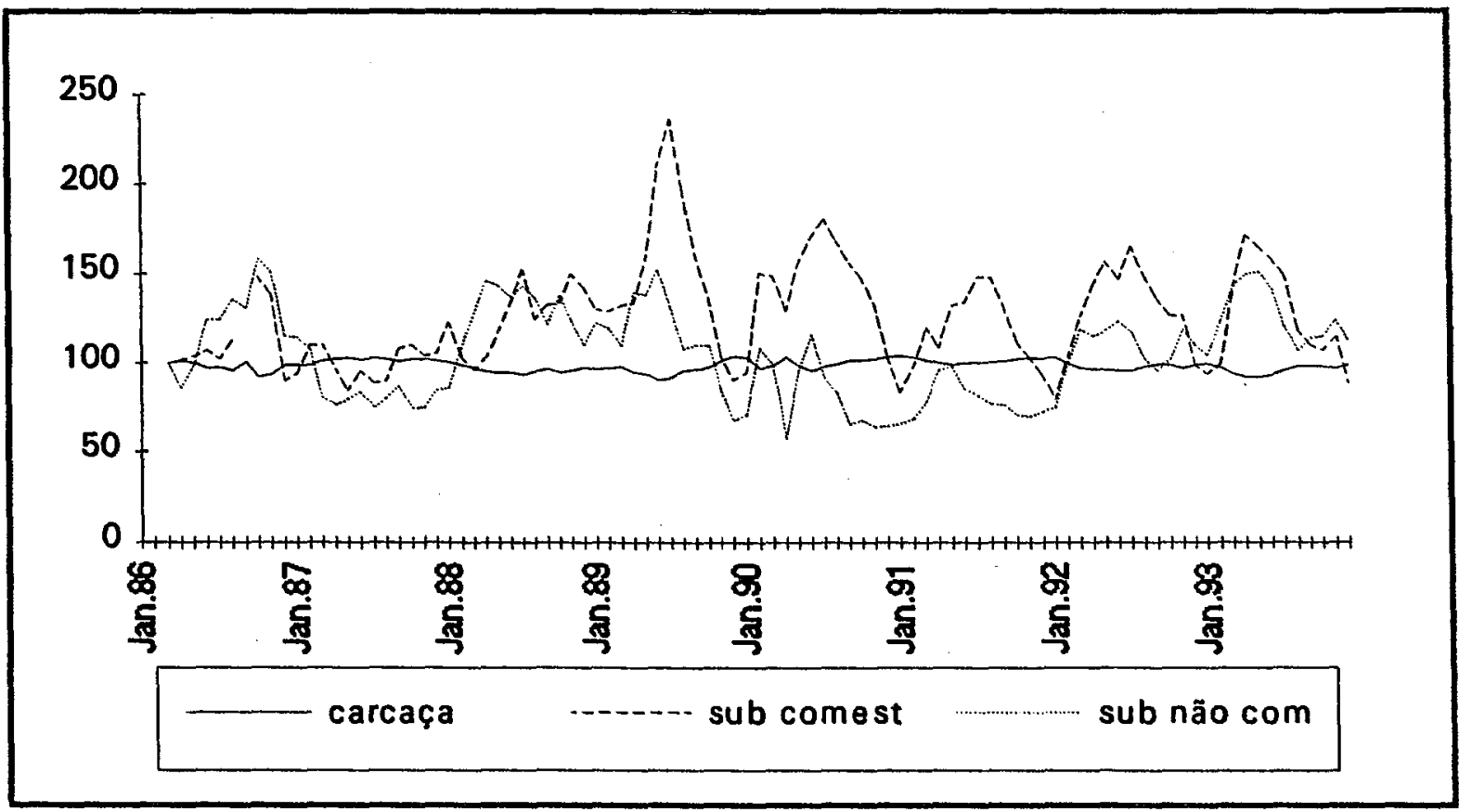

Figura 5: Índices da participação da carcaça, dos subprodutos comestiveis e dos subprodutos não comestiveis no valor do boi ao atacado. Mês base: março de 1986.

Fonte: CANTO (1986), IEA e INTERCARNES; elaboração do autor. 


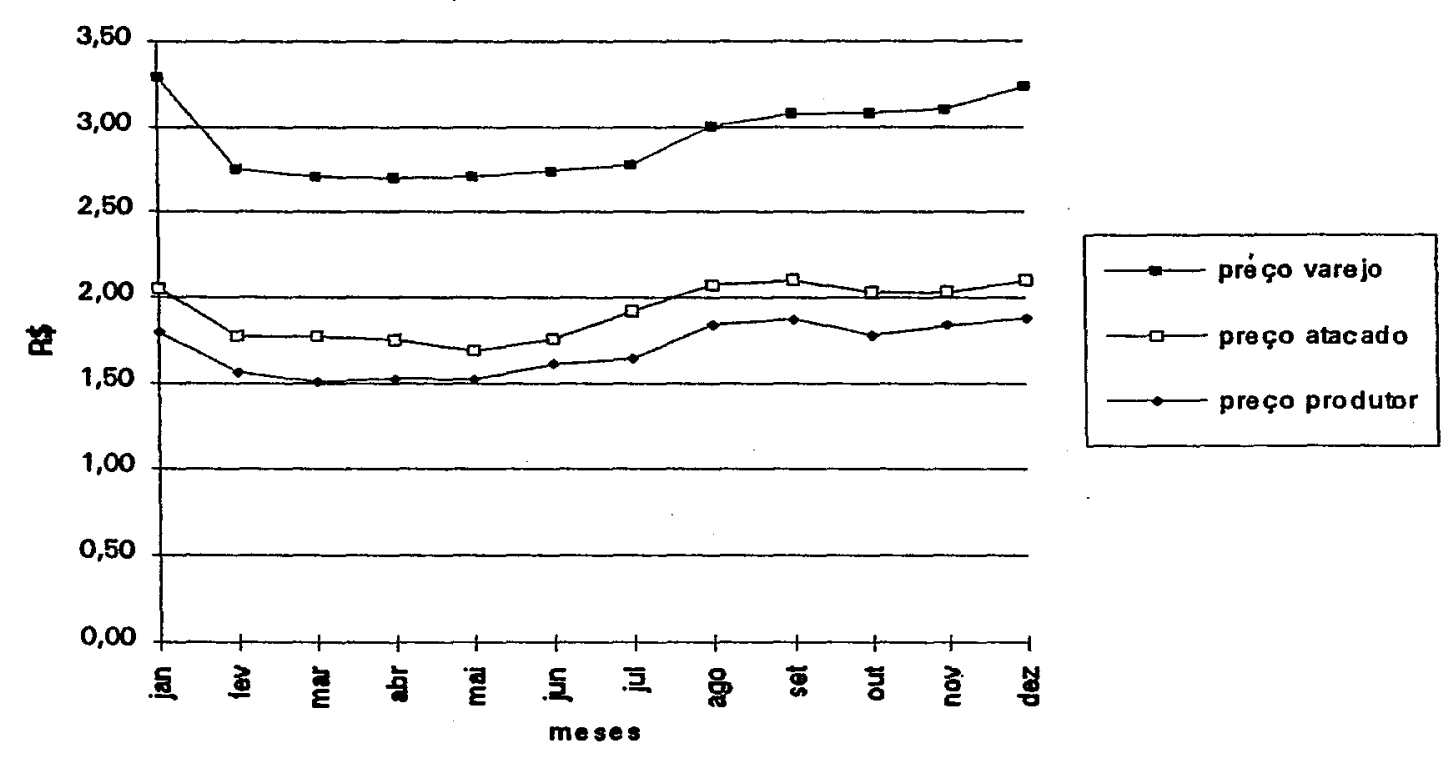

Figura 6: Preços médios mensais da carne bovina recebidos pelos produtores do Estado de São Paulo; atacadistas e varejistas da cidade de São Paulo, em $\mathrm{R} \$ / \mathrm{kg}, 1986 / 1993$.

Fonte: IEA.

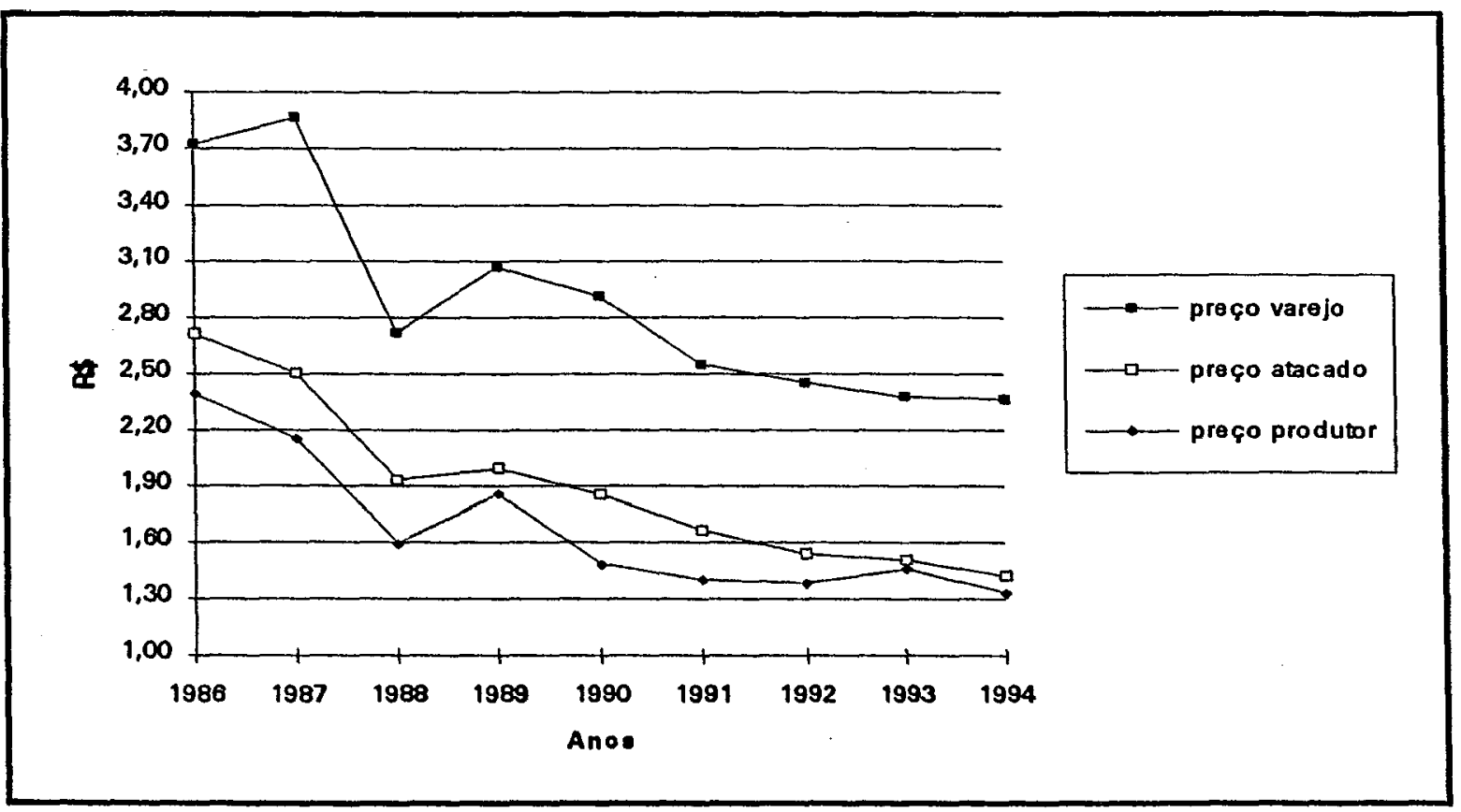

Figura 7: Preços médios anuais da carne bovina recebidos pelos produtores do Estado de São Paulo; atacadistas e varejistas da cidade de São Paulo, em R\$/kg, 1986/1994. Obs: Os preços de 1994 são a média até julho.

Fonte: IEA. 


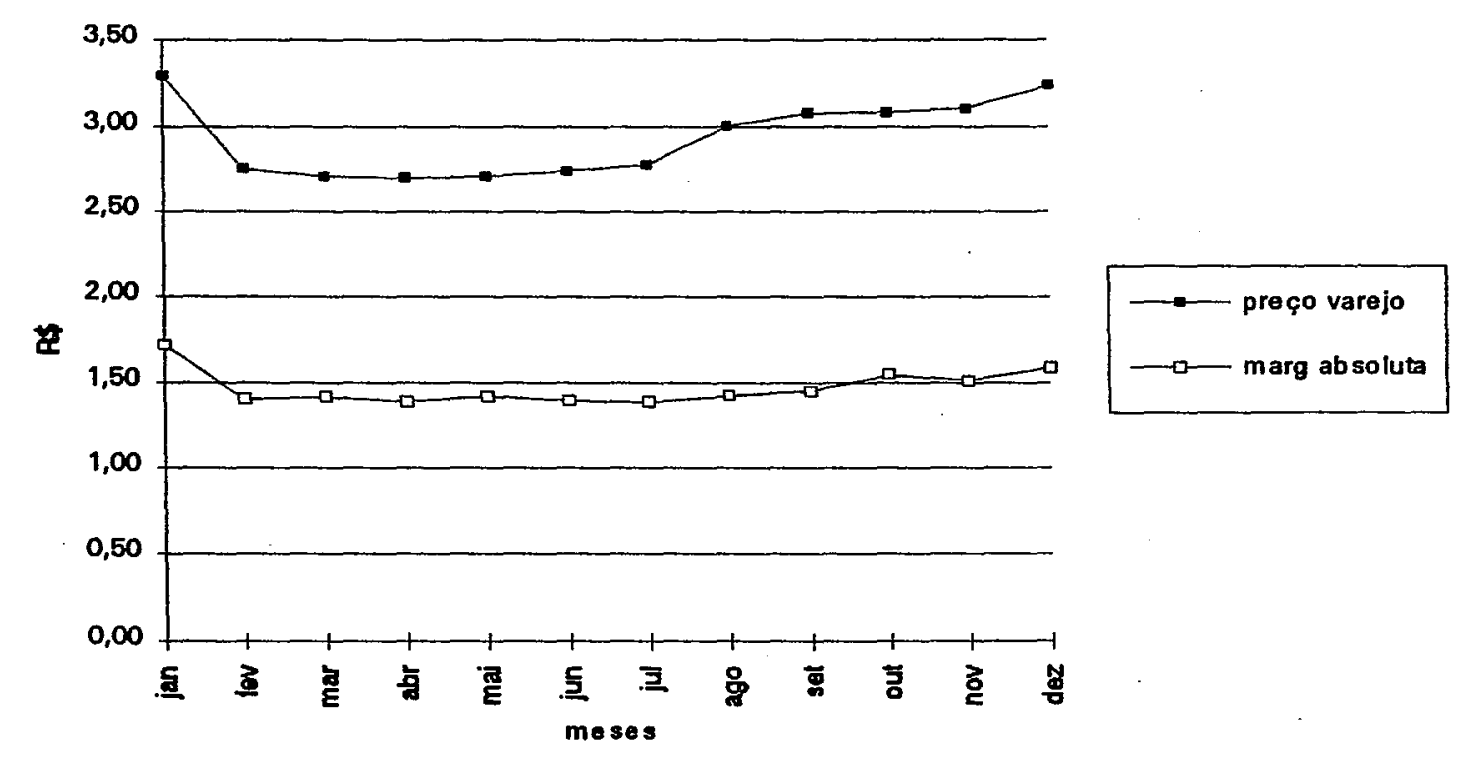

Figura 8: Preços médios mensais do varejo da cidade de São Paulo e margem total absoluta(médias mensais) do Estado de São Paulo, em R\$/kg, 1986/1993. Fonte: CANTO (1986), IEA e INTERCARNES; elaboração do autor.

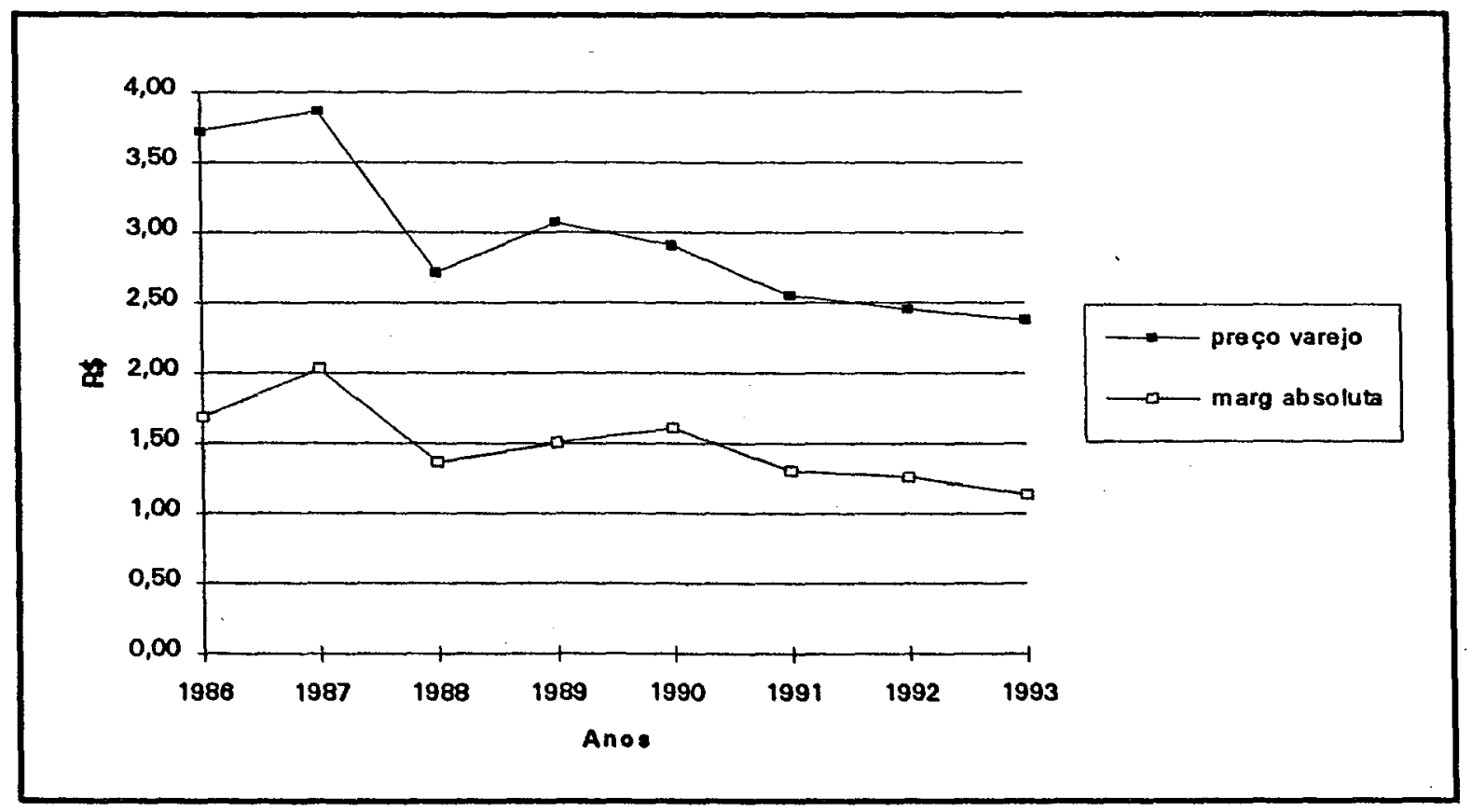

Figura 9: Preços médios anuais do varejo da cidade de São Paulo e margem total absoluta (médias anuais) do Estado de São Paulo, em R\$/kg, 1986/1993.

Fonte: CANTO (1986), IEA e INTERCARNES; elaboração do autor. 

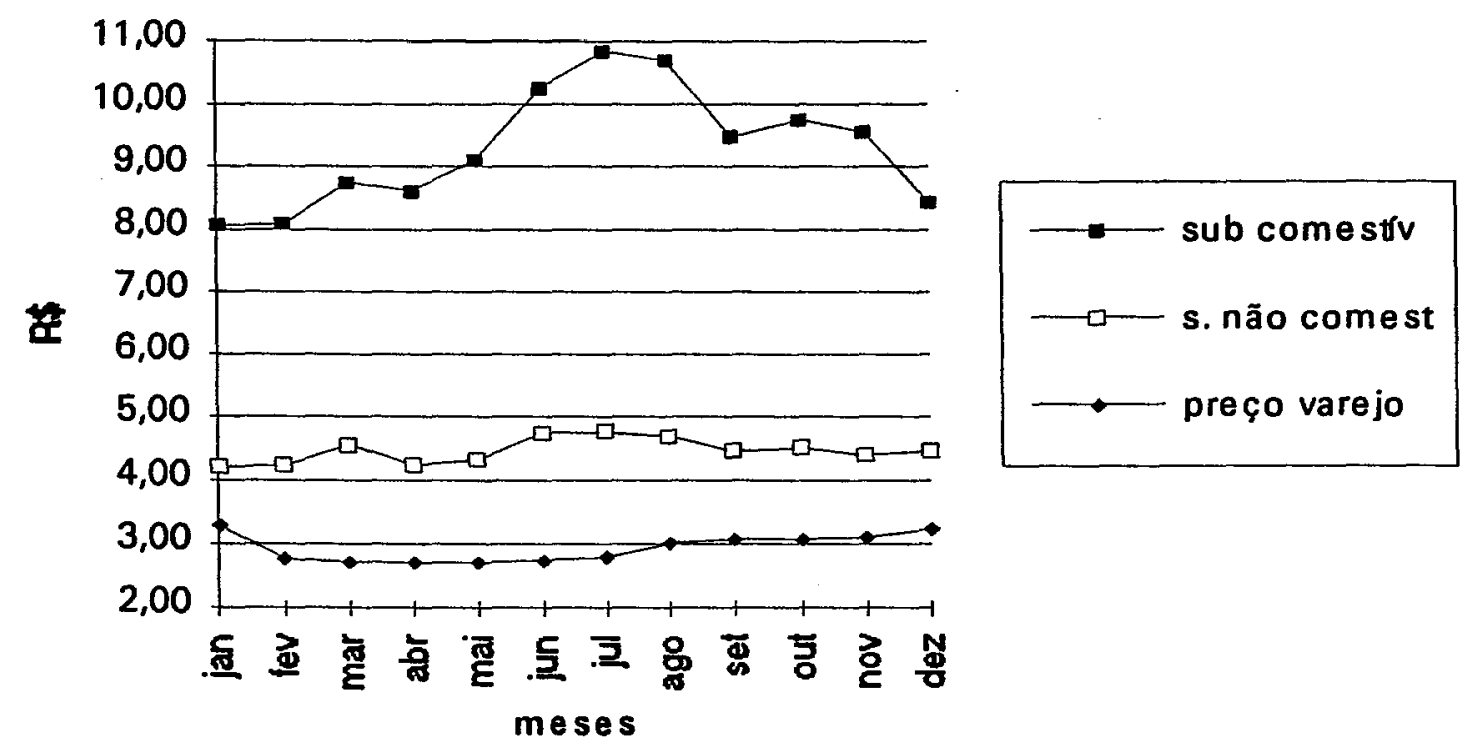

Figura 10:Preços médios mensais dos subprodutos comestíveis, dos subprodutos não comestíveis e do preço ao varejo da carne bovina, em $\mathrm{R} \$ / \mathrm{kg}$, 1986/1993.

Fonte: CANTO (1986), IEA e INTERCARNES; elaboração do autor.

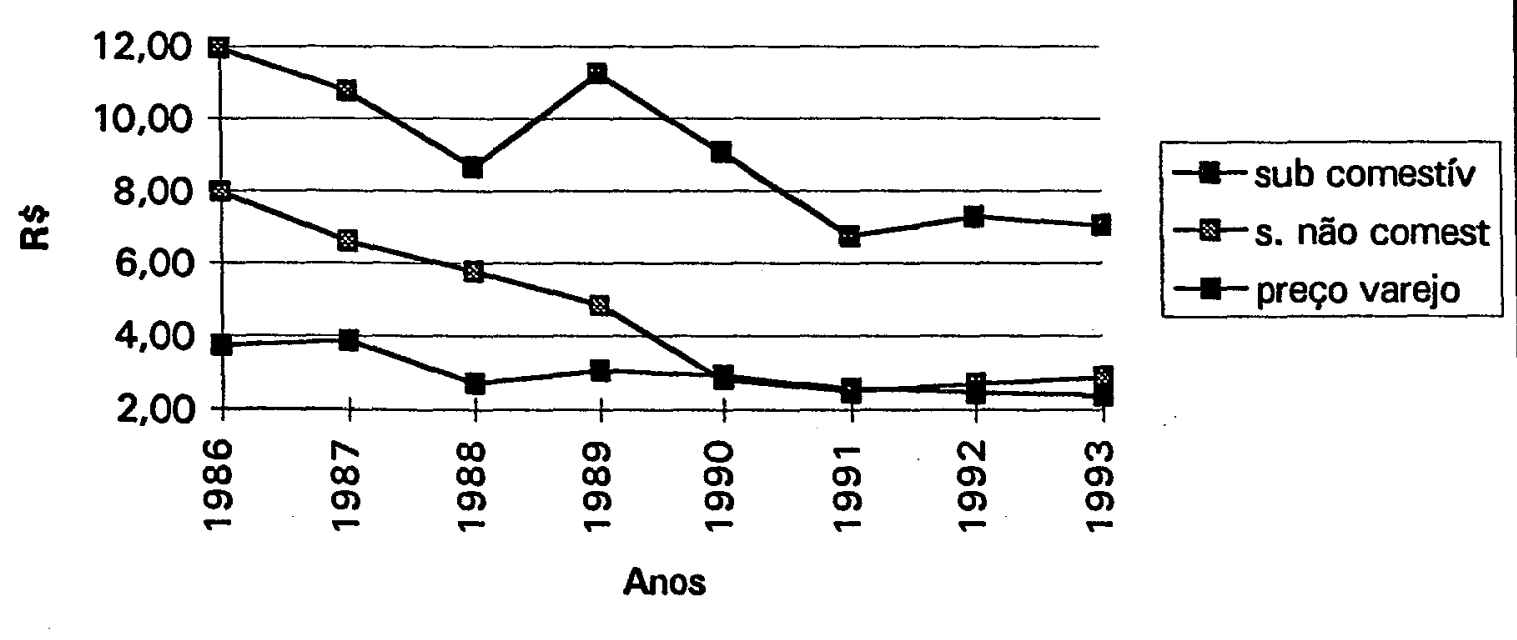

Figura 11: Preços médios anuais dos subprodutos comestiveis, dos subprodutos não comestíveis e preço ao varejo da carne bovina, em $\mathrm{R} \$ \mathrm{~kg}, 1986 / 1993$.

Fonte: CANTO (1986), IEA e INTERCARNES; elaboração do autor. 


\section{MODELOS ECONÔMICOS}

Nesse ítem são expostos modelos teóricos de margens de comercialização que procuram explicar a formação dos preços em diferentes níveis de mercados. Inicia-se pelo modelo de GARDNER (1975), que pressupõe concorrência perfeita e equilíbrio instantâneo tanto nos mercados de insumos quanto no de produto. Esse modelo assume importância pelo fato de que a maioria dos modelos de margens e formação de preços desenvolvidos desde 1975 parte da estrutura montada por GARDNER acrescentando-lhe ou excluindo-lhe pressupostos. A seguir, discute-se o modelo de HEIEN (1980), que baseia-se no de GARDNER, mas avança ao admitir a ocorrência de desequilíbrio nos mercados no curto prazo. E, por fim, apresenta-se o modelo de BARROS (1990) que, juntamente com o de HEIEN, fundamentará o modelo proposto neste trabalho.

\subsection{Modelo Competitivo de GARDNER (1975)}

O modelo de GARDNER $^{6}$ pretende representar uma indústria (agregado de firmas) que comercializa um dado produto agrícola ao qual săo adicionadas atividades (transporte, beneficiamento, armazenamento, etc) para atendimento da demanda pelo produto final. 6 A discussão deste modelo baseia-se nos trabalhos de GARDNER (1975), BARROS (1987); MARTINES F'
(1988); AGUIAR (1990) e AGUIAR (1994) 
É um modelo estático-comparativo, com um produto final e dois insumos utilizados em sua produção; que permite examinar as consequências do equilibrio competitivo nos mercados de insumos e produto sobre a relação entre o preço recebido pelo produtor agrícola e o preço do produto final ao varejo.

Representando o produto final por $\boldsymbol{x}$, a matéria-prima agrícola por $\boldsymbol{a}$ e o agregado de insumos de comercialização por $b$, o modelo seria composto pelo seguinte sistema de equações :

$$
\begin{aligned}
& x=f(a, b) \\
& x=D(P x, N) \\
& P b=P x f_{b} \\
& P a=P x f_{a} \\
& P b=g(b, T) \\
& P a=h(a, W)
\end{aligned}
$$

onde:

(1) representa a função de produção do agregado de firmas de comercialização (com retornos constantes à escala).

(2) representa a função de demanda primária (ao varejo), sendo $\boldsymbol{P x}$ o preço ao varejo e $N$ uma variável exógena deslocadora da demanda primária (população, por exemplo).

(3) e (4) representam as demandas por insumos que são dadas pela igualdade entre seus preços e os valores dos seus produtos físicos marginais; são condições de maximização de lucro em que $f_{a}$ e $f_{b}$ são produtos físicos 
marginais (derivadas parciais de $\boldsymbol{x}$ em relação aos insumos $\boldsymbol{a}$ e $\boldsymbol{b}$ ) e $\boldsymbol{P a}$ e $\boldsymbol{P b}$ são, respectivamente, os preços de $a$ e $b$.

(5) e (6) representam as ofertas dos dois insumos considerados, em que $T$ e $W$ são variáveis deslocadoras das ofertas de $b$ e $a$, respectivamente (por exemplo, tributos e clima).

Considerando equilíbrio nos três mercados $(\boldsymbol{x}, \boldsymbol{a}$ e $\boldsymbol{b})$ e aplicando o método da análise estático-comparativa, Gardner demonstra que:

a) eventos que aumentam a demanda ao varejo reduzirão a margem relativa de comercialização, desde que a oferta de insumos de comercialização seja mais elástica que a oferta de matéria-prima agrícola.

b) eventos que aumentam a oferta da matéria-prima agrícola aumentam a margem de comercialização.

c) eventos que aumentam a oferta dos insumos de comercialização diminuem a margem de comercialização.

d) um acréscimo na margem de comercialização provoca uma redução na parcela do produtor agricola se a elasticidade de substituição de $\boldsymbol{a}$ por $\boldsymbol{b}$ for menor que um e acréscimo se for maior que um .

e) a demanda de produtos agrícolas será, em geral, menos elástica ao nível do produtor do que ao nivel de varejo. 
f) a elasticidade de transmissão de preços entre produtor e varejo depende da origem da variação, podendo ser negativa para choques oriundos da oferta de insumos de comercialização, e devendo ser positiva e menor ou igual à unidade para variações originadas na oferta ou na demanda primária. 


\subsection{Modelo de HEIEN (1980)}

HEIEN (1980) ${ }^{7}$ desenvolveu um modelo explicativo do comportamento dos mercados agrícolas no período intermediário entre duas situações de equilíbrio.

Ao dar sustentação teórica ao seu modelo, HEIEN considera que a pressuposição de GARDNER de que ocorre equilíbrio instantâneo entre oferta e demanda nos níveis de varejo, atacado e produtor é válida apenas em períodos de tempo no qual a variação de estoque é pequena em relação à demanda total. $\mathrm{Na}$ medida em que se reduz o período de tempo considerado, cria-se uma condição de desequilíbrio no mercado, tornando-se necessária a passagem de algum tempo para que o mercado se equilibre. HEIEN argumenta ainda que esse período de desequilibrio durante o processo de ajustamento dos mercados ocorre em função da não fluidez perfeita das informações, das diferentes velocidades de decodificação dessas informações e das próprias dificuldades de ajuste às novas condições após a decodificação das informações do mercado.

O modelo teórico de determinação de preços e margens dsenvolvido por HEIEN engloba os niveis de varejo, de atacado e de produtor; apresentando funções de oferta e demanda, e também, excluindo o mercado de insumos de comercialização; diferenciando-se, assim, do modelo de GARDNER.

Considerando as letras maiúsculas representando quantidades, as minúsculas representando preços e os sobrescritos $d$ e $s$ representando, respectivamente, demanda e oferta, o modelo é dado pelas seguintes funções:

\section{Varejo:}

$$
R^{d}=h_{l}(r, y)
$$

7 A discusstio a seguir baseia-se nos trabalhos de HEIEN (1980), TELXEIRA (1982) e AGUIAR (1994). 
em que $\boldsymbol{R}$ é a quantidade ao varejo, $\boldsymbol{r}$ é o preço ao varejo e $\boldsymbol{y}$ representa fatores exógenos, tal como renda;

$$
R^{s}=h_{2}(r, w, z)
$$

em que $w$ é o preço ao atacado e $z$ representa preços de fatores exógenos, tais como serviços de comercialização.

\section{Atacado:}

$$
W^{d}=h_{3}(r, w, z)
$$

em que $W$ é a quantidade ao atacado (demanda do varejista pelo produto do atacadista);

$$
W^{s}=h_{4}(w, f, x),
$$

onde $\boldsymbol{f}$ é o preço ao produtor rural e $\boldsymbol{x}$ representa os preços de outros itens de custo dos atacadistas.

\section{Produtor:}

$$
F^{d}=h_{5}(w, f, x)
$$

onde $F$ é a quantidade ao nível de produtor;

$$
F s=h_{6}(t)
$$

Outra diferença (a principal) desse modelo em relação ao de GARDNER está em não pressupor equilibrio entre oferta e procura nos mercados de produto e de fatores, ou seja: $R^{d} \neq R^{s}, W^{d} \neq W^{s}$ e $F^{d} \neq \boldsymbol{F}$. A constatação da ocorrência 
de variações no nível dos estoques, de diversos produtos agrícolas, indica que oferta e procura não se equilibram permanentemente.

Para fechar o modelo em termos de igualdade entre equações e incógnitas, e para determinar a forma de ajustamento dos preços, o autor apresenta mais três equações, as quais expressam os preços como funções do excesso de demanda:

$$
\begin{aligned}
& r=h_{7}\left(R^{d}-R^{s}\right), \\
& w=h_{8}\left(W^{d}-W^{s}\right), \\
& f=h_{9}\left(F^{d}-F s\right) .
\end{aligned}
$$

O autor observa que, para alguns níveis do sistema de comercialização agrícola, as relações de excesso de demanda como as anteriores são inapropriadas. Particularmente, isso se verifica no caso do varejo. Pois neste nível existe um número grande de produtos comercializados pelos supermercados; o que torna inviável aos agentes de comercialização o acompanhamento de todos os produtos. Neste caso, o autor sugere que uma teoria operacionalmente mais realista considera que o comerciante aplica um markup sobre o custo (preço de compra) de cada produto, a fim de obter o preço de venda. Como todos os agentes receberiam os mesmos "sinais", dados pelo preço pago pelos insumos, tenderia a haver resposta similar em todo o mercado. Este procedimento também é consistente com a teoria econômica.

Sendo assim, e assumindo retornos constantes à escala, a função de custo das firmas varejistas é dada por:

$$
C=h_{10}(R s, w, z)=h_{10}(w, z) R^{s}
$$


Desse modo, a função de custo marginal é:

$$
\frac{\partial C}{\partial R}=h_{10}(w, z)
$$

Como em condições competitivas o custo marginal iguala-se ao preço:

$$
r=h_{10}(w, z)
$$

Assumindo que, para cada unidade de produto, insumos são requeridos em proporções fixas (pressuposto próximo, da realidade no curto prazo), a função de produção básica do modelo será a função de Leontief:

$$
\mathrm{R}=\min \left(\frac{\mathrm{W}}{\mathrm{a}_{1}}, \frac{\mathrm{Z}}{\mathrm{a}_{2}}\right)
$$

Essa função de produção conduz às demandas por insumos: $W=a_{1} R$ e $Z=a_{2} R$; para retornos constantes à escala, a função de custo é:

$$
\begin{aligned}
& C=\left(a_{1} w+a_{2} z\right) R . \\
& \operatorname{Da} \text { equação }(7): \\
& r=a_{1} w+a_{2} z .
\end{aligned}
$$

Este tipo de análise é adequada para períodos curtos de tempo porque a função de Leontief pressupõe elasticidade de substituição entre os insumos $w$ e $z$ igual a zero. Isso é verdadeiro porque no curto prazo a tecnologia, e portanto a relação entre os insumos, não pode ser afetada em função das variações nos preços. No longo prazo, o autor sugere, como alternativa, a pressuposição de elasticidade de substituição não nula, mas constante, através da inclusão de uma função CES (constant elasticity of substitution). 
A equação (9) pode ser entendida como uma função de oferta com retornos constantes à escala e proporções fixas, sendo também a política de preços ótima para as firmas, relacionando o preço do produto com os preços dos insumos, o autor inclui a política de estoques como elemento capaz de registrar o desequilibrio no curto prazo. Para simplificação, passa-se agora a considerar apenas dois níveis de mercado, varejo e produtor rural.

Com os dois níveis, a oferta ao varejo será dada por:

$$
R=\min \left(\frac{F}{a_{1}}, \frac{Z}{a_{2}}\right) .
$$

A equação (9) passa a ser:

$$
r_{t}=a_{1} f_{t}+a_{2} z_{t}
$$

A demanda derivada torna-se:

$$
F^{d}=a_{1} R^{s}, \quad a_{1}>0 .
$$

A demanda ao varejo é uma relação linear do preço:

$$
R_{t}^{d}=\alpha_{0}+\alpha_{1} r_{t} \quad \alpha_{1}<0
$$

A oferta do produtor será:

$$
F_{t}^{s}=\gamma_{0}+\gamma_{1} f_{t} \quad \gamma_{1}>0
$$

demanda:

O preço recebido pelo produtor é determinado por excesso de

$$
\Delta f_{t}=\beta_{0}\left(F^{d}-F^{s}\right) \quad \beta_{0}>0
$$


Como o preço é dado pela equação (10), a variável que resta a ser determinada pelo varejista é a quantidade oferecida no período t. Visto que a demanda pode sofrer variações (mudança em $\boldsymbol{\alpha}_{\boldsymbol{0}}$ ), HEIEN sugere utilizar como regra igualar a oferta de um período com a demanda do período anterior:

$$
R_{t}^{s}=R_{t-1}^{d}
$$

Combinando as relações vistas até o momento, pode-se compreender como ocorre o ajustamento em um mercado descrito por esse modelo. Dada uma expansão na demanda ao varejo, os estoques sofrem redução maior que a esperada, mas os preços de varejo e de produtor não se alteram. No início do período seguinte, os estoques sofrem acréscimos de acordo com a relação (15), ou seja, os varejistas aumentarão sua oferta no período $t$ para atender $o$ aumento da demanda verificado no período t-1. O aumento da oferta ao varejo será transmitido ao produtor através da regra (11) e os preços em ambos os níveis aumentarão seguindo (14) e (10). O aumento do preço ao varejo vai diminuir a quantidade demandada nesse nível [equação (12)], o que fará com que os estoques do varejista tornem-se maiores do que esses esperavam. Esse aumento no volume de estoque sinaliza para diminuição das compras junto ao produtor e o processo continuará por vários periodos até que preço e quantidade encontrem seu novo equilibrio, supondo que a solução seja estável.

HEIEN demonstrou que o modelo formado pelas equações (10) a (15) pode dar origem a soluções estáveis e que, para estas soluções, a regra ótima de determinação de preços é aquela dada pela equação (10). 


\subsection{Modelo de BARROS (1990)}

O modelo econômico desenvolvido por BARROS baseia-se fundamentalmente em HEIEN. Entretanto, no modelo de BARROS o setor atacadista assume papel importante, pois, o autor acredita que neste nível os preços se ajustam instantâneamente, de acordo com o excesso de demanda. Isto ocorre, segundo o autor, pelo fato de que os atacadistas, especializando-se no comércio de um pequeno grupo de produtos, teriam maior acesso a informações, baixo custo de mudança de preços e elevada frequência de transações. $O$ nível de produtor, por atuar em pequena parcela do mercado e de forma descentralizada, se ajusta com alguma defasagem em relação às transações feitas ao atacado; o mesmo ocorrendo com o nível de varejo, este por ser pouco especializado. As mudanças de preço para os produtores se processam por meio de ajustes parciais. $O$ varejo utilizaria uma política de markup sobre os custos, utilizando, também, ajustes parciais para atingir um "preço-meta".

Estabelecendo-se que, no curto prazo, os setores de atacado e varejo operam de acordo com uma função do tipo de Leontief (proporções fixas) tem-se:

$$
V=\min \left(\frac{A}{b_{1}}, \frac{Z}{b_{2}}\right) \quad \text { e } \quad A=\min \left(\frac{P}{c_{1}}, \frac{X}{c_{2}}\right)
$$

onde $\boldsymbol{V}, \boldsymbol{A}$ e $\boldsymbol{P}$ são quantidades do produto ao varejo, atacado e produtor, respectivamente; $\boldsymbol{Z}$ e $\boldsymbol{X}$ são quantidades de insumos de comercialização usados ao varejo e ao atacado, respectivamente; $b_{1}, b_{2}, c_{1}$ e $c_{2}$ são coeficientes técnicos de produção.

A demanda ao varejo é uma função linear do preço ao varejo $\left(v_{t}\right)$ :

$$
V_{t}^{d}=\theta_{0}+\theta_{1} v_{t} \quad \theta_{1}<0
$$


O "preço-meta" dos agentes varejistas ${ }^{8}$ é dado por:

$$
v_{t}^{*}=b_{1} a_{t}+b_{2} z_{t}
$$

onde $a$ e $z$ são preços do produto ao atacado e do insumo de comercialização $Z$.

O ajuste de preço ao varejo se dá por ajustes parciais:

$$
\begin{array}{rc}
v_{t}-v_{t-1}=\alpha\left(v_{t}^{*}-v_{t-1}\right) & 0<\alpha<1 . \\
\text { O preço ao atacado se ajusta por excesso de demanda: } \\
a_{t}-a_{t-1}=\delta\left(A_{t}^{d}-A_{t}^{s}\right) & \delta>0
\end{array}
$$

A demanda ao atacado $\left(A^{d}\right)$ é obtida pela conversão da demanda ao varejo do período anterior:

$$
A_{t}^{d}=b_{1} V_{t-1}^{d}
$$

A oferta ao atacado $\left(A^{s}\right)$ é obtida por conversão da oferta ao produtor $\left(P_{t}^{s}\right):$

$$
A_{t}^{s}=\frac{P_{t}^{s}}{c_{1}}
$$

A oferta ao produtor é uma função linear do preço recebido $(p)$ no período anterior:

$$
P_{t}^{s}=\gamma_{0}+\gamma_{1} p_{t-1} \quad \gamma_{1}>0
$$

8 Notar que este "preço-meti"é o preço de equilibrio para funçăo de produção de Leontief e retornos constantes à escalia, visto em HEIEN 
O "preço-meta" ao produtor é estabelecido segundo:

$$
p_{t}^{*}=\frac{a_{t}-c_{2} x_{t}}{c_{1}}
$$

No curto prazo, o ajustamento do preço ao produtor se dá por ajustes parciais:

$$
p_{t}-p_{t-1}=\beta\left(p_{t}^{*}-p_{t-1}\right) \quad 0<\beta<1
$$




\section{MODELO PROPOSTO}

O modelo econômico proposto a seguir baseia-se, fundamentalmente, nos modelos de Heien e de Barros. Serão considerados os três níveis de mercado (produtor, atacado e varejo). As variações de preços se iniciarão, por hipótese, ao nível de atacado, ou seja, ao nível de atacado os preços se ajustam instantâneamente, de acordo com o excesso de demanda. Considerando que, nos níveis de varejo e produtor, as transações são descentralizadas e ocorrem com defasagem em relação às transações ao atacado; as mudanças de preços nestes niveis se darão por meio de ajustes parciais até atingirem o preço de equilíbrio ou "preço-meta".

Como não existe certeza que a mudança de preços observada ao atacado tem caráter permanente, ao invés de cobrar imediatamente o "preço-meta", existe uma tendência de ir ajustando-se os preços, lentamente, em direção ao "preço-meta". Os ajustamentos parciais e por excesso de demanda são formas de se admitir a existência de desequilibrio nos mercados no curto prazo.

A principal mudança que será feita no modelo de BARROS, visa considerar os subprodutos que são obtidos ao nível de atacado, portanto, baseado na função de produção do atacadista assume-se que:

$$
a_{t}=c_{1}\left(p_{t}^{*}-\rho s_{t}\right)+c_{2}, x_{1}
$$


onde $0 \leq \rho \leq 1$ mede o grau em que os subprodutos são levados em consideração ao se determinar $a_{t}$. Sendo assim, a equação (23), que representa o "preço-meta" ao produtor sofre uma alteração ficando:

$$
p_{t}^{*}=\frac{a_{t}-c_{2} x_{t}}{c_{1}}+\rho s_{t}
$$

em que $a, x$ e $s$ são, respectivamente, os preços do produto ao atacado, dos insumos de comercialização e dos subprodutos obtidos ao atacado por kg de carcaça.

Das equações (19), (20), (16), (21) e (22) chega-se à seguinte expressão do preço ao atacado:

$$
a_{t}=\delta\left(b_{1} \theta_{0}-\frac{\gamma_{0}}{c_{1}}\right)+\delta b_{1} \theta_{1} v_{t-1}-\delta \frac{\gamma_{1}}{c_{1}} p_{t-1}+a_{t-1}
$$

Analisado-se os sinais da expressão (26) verificamos que o preço ao atacado é influenciado negativamente pelos preços defasados ao varejo e ao produtor.

Das equações (17) e (18) obtém-se:

$$
v_{t}-v_{t-1}=\alpha\left(b_{1} a_{t}+b_{2} z_{t}-v_{t-1}\right)
$$

Isolando-se o preço corrente ao varejo:

$$
v_{t}=(1-\alpha) v_{t-1}+\alpha b_{1} a_{t}+\alpha b_{2} z_{t}
$$


A expressão (27) mostra que o preço ao varejo é influenciado positivamente pelo preço ao varejo defasado e pelo preço ao atacado corrente, e também sofre influência positiva dos insumos de comercialização utilizados ao varejo.

Substituindo-se a equação (25) na (24):

$$
p_{t}-p_{t-1}=\beta\left(\frac{a_{t}-c_{2} x_{t}}{c_{1}}+\rho \dot{s}_{t}-p_{t-1}\right)
$$

Isolando-se o preço ao produtor:

$$
p_{t}=(1-\beta) p_{t-1}+\frac{\beta}{c_{1}} a_{t}-\beta \frac{c_{2}}{c_{1}} x_{t}+\beta \rho s_{t}
$$

A equação (28) mostra que o preço ao produtor é positivamente influenciado pelos preços ao produtor defasado e pelo preço ao atacado atualizado, negativamente influenciado pelos preços dos insumos de comercialização usados ao atacado e positivamente influenciado pelos preços dos subprodutos.

As equações (26), (27) e (28) constituem a forma estrutural do modelo. Examinando-se a forma estrutural percebe-se que as hipóteses do modelo resultam numa estrutura causal de $a_{t}$ para $p_{t}$ e $v_{t}$. 
Também observa-se facilmente que, de posse das estimativas dos coeficientes dessas equações, pode-se obter os valores de alguns parâmetros que, a princípio, parecem de difícil determinação.

A obtenção dos valores desses parâmetros será de grande importância para uma interpretação mais detalhada dos resultados.

$\mathrm{Na}$ equação (27), sabendo-se a estimativa do coeficiente de $v_{t-1}$, facilmente obtém-se o valor do parâmetro $\alpha$ e sabendo-se a estimativa do coeficiente de $a_{t}$, juntamente com o valor de $\alpha$ ( já obtido), chega-se ao valor de $b_{1}$. Da mesma forma, sabendo-se a estimativa do coeficiente de $z_{t}$, chega-se ao valor de $b_{2}$.

A partir da equação (28), sabendo-se a estimativa dos coeficientes de $p_{t-1}, a_{t}, x_{t}$ e $s_{t}$; obtêm-se, da mesma maneira que foi explicado acima, os valores de $\beta, c_{1}, c_{2}$ e $\rho$. 


\section{Margens de comercialização}

Como foi definido no capítulo 2 , a margem de comercialização é a diferença de preços de quantidades equivalentes em diferentes níveis de mercado. Então utilizando-se a notação do modelo dinâmico, serão descritas três equações de margem: margem total estrutural, margem do varejo estrutural, margem do atacado estrutural.

\section{Margem total estrutural}

Como:

$$
M T E_{t}=v_{t}-b_{1} c_{1}\left(p_{t}-s_{t}\right)
$$

Tem-se,das equações (27) e (28):

$$
\begin{aligned}
M T E_{t}= & (1-\alpha) v_{t-1}+b_{1} c_{1}(\beta-1) p_{t-1}+\left(\alpha b_{1}-b_{1} \beta\right) a_{t}+ \\
& (1-\beta \rho) b_{1} c_{1} s_{t}+\alpha b_{2} z_{t}+b_{1} \beta c_{2} x_{t} .
\end{aligned}
$$

Analisando-se a equação (29), verifica-se que o preço ao varejo defasado tende a ser positivo, ou seja, quanto maior o preço ao varejo maior deve ser a margem de comercialização no periodo seguinte. $O$ coeficiente do preço ao produtor defasado tende a ser negativo. $O$ preço ao atacado afetará positivamente a margem total estrutural se $\boldsymbol{\alpha}>\boldsymbol{\beta}$ e, negativamente caso contrário. Os valores dos 
subprodutos tendem a influenciar positivamente a margem. Os insumos de comercialização, usados ao atacado e ao varejo, afetam positivamente a margem total estrutural de comercialização.

\section{Margem do varejo estrutural}

Como:

$$
M V E_{t}=v_{t}-b_{1} a_{t}
$$

Tem-se, das equações (26) e (27):

$$
\begin{gathered}
M V E_{t}=-b_{1} \delta\left(b_{1} \theta_{0}-\frac{\gamma_{0}}{\gamma_{1}}\right)-b_{1}\left(\delta b_{1} \theta_{1}\right)(1-\alpha) v_{t-1}+ \\
b_{1} \delta \frac{\gamma_{1}}{c_{1}} p_{t-1}-b_{1} a_{t-1}+\alpha b_{1} a_{t}+\alpha b_{2} z_{t}
\end{gathered}
$$

Analisando a equação (30), verifica-se que o preço ao varejo defasado afeta positivamente a margem estrutural dos varejistas. O preço ao produtor defasado também afeta positivamente a margem estruturada ao varejo. $O$ preço ao atacado defasado tende a afetar negativamente esta margem do varejo; enquanto que o preço ao atacado atualizado afeta positivamente. Os insumos de comercialização usados ao varejo afetam positivamente a margem estrutural dos varejistas. 


\section{Margem do atacado estrutural}

Como:

$$
M A E_{t}=a_{t}-c_{1}\left(p_{t}-s_{t}\right)
$$

Tem-se,das equações (26) e (28):

$$
\begin{aligned}
M A E_{t}= & \delta\left(b_{1} \theta_{0}-\frac{\gamma_{0}}{\gamma_{1}}\right)+\delta b_{1} \theta_{1} v_{t-1}+\delta \gamma_{1}(1-\beta) p_{t-1}+a_{t-1}- \\
& \beta_{1} a_{t}+(1-\beta \rho) c_{1} s_{t}+\beta c_{2} x_{t}
\end{aligned}
$$

Analisando-se a equação (31), pode-se verificar que a preço ao varejo defasado influencia negativamente a margem estrutural ao atacado. Quanto maior o preço ao produtor, maior a margem ao atacado no periodo seguinte. O preço ao atacado defasado afeta positivamente a margem ao atacado, enquanto que o preço ao atacado atualizado afeta negativamenta está mesma margem. $O$ preço dos subprodutos afeta positivamente a margem estrutural ao atacado. Os insumos de comercialização usados ao atacado afetam positivamente a margem ao atacado. 


\subsection{Forma final}

A forma reduzida é mais conveniente que a estrutural para analisar os efeitos de mudanças exógenas no comportamento das variáveis endógenas, embora não permita verificar a estrutura de funcionamento do mercado. Porém, quando ocorrem variáveis endógenas defasadas, THEIL (1971) apresenta uma terceira forma, a forma final, que seria mais adequada para mensurar o efeito dos choques nas variáveis exógenas, por apresentar as variáveis endógenas como função apenas das variáveis exógenas correntes e defasadas.

A obtenção da forma final inicia-se com as equações reduzidas dos preços ao varejo, ao produtor e ao atacado e da margem total de comercialização9 .

\section{Equações reduzidas dos preços}

Substituindo-se a equação (26) na equação (27):

$$
\begin{gathered}
v_{t}=\alpha b_{1} \delta\left(b_{1} \theta_{0}-\frac{\gamma_{0}}{c_{1}}\right)+\left[1-\alpha\left(\alpha b_{1}^{2} \delta \theta_{1}\right)\right] v_{t-1}- \\
\alpha b_{1} \delta \frac{\gamma_{1}}{c_{1}} p_{t-1}+\alpha b_{1} a_{t-1}+\alpha b_{2} z_{t}
\end{gathered}
$$

A expressão (32) mostra que o preço ao varejo é negativamente afetado pelos preços ao produtor defasados, positivamente afetado pelos preços do atacado defasados e positivamente pelos preços dos insumos do varejo.

9 Neste caso será usida a margem total, porém, a metodologia usando as margens ao varejo e ao atacado é basicamente a mesma. 
Substituindo-se a equação (26) na (28):

$$
\begin{aligned}
p_{t}= & \delta \frac{\beta}{c_{1}}\left(b_{1} \theta_{0}-\frac{\gamma_{0}}{c_{1}}\right)+\frac{\beta}{c_{1}} \delta b_{1} \theta_{1} v_{t-1}+\left[(1-\beta)-\frac{\beta}{c_{1}}\left(\delta \frac{\gamma_{1}}{c_{1}}\right)\right] p_{t-1}+ \\
& \frac{\beta}{c_{1}} a_{t-1}-\beta \frac{c_{2}}{c_{1}} x_{t}+\beta \rho s_{t}
\end{aligned}
$$

A expressão (33) mostra que o preço ao produtor é negativamente influenciado pelos preços do varejo defasados, positivamente influenciado pelos preços do atacado defasados e dos subprodutos; e negativamente pelos preços dos insumos de comercialização usados ao atacado.

No caso do preço ao atacado as formas estrutural e reduzida são representadas pela equação (26) :

$$
a_{t}=\delta\left(b_{1} \theta_{0}-\frac{\gamma_{0}}{c_{1}}\right)+\delta b_{1} \theta_{1} v_{t-1}-\delta \frac{\gamma_{1}}{c_{1}} p_{t-1}+a_{t-1}
$$

\section{Margem total reduzida}

Como:

$$
M T R_{t}=v_{t}-b_{1} c_{1}\left(p_{t}-s_{t}\right)
$$

Tem-se, das equações (32) e (33):

$$
\begin{aligned}
M T R_{t}= & \left\{(\alpha-\beta)\left[b_{1} \delta\left(b_{1} \theta_{0}-\frac{\gamma_{0}}{c_{1}}\right]\right\}+\left[(1-\alpha)+\left(\alpha b_{1}^{2} \delta \theta_{1}\right)-b_{1}^{2} \beta \delta \theta_{1}\right] p_{t-1}+\right. \\
& \left\{\left(-\alpha b_{1} \delta \frac{\gamma_{1}}{c_{1}}\right)-\left[b_{1} c_{1}(1-\beta)\right]+\left(b_{1} \beta \delta \frac{\gamma_{1}}{c_{1}}\right)\right\} p_{t-1}+\left[b_{1}(\alpha-\beta)\right] a_{t-1}+ \\
& (1-\beta \rho) b_{1} c_{1} s_{t}+\alpha b_{2} z_{t}+b_{1} \beta c_{2} x_{t}
\end{aligned}
$$


Fazendo-se:

$k_{0}=\left\{(\alpha-\beta)\left[b_{1} \delta\left(b_{1} \theta_{0}-\frac{\gamma_{0}}{c_{1}}\right]\right\}\right.$

$k_{1}=\left[(1-\alpha)+\left(\alpha b_{1}^{2} \delta \theta_{1}\right)-b_{1}^{2} \beta \delta \theta_{1}\right]$

$k_{2}=\left\{\left(-\alpha b_{1} \delta \frac{\gamma_{1}}{c_{1}}\right)-\left[b_{1} c_{1}(1-\beta)\right]+\left(b_{1} \beta \delta \frac{\gamma_{1}}{c_{1}}\right)\right\}$

$k_{3}=\left[b_{1}(\alpha-\beta)\right] \quad k_{4}=(1-\beta \rho) b_{1} c_{1}$

Tem-se:

$$
M T R_{t}=k_{0}+k_{1} v_{t-1}+k_{2} p_{t-1}+k_{3} a_{t-1}+k_{4} s_{t}+\alpha b_{2} z_{t}+b_{1} \beta c_{2} x_{t}
$$

A equação (34') representa a margem total reduzida de comercialização a ser estimada, sendo que, os valores em negrito são as variáveis envolvidas na estimação. Analisando o sinal de $k_{1}$, espera-se que o preço ao varejo defasado afete positivamente a margem total reduzida, caso $\alpha>\beta$, e negativamente caso contrário. O coeficiente do preço ao produtor defasado, $k_{2}$, é de difícil determinação, pois depende de uma expressão que envolve um número grande de coeficientes de valores desconhecidos. O preço ao atacado defasado afetará positivamente a margem de comercialização, se $\alpha>\beta$, e negativamente caso contrário. Os valores dos subprodutos tendem a influenciar positivamente a margem. Os insumos de comercialização, usados ao atacado e ao varejo, afetam positivamente a margem total reduzida de comercialização. 
A seguir, coloca-se na forma de vetores e matrizes as variáveis e os coeficientes desse sistema de equações reduzidas:

$$
\begin{aligned}
& y_{t}=\left[\begin{array}{c}
v_{t} \\
p_{t} \\
a_{t} \\
M T_{t}
\end{array}\right] \quad w_{t}=\left[\begin{array}{l}
z_{t} \\
x_{t} \\
s_{t}
\end{array}\right] \\
& d_{0}=\left[\begin{array}{c}
\alpha b_{1} \delta\left(b_{1} \theta_{0}-\frac{\gamma_{0}}{c_{1}}\right) \\
\delta \frac{\beta}{c_{1}}\left(b_{1} \theta_{0}-\frac{\gamma_{0}}{c_{1}}\right) \\
\delta\left(b_{1} \theta_{0}-\frac{\gamma_{0}}{c_{1}}\right) \\
(\alpha-\beta)\left(b_{1} \delta\left(b_{1} \theta_{0}-\frac{\gamma_{0}}{c_{1}}\right)\right)
\end{array}\right]
\end{aligned}
$$

$D_{1}=\left[\begin{array}{cccc}1-\alpha\left(\alpha b_{1}^{2} \delta \theta_{1}\right) & \left(\alpha b_{1} \delta \frac{\gamma_{1}}{c_{1}}\right) & \alpha b_{1} & 0 \\ \left(\frac{\beta}{c_{1}} \delta b_{1} \theta_{1}\right) & \left.(1-\beta)-\frac{\beta}{c_{1}}\left(\delta \frac{\gamma_{1}}{c_{1}}\right)\right) & \frac{\beta}{c_{1}} & 0 \\ \left(\delta b_{1} \theta_{1}\right) & \left(-\delta \frac{\gamma_{1}}{c_{1}}\right) & 1 & 0 \\ \left((1-\alpha)+\left(\alpha b_{1}^{2} \delta \theta_{1}\right)-b_{1}^{2} \beta \delta \theta_{1}\right) & \left(\left(-\alpha b_{1} \delta \frac{\gamma_{1}}{c_{1}}\right)-\left[b_{1} c_{1}(1-\beta)\right]+\left(b_{1} \beta \delta \frac{\gamma_{1}}{c_{1}}\right)\right) & \left(b_{1}(\alpha-\beta)\right) & 0\end{array}\right]$

$$
D_{2}=\left[\begin{array}{ccc}
\alpha b_{2} & 0 & 0 \\
0 & -\beta \frac{c_{2}}{c_{1}} & \beta \rho \\
0 & 0 & 0 \\
\alpha b_{2} & b_{1} \beta c_{2} & (1-\beta) b_{1} c_{1} \rho
\end{array}\right]
$$


Após definir as matrizes e os vetores, o sistema formado pelas equações reduzidas é representado pela seguinte equação:

$$
y_{t}=d_{0}+D_{1} y_{t-1}+D_{2} w_{t}+\varepsilon_{t}
$$

onde $\varepsilon t$ é o vetor de desvios das equações reduzidas, incluído na forma ser estimada.

Defasando $y_{t}$ de um período e substituindo o resultado no lado direito da equação anterior:

$$
\begin{aligned}
& y_{t}=d_{0}+D_{1}\left(d_{0}+D_{1} y_{t-2}+D_{2} w_{t-1}+\varepsilon_{t-1}\right)+D_{2} w_{t}+\varepsilon_{t} \\
& y_{t}=\left(I+D_{1}\right) d_{0}+D_{1}^{2} y_{t-2}+D_{2} w_{t}+D_{1} D_{2} w_{t-1}+\varepsilon_{t}+D_{1} \varepsilon_{t-1}
\end{aligned}
$$

A condição necessária e suficiente para que $D_{1} s$ se aproxime de uma matriz nula à medida que $s$ aumenta indefinidamente, é que todas as raizes características da matriz $D_{1}$ estejam dentro do círculo unitário ${ }^{10}$.Diz-se, então, que houve convergência do modelo e as estimativas dos parâmetros de $D_{1}$ podem ser utilizados na verificação da convergência.

Para concluir a obtenção da forma final, substitui-se continuamente os valores defasados de $y$ :

$$
y_{t}=\left(I-D_{1}\right)^{-1} d_{0}+D_{2} w_{t}+\sum_{j=1}^{\infty} D_{1}^{j} D_{2} w_{t-j}+\sum_{j=0}^{\infty} D_{1}^{j} \varepsilon_{t-j}
$$

Através dos multiplicadores de impacto, pode-se visualizar em quantos reais variam as variáveis endógenas quando ocorre uma variação de um real nas variáveis exógenas. $\mathrm{O}$ efeito imediato é dado pela primeira matriz de coeficientes: $D_{2}$; o efeito com defasagem de um periodo é dado por $D_{1} D_{2}$; o efeito com defasagem de 2 períodos é dado por $D_{1}^{2} D_{2}$; o efeito com defasagem $k$ é igual a $D_{1}{ }^{k} D_{2}$; e o efeito total é dado por $\left(I-D_{1}\right)^{-1} D_{2}$.

10 CHIANG (1982,p. 297) explica como calcular as raizes caracteristicas de uma matriz. 


\section{PROCEDIMENTOS}

\subsection{Dados Básicos}

As séries de preços utilizadas nesta pesquisa foram obtidas de três fontes básicas a saber: Instituto de Economia Agrícola (IEA), Boletim Informativo INTERCARNES e Fundação Getúlio Vargas (FGV) no período de janeiro de 1986 a junho de 1994. Todas as séries foram deflacionadas com base no Índice Geral de Preços - disponibilidade interna (IGP-DI), elaborado pela Fundação Getúlio Vargas, com base em junho de 1994.

As séries de preços mensais aos níveis de produtor, atacado e varejo foram obtidas do IEA, sendo que a nível de produtor foi obtido o preço da arroba do boi gordo ponderado para várias regiões de produção do Estado de São Paulo, a nível de atacado foram obtidos os preços do quilo de quarto traseiro, quarto dianteiro e ponta de agulha para a cidade de São Paulo e os preços de varejo correspondem ao valor médio do quilo de carne vendido aos consumidores também para a cidade de São Paulo.

Como os preços aos produtores que são publicados correspondem a 15 $\mathrm{kg}$, estes preços foram divididos por 15 para se tornarem compativeis com os preços dos outros níveis de mercado.

As séries com os preços dos subprodutos foram obtidas de levantamentos diários realizados pelo boletim informativo INTERCARNES. Tendo 
por base estes dados foram calculadas as médias mensais. Esses preços estão expressos em valor médio do conjunto de subprodutos gerado por animal abatido.

Os insumos de comercialização utilizados são: óleo diesel, cujos preços mensais foram obtidos do IEA; salário-mínimo, cujos valores mensais foram obtidos da FGV e taxas de juros, cuja fonte foi Taxa de Juros do Brasil(1992). A taxa de juros utilizada é o custo real efetivo do financiamento do capital de giro (pagamento em 6 meses) cobrado pelas instituições financeiras.

\subsection{Procedimentos}

Um dos procedimentos adotado foi a inclusão dos valores do salário mínimo, do óleo diesel e da taxa de juros como medidas aproximadas dos custos dos insumos de comercialização utilizados ao varejo e ao atacado (respectivamente $z \mathrm{e}$ $\boldsymbol{x}$ ). $\mathrm{Na}$ impossibilidade de se conseguir variáveis que diferenciassem os custos de comercialização nos mercados de varejo e de atacado; optou-se por utilizar as mesmas variáveis para ambos os mercados.

$\mathrm{Na}$ tentativa de melhor ajustamento dos modelos foi incluída uma variável binária para o período de outubro de 1986 a maio de 1987, quando as séries apresentaram comportamento atípico pelo efeito das distorções causadas pelo Plano Cruzado; e também foi incluída uma variável tendência.

Serão estimados, primeiramente, os diversos modelos empíricos de margem de comercialização elaborados a partir do modelo teórico proposto no capítulo 4. A seguir será feita uma análise da importância estática e dinâmica das variáveis predeterminadas (incluindo as variáveis de custo de comercialização e os preços defasados) sobre a margem de comercialização e sobre os preços nos 3 niveis de mercado considerados. 


\section{- Análise dos Modelos Dinâmicos de Margem de Comercialização}

Como visto no capitulo 4 foram desenvolvidos diversos modelos teóricos de margem de comercialização. Todos estes modelos serão estimados nesta pesquisa; utilizando-se dados mensais para todas as variáveis.

Sendo assim, as equações a serem estimadas são as seguintes:

- Margem Total Estrutural:

$$
M T E_{t}=\beta_{1} v_{t-1}+\beta_{2} p_{t-1}+\beta_{3} a_{t}+\beta_{4} s_{t}+\beta_{5} S M_{t}+\beta_{6} O D_{t}+\beta_{7} T J_{t}+\beta_{8} Z 1_{t}+\beta_{g} t d_{t}+\varepsilon_{t}
$$

- Margem do Varejo Estrutural:

$$
M V E_{t}=\beta_{0}+\beta_{1} v_{t-1}+\beta_{2} p_{t-1}+\beta_{3} a_{t-1}+\beta_{4} a_{t}+\beta_{5} S M_{t}+\beta_{6} O D_{t}+\beta_{7} T J_{t}+\beta_{8} Z I_{t}+\beta g t d_{t}+\varepsilon_{t}
$$

- Margem do Atacado Estrutural:

$$
\begin{aligned}
M A E_{t}=\beta_{0}+\beta_{1} v_{t-1}+\beta_{2} p_{t-1}+\beta_{3} a_{t-1}+ & \beta_{4} P a_{t}+\beta_{5} s_{t}+\beta_{6} S M_{t} \\
& +\beta_{7} O D_{t}+\beta_{8} T J_{t}+\beta_{9} Z I_{t}+\beta_{10} t d_{t}+\varepsilon_{t}
\end{aligned}
$$

As variáveis utilizadas nas estimações são as seguintes:

$M T_{t}$, a margem total de comercialização (produtor-varejo) da carne bovina; $M V_{t}$, a margem de comercialização atacado-varejo; $M A_{t}$, a margem de comercialização produtor-atacado; $v_{t}$, o preço ao varejo no mês $t ; p_{t}$, o preço ao produtor no mês $t$; $a_{t}$; o preço ao atacado no mês $t ; s_{t}$, o valor dos subprodutos no mês $t ; S M_{t}$, o salário-mínimo do mês $t ; O D_{t}$, o preço do óleo diesel no mês $t ; T J_{t}$, a 
taxa real de juros no mês $t ; \boldsymbol{I}_{t}$, uma variável binária que assume valor um nos meses de outubro de 86 a maio de 87 e valor zero nos demais meses; $t d_{t}$, uma variável tendência e $\varepsilon_{t}$ é o erro.

As estimações serão feitas por mínimos quadrados ordinários (MQO) e os critérios utilizados para analisá-las serão relacionados no capítulo referente à análise dos resultados (cap. 6).

- Efeito estático do custo de comercialização e dos subprodutos

Nesta pesquisa assume-se que o óleo diesel é uma proxy do custo de transporte; o sálario-mínimo é uma proxy de todo custo de mão-de-obra do processo de comercialização e a taxa de juros é uma proxy do custo (de oportunidade) de armazenamento. Portanto, essas variáveis, juntamente com o valor dos subprodutos, dão uma idéia de como as atividades por elas representadas influenciam a margem de comercialização e os preços de cada um dos mercados estudados.

No caso dos preços, as equações (26), (27) e (28) serão estimadas por mínimos quadrados em dois estágios, pois esse sistema apresenta simultaneidade. Essas estimativas servirão também para determinar os valores dos parâmetros $\alpha, b_{1}$ $, b_{2}, \boldsymbol{\beta}, c_{1}$ e $c_{2} ;$ como descrito no capítulo 4 .

Portanto, as equações a serem estimadas são:

- Preço ao Atacado:

$a_{t}=\theta_{0}+\theta_{1} v_{t-1}+\theta_{2} p_{t-1}+\theta_{3} a_{t-1}+\theta_{4} z 1_{t}+\varepsilon_{t}$

- Preço ao Varejo:

$v_{t}=\theta_{l} v_{t-l}+\theta_{2} a_{t}+\theta_{3} S M_{t}+\theta_{t} O D_{t}+\theta_{5} T J_{t}+\theta_{6} Z I_{t}+\varepsilon_{t}$

-Preço ao Produtor:

$p_{t}=\theta_{1} p_{t-1}+\theta_{2} a_{t}+\theta_{3} s_{t}+\theta_{4} S M_{t}+\theta_{5} O D_{t}+\theta_{6} T J_{t}+\theta_{7} Z I_{t}+\delta_{t}$ 
- Efeito dinâmico do custo de comercialização e dos subprodutos

Nesta parte serão analisados os efeitos de curto e de longo prazo. $\mathrm{O}$ procedimento utilizado para obter estes efeitos é conhecido por multiplicadores de THEIL. O método de Theil inicia-se obtendo a forma final do modelo dinâmico, como demonstrado no capítulo 4, até chegar aos multiplicadores de impacto. Serão estimados os coeficientes das equações reduzidas de preços nos três níveis de mercado e da margem total, a seguir serão definidas as matrizes de relações entre as variáveis endógenas $\left(D_{1}\right)$ e de choques das variáveis exógenas $\left(D_{2}\right)$; e essas matrizes serão então multiplicadas de maneira contínua (como explicado no capítulo 4) para se obter o efeito de choques nas variáveis exógenas sobre as endógenas, mês a mês.

Como já foi visto neste capítulo, as variáveis $\boldsymbol{z}$ e $\boldsymbol{x}$ foram substituídas pelos insumos já listados; portanto o vetor $w_{t}$ da forma final também foi alterado.

Nas estimações das equações de preços e margem, será utilizado o método de Zellner ou método SUR; pois os erros destas equações podem apresentar correlação contemporânea, pelo fato de serem equações reduzidas originadas do mesmo sistema estrutural.

\section{- Método SUR}

Para tornar os estimadores mais eficientes as 4 equações da forma final foram estimadas conjuntamente, utilizando-se para isto o método SUR ( Seemingly Unrelated Regression Equations ).

O método SUR é utilizado quando o erro de uma das equações de regressão está correlacionado com o erro de alguma outra equação de regressão, no 
mesmo período de tempo. Correlação entre erros de diferentes equações em um dado período de tempo é conhecida como "correlação contemporânea " ( note que existe uma diferença para autocorrelação, que surge quando o erro da observação relativa a um período está correlacionado com o erro da observação anterior ).

Portanto, além de todos os pressupostos do modelo de regressão linear clássico, deve-se assumir que:

$$
\operatorname{covar}\left(e_{i t} e_{j t}\right)=E\left[e_{i t} e_{j t}\right]=\sigma_{i j} \quad i, j=1,2, \ldots K \quad\left(K=\mathrm{n}^{\circ} \text { de equações }\right)
$$

Matricialmente, esta pressuposição se torna (para um sistema de 4 equações):

$$
\begin{aligned}
\Phi=E\left[\mathrm{ee}^{\prime}\right]= & E\left[\left(\begin{array}{l}
e_{1} \\
e_{2} \\
e_{3} \\
e_{4}
\end{array}\right)\left(\begin{array}{llll}
e_{1}^{\prime} & e_{2}^{\prime} & e_{3}^{\prime} & e_{4}^{\prime}
\end{array}\right)\right] \\
& =\left[\begin{array}{llll}
E e_{1} e_{1}^{\prime} & E e_{1} e_{2}^{\prime} & E e_{1} e_{3}^{\prime} & E e_{1} e_{4}^{\prime} \\
E e_{2} e_{1}^{\prime} & E e_{2} e_{2}^{\prime} & E e_{2} e_{3}^{\prime} & E e_{2} e_{4}^{\prime} \\
E e_{3} e_{1}^{\prime} & E e_{3} e_{2}^{\prime} & E e_{3} e_{3}^{\prime} & E e_{3} e_{4}^{\prime} \\
E e_{4} e_{1}^{\prime} & E e_{4} e_{2}^{\prime} & E e_{4} e_{3}^{\prime} & E e_{4} e_{4}^{\prime}
\end{array}\right] \\
& =\left[\begin{array}{llll}
\sigma_{11} I & \sigma_{12} I & \sigma_{13} I & \sigma_{14} I \\
\sigma_{12} I & \sigma_{22} I & \sigma_{23} I & \sigma_{24} I \\
\sigma_{13} I & \sigma_{23} I & \sigma_{33} I & \sigma_{34} I \\
\sigma_{14} I & \sigma_{24} I & \sigma_{34} I & \sigma_{44} I
\end{array}\right] \\
& =\left[\begin{array}{llll}
\sigma_{11} & \sigma_{12} & \sigma_{13} & \sigma_{14} \\
\sigma_{12} & \sigma_{22} & \sigma_{23} & \sigma_{24} \\
\sigma_{13} & \sigma_{23} & \sigma_{33} & \sigma_{34} \\
\sigma_{14} & \sigma_{24} & \sigma_{34} & \sigma_{44}
\end{array}\right] \otimes I_{T} \\
& =\Sigma \otimes I_{T}
\end{aligned}
$$


A matriz de covariância do erro $\Phi$ é de dimensão $(4 \mathrm{~T} \times 4 \mathrm{~T})$ com cada submatriz $(T \times T)$ sendo igual a um escalar multiplicado pela matriz identidade $T$ dimensional ${ }^{11}$.

JUDGE et al. (1988) apresentam um teste para verificar a existência de correlação contemporânea; caso não exista, pode-se estimar as equações separadamente utilizando-se mínimos quadrados. As hipóteses nula e alternativa para esse teste são (no caso de um sistema com 4 equações):

$H_{0}: \sigma_{12}=\sigma_{13}=\sigma_{14}=\sigma_{23}=\sigma_{24}=\sigma_{34}=0$

$H_{1}$ : todas as covariâncias são diferentes de zero

Utilizando-se a estatística do multiplicador de Lagrange, para um caso geral de $M$ equações:

$$
\lambda=T \sum_{i=2}^{M} \sum_{j=1}^{i-1} r_{i j}^{2} \quad \text { onde } r_{i j}^{2}=\frac{\hat{\sigma}_{i j}^{2}}{\hat{\sigma}_{i i} \hat{\sigma}_{i j}}
$$

Sob $H_{0}, \lambda$ tem uma distribuição $\chi^{2}$ com $\mathrm{M}(\mathrm{M}-1) / 2$ graus de liberdade. Além disso, rejeita-se $H_{0}$ se $\lambda$ for maior que o valor crítico da distribuição de $\chi^{2}$, para determinado nível de significância.

Aplicando-se este teste para as equações da forma final, a estatística é dada por:

$$
\lambda=T\left(r_{12}^{2}+n_{3}^{2}+n_{4}^{2}+r_{23}^{2}+r_{24}^{2}+r_{34}^{2}\right)
$$

11 É utilizada a notaçăo do produto de Kronecker. JUDGE et alli (1988) apresentam, na seçđo A. 15 do Apêndice $A$, esta notaçĩo. 
Caso a hipótese nula seja rejeitada, pode-se afirmar que existe correlação contemporânea e deve-se estimar as equações pelo método SUR.

Deste modo, o melhor estimador linear não viesado para $\boldsymbol{\beta}$ é o estimador de mínimos quadrados generalizados dado pela seguinte relação:

$$
\begin{aligned}
& \hat{\boldsymbol{\beta}}=\left(X^{\prime} \Phi^{-1} X\right)^{-1} X^{\prime} \Phi^{-1} y \\
& \hat{\boldsymbol{\beta}}=\left[X^{\prime}\left(\Sigma^{-1} \otimes I\right) X\right]^{-1} X^{\prime}\left(\Sigma^{-1} \otimes I\right) y
\end{aligned}
$$

Entretanto, os elementos da matriz de variâncias e covariâncias do erro, $\Phi$, não são conhecidos. Então, o primeiro passo é obter, por mínimos quadrados, estimadores consistentes para esta matriz.

Se definirmos $\hat{\Sigma}$ como sendo a estimativa da matriz $\Sigma$, então o correspondente estimador de mínimos quadrados generalizados para $\boldsymbol{\beta}$ pode ser definido por:

$$
\hat{\hat{\beta}}=\left[X^{\prime}\left(\hat{\Sigma}^{-1} \otimes I\right) X\right]^{-1} X^{\prime}\left(\hat{\Sigma}^{-1} \otimes I\right) y
$$




\section{ANÁLISE DOS RESULTADOS}

Neste capítulo serão discutidas as estimativas dos coeficientes das equações de margem obtidas de acordo com o modelo teórico do capítulo 4 . Também serão analisados os multiplicadores de Theil para as equações de preços $\mathrm{e}$ da margem total reduzida. A análise será feita sob um ponto de vista estatístico e econômico, o que permitirá detectar os fatores mais importantes que determinam a formação da margem de comercialização de carne bovina para o Estado de São Paulo.

\subsection{Equações de margem}

Os resultados apresentados na tabela 7 são provenientes da estimação das expressões (29), (30) e (31) do capítulo 4, com as modificações já comentadas .

Iniciando-se pelo modelo de margem total, equação(29), observa-se um alto valor para o coeficiente de determinação $(98,8 \%)$. Os coeficientes dos preços da carne bovina nos diferentes mercados estudados apresentaram bom comportamento, sendo que, os preços ao varejo e ao produtor defasados e o preço ao atacado corrente apresentaram sinais compatíveis com o previsto pelo modelo teórico e também todos os coeficientes apresentaram valores significativos. Já o coeficiente dos subprodutos, apesar de apresentar sinal positivo, de acordo com o modelo, não foram significativos. 
Tabela 7 - Estimativas dos modelos estruturais de margem de comercialização total, do varejo e do atacado; da carne bovina no estado de São Paulo; dados mensais de 1986 a 1993.

\begin{tabular}{|c|c|c|c|}
\hline $\begin{array}{l}\text { Variáveis e } \\
\text { Estatísticas } \\
\end{array}$ & $\begin{array}{c}\text { Margem } \\
\text { Total }\end{array}$ & $\begin{array}{c}\text { Margem } \\
\text { do Varejo }\end{array}$ & $\begin{array}{c}\text { Margem } \\
\text { do Atacado }\end{array}$ \\
\hline Constante & - & $\begin{array}{l}0,2214 \\
(0,824)\end{array}$ & $\begin{array}{l}0,2169 \\
(1,439)\end{array}$ \\
\hline$v_{t-1}$ & $\begin{array}{l}0,5103 \\
(7,463)^{* * *}\end{array}$ & $\begin{array}{c}0,5246 \\
(5,790)^{* * *}\end{array}$ & $\begin{array}{l}0,0495 \\
(0,962)\end{array}$ \\
\hline$p_{t-1}$ & $\begin{array}{c}-0,5300 \\
(-3,859)^{* * *}\end{array}$ & $\begin{array}{l}0,1235 \\
(0,799)\end{array}$ & $\begin{array}{c}-0,2987 \\
(-2,895)^{* * *}\end{array}$ \\
\hline$a_{t-1}$ & - & $\begin{array}{l}-0,7078 \\
(-3,827)^{* * *}\end{array}$ & $\begin{array}{c}0,1801 \\
(1,668)^{*}\end{array}$ \\
\hline$a_{t}$ & $\begin{array}{c}0,4469 \\
(5,878)^{* * *}\end{array}$ & $\begin{array}{c}0,3266 \\
(3,883)^{* * *}\end{array}$ & $\begin{array}{c}0,1768 \\
(3,522)^{* * *}\end{array}$ \\
\hline$s_{t}$ & $\begin{array}{l}0,0019 \\
(1,541)\end{array}$ & - & $\begin{array}{l}0,0006 \\
(0,887)\end{array}$ \\
\hline$S M_{t}$ & $\begin{array}{l}-0,0010 \\
(-0,653)\end{array}$ & $\begin{array}{l}-0,0019 \\
(-1,013)\end{array}$ & $\begin{array}{l}-0,0002 \\
(-0,245)\end{array}$ \\
\hline$O D_{t}$ & $\begin{array}{c}-0,5901 \\
(-1,787)^{*}\end{array}$ & $\begin{array}{l}-0,5521 \\
(-1,450)\end{array}$ & $\begin{array}{l}-0,1887 \\
(-0,901)\end{array}$ \\
\hline$T J_{t}$ & $\begin{array}{l}-0,0022 \\
(-0,516)\end{array}$ & $\begin{array}{l}-0,0038 \\
(-0,868)\end{array}$ & $\begin{array}{l}0,0015 \\
(0,632)\end{array}$ \\
\hline Binária & $\begin{array}{l}0,1032 \\
(1,186)\end{array}$ & $\begin{array}{l}0,1474 \\
(1,521)\end{array}$ & $\begin{array}{l}0,0225 \\
(0,421)\end{array}$ \\
\hline Tend & $\begin{array}{c}0,0025 \\
(3,554)^{* * *}\end{array}$ & $\begin{array}{l}0,0015 \\
(1,257)\end{array}$ & $\begin{array}{c}-0,0014 \\
(-1,991)^{* *}\end{array}$ \\
\hline$R^{2}$ & 0,9878 & 0,7060 & 0,6529 \\
\hline G.L. & 84 & 83 & 82 \\
\hline$d w$ & 1,943 & 1,917 & 2,209 \\
\hline
\end{tabular}

a Entre parênteses, estão os valores do teste $t$; os testes " $F$ " são significativos ao nivel de $1 \%$ bos testes de Durbin-Watson (dw), indicaram a rejeição da hipótese de autocorrelação dos residuos *** significativo, a $1 \%$;

Fonte: dados da pesquisa. 
Os coeficientes do salário-mínimo (não significativo), do preço do óleo diesel (não significativo) e da taxa de juros (não significativo) tiveram sinais negativos, enquanto se previa sinais positivos para os coeficientes dessas variáveis.

O modelo de margem de comercialização do setor varejista, equação (30), apresenta comportamento semelhante ao de margem total. O coeficiente de determinação estimado é razoável $(70,4 \%)$. Todos os preços da carne apresentaram sinais de acordo com o previsto pelo modelo, sendo que, apenas o preço ao produtor defasado apresentou coefíciente não significativo para este modelo.

Os coeficientes das variáveis salário-mínimo, óleo diesel e taxa de juros, todos não significativos, apresentaram sinais negativos, enquanto se previa sinais positivos para essas variáveis.

O modelo estrutural de margem de comercialização do setor atacadista, equação (31), apresenta estimativas pouco satisfatórias. $O$ coeficiente de determinação é o menor dos três $(65,3 \%)$. Das variáveis de custo de comercialização, apenas a taxa de juros apresentou sinais compatíveis com o previsto pelo modelo, mas mesmo assim, os coeficientes não foram significativos. $O$ coeficiente do preço dos subprodutos apresentou sinal positivo, estando de acordo com o previsto para esta variável. Dos preços da carne bovina nos diferentes mercados estudados, somente o coeficiente do preço ao atacado defasado apresentou sinal compativel com o previsto pelo modelo teórico.

\subsection{Equações de transmissão de preços}

Na tabela 8 estão representadas as estimativas feitas por mínimos quadrados em dois estágios das equações de preços. De acordo com o modelo estrutural os preços ao atacado não sofrem influência instantânea dos insumos de comercialização. Quando analisa-se a significância dos coeficientes dos preços 
defasados, observa-se que todos apresentam-se significativos, sendo que o preço defasado ao produtor apresenta sinal contrário ao previsto pela equação 26 . Já o preço ao varejo, de acordo com a equação 27 , sofre influência positiva e significativa do preço ao atacado corrente, estando os resultados de acordo com o previsto; os insumos de comercialização não apresentaram coeficientes significativos, porém o óleo diesel e a taxa de juros apresentaram coeficientes com sinais positivos de acordo com o previsto. O preço ao produtor (equação 28) foi positivamente influenciado pelo preço defasado ao produtor (significativo) e pelo preço ao atacado atualizado (significativo), de acordo com o esperado; o preço dos subprodutos (significativo) também apresentou coeficientes com sinal positivo de acordo com o previsto; dos insumos de comercialização (todos não significativos) apenas o óleo diesel apresentou coeficiente com sinal positivo, contrário ao esperado.

Como explicado no capitulo 4, essas estimativas permitem que se calcule o valor de alguns dos parâmetros do modelo estrutural.

As estimativas da equação de preço ao varejo [equação (27)] permitem que se calcule o valor de $\alpha$ e de $b_{1}$. O valor de $b_{2}$ não foi calculado pois $z_{t}$ foi transformado em um vetor de variáveis. Fazendo-se os cálculos estima-se que 0 valor de $\alpha$ é 0,6288 e o valor de $b_{1}$ é 1,5547 .

Esses resultados podem ser interpretados da seguinte maneira:

Como $\alpha$ determina como se ajusta o preço ao varejo [equação (18)], pode-se dizer que a cada período o preço observado ao varejo tende em direção ao " preço-meta" dos varejistas a uma taxa de 0,6288.

Como $b_{1}$ é o coeficiente técnico de produção entre os níveis de atacado e varejo, conclui-se que $1 \mathrm{~kg}$ do produto (carne) ao varejo equivalem a $1,5547 \mathrm{~kg}$ do produto ao atacado, com um rendimento em torno de $64 \%$. 
As estimativas da equação de preço ao produtor [equação (28)] permitem que se calcule o valor de $\beta$, de $c_{1}$ e de $\rho$. O valor de $c_{2}$ também não foi calculado pelo fato de $x_{t}$ também ser um vetor de variáveis. Após os cálculos chega-se aos valores de 0,8183 para $\beta, 1,5528$ para $c_{1}$ e 1,5 para $\rho$. Para o cálculo de $\rho$ é preciso lembrar que o valor dos subprodutos $\left(s_{t}\right)$ corresponde a um boi inteiro que no frigorífico gera $235,2 \mathrm{~kg}$ de carcaça. Logo o valor dos subprodutos por kg de carcaça será $s_{t} \mathbf{2 3 5 , 2}$.

Na regressão tem-se:

$$
0,0053=\frac{\beta \rho}{235,2} \quad, \text { portanto } \rho=1,5
$$

A interpretação desses resultados é a seguinte :

O parâmetro $\beta$ determina como se comporta o ajuste de preços ao produtor [equação (24)], podendo-se, então, afirmar que a cada período o preço observado ao produtor tende em direção ao "preço-meta" dos produtores a uma taxa de 0,8183 .

Como $c_{1}$ é o coeficiente técnico de produção entre os níveis de produtor e atacado, conclui-se que $1 \mathrm{~kg}$ do produto ao atacado equivale a $1,5528 \mathrm{~kg}$ do produto ao produtor, também com rendimento em torno de $64 \%$.

Foi visto que $\rho$ mede o grau em que os subprodutos são considerados ao se determinar o preço ao atacado; portanto, como o valor de $\rho$ é relativamente alto, conclui-se que os subprodutos são considerados ao se determinar o preço ao atacado. $O$ valor de $\rho$, segundo o modelo teórico, estaria entre 0 e 1; na impossibilidade de se aplicar um teste para analisar a probabilidade de $\rho$ assumir valor maior que 1, pode-se concluir, pelo menos, que $\boldsymbol{\rho}$ tem uma magnitude não desprezivel. 
Tabela 8 - Estimativas do ajustamento em dois estágios das equações simultâneas dos preços aos níveis de produtor, atacado e varejo; no mercado de carne bovina no estado de São Paulo; dados mensais de 1986 a 1993.

\begin{tabular}{|c|c|c|c|}
\hline $\begin{array}{l}\text { Variáveis e } \\
\text { Estatisticas }\end{array}$ & $\begin{array}{l}\text { preço ao } \\
\text { atacado }\end{array}$ & $\begin{array}{c}\text { preço ao } \\
\text { varejo }\end{array}$ & $\begin{array}{l}\text { preço ao } \\
\text { produtor }\end{array}$ \\
\hline Constante & $\begin{array}{c}0,5484 \\
(4,459)^{* * *}\end{array}$ & - & - \\
\hline$v_{t-1}$ & $\begin{array}{l}-0,4547 \\
(-4,526)^{* * *}\end{array}$ & $\begin{array}{c}0,3712 \\
(7,353)^{* * *}\end{array}$ & - \\
\hline$p_{t-1}$ & $\begin{array}{l}0,4287 \\
(2,466)^{* *}\end{array}$ & - & $\begin{array}{c}0,1817 \\
(2,379)^{* *}\end{array}$ \\
\hline$a_{t-1}$ & $\begin{array}{c}1,0169 \\
(5,275)^{* * *}\end{array}$ & - & - \\
\hline$a_{t}$ & - & $\begin{array}{c}0,9776 \\
(10,262)^{* * *}\end{array}$ & $\begin{array}{c}0,5270 \\
(5,287)^{* * *}\end{array}$ \\
\hline$s_{t}$ & - & - & $\begin{array}{c}0,0053 \\
(5,727)^{* * *}\end{array}$ \\
\hline$S M_{t}$ & - & $\begin{array}{l}-0,0016 \\
(-0,833)\end{array}$ & $\begin{array}{l}-0,0008 \\
(-0,707)\end{array}$ \\
\hline$O D_{t}$ & - & $\begin{array}{l}0,1834 \\
(0,494)\end{array}$ & $\begin{array}{l}0,2067 \\
(0,889)\end{array}$ \\
\hline$T J_{t}$ & - & $\begin{array}{l}0,0021 \\
(0,444)\end{array}$ & $\begin{array}{c}-0,0002 \\
(0,081)\end{array}$ \\
\hline Binária & $\begin{array}{l}0,2270 \\
(1,877)^{*}\end{array}$ & $\begin{array}{l}0,0163 \\
(0,163)\end{array}$ & $\begin{array}{l}0,0106 \\
(0,172)\end{array}$ \\
\hline$R^{2}$ & 0,8153 & 0,9951 & 0,9948 \\
\hline G.L. & 88 & 87 & 86 \\
\hline$d w$ & 2,030 & 1,486 & 1,536 \\
\hline
\end{tabular}

a Entre parênteses, estão os valores do teste $t$; os testes "F" são significativos ao nivel de $1 \%$ bos testes de Durbin-Watson (div), indicaram a rejeição da hipótese de autocorrelação dos residuos *** significativo, a $1 \%$; $\quad$ ** significativo, a $5 \%$; $\quad{ }^{*}$ significativo, a $10 \%$;

Fonte: dados da pesquisa. 


\subsection{Multiplicadores de THEIL}

O resultado do teste para verificar a existência de correlação contemporânea apresentou o seguinte resultado:

$$
\lambda=93(0,7500+0,5745+0,6047+0,5714+0,2632+0,1429)=270,3231 .
$$

Para 6 graus de liberdade e ao nivel de significância de 1\%; o valor crítico da distribuição de $\chi^{2}$ é 16,81 . Portanto, rejeita-se a hipótese nula e pode-se afirmar que existe correlação contemporânea, sendo necessário, então, estimar as equações pelo método SUR.

A tabela 9 apresenta as equações reduzidas de preço ao atacado (26), preço ao varejo (32), preço ao produtor (33) e margem total reduzida (34); estimadas conjuntamente pelo método SUR, como explicado no capítulo 5. Estas estimativas serão utilizadas para constituir as matrizes de relações das variáveis endógenas $\left(D_{1}\right)$ e de choques das variáveis exógenas $\left(D_{2}\right)$, vistas no capítulo 4 .

Estas estimativas nos mostram que os subprodutos influenciam positivamente o preço ao produtor e a margem total reduzida, como previsto pelo modelo teórico. Esta influência pode ser explicada pelo fato de que o preço ao produtor não aumenta na mesma proporção dos subprodutos, portanto, a margem aumenta pela incorporação de parte da variação dos subprodutos. Deve ser levado em conta, também, o fato de que os preços ao produtor e dos subprodutos vão afetar os preços ao varejo no próximo período. 
Tabela 9 - Estimativas das equações reduzidas da margem total e dos preços aos níveis de produtor, atacado e varejo; utilizando método SUR ; no mercado de carne bovina no estado de São Paulo; dados mensais de 1986 a 1993.

\begin{tabular}{|c|c|c|c|c|}
\hline $\begin{array}{l}\text { Variáveis e } \\
\text { Estatisticas }\end{array}$ & $\begin{array}{l}\text { preço ao } \\
\text { atacado }\end{array}$ & $\begin{array}{l}\text { preço ao } \\
\text { varejo }\end{array}$ & $\begin{array}{l}\text { preço ao } \\
\text { produtor }\end{array}$ & $\begin{array}{c}\text { margem } \\
\text { total }\end{array}$ \\
\hline Constante & $\begin{array}{c}0,5484 \\
(4,459)^{* * *}\end{array}$ & $\begin{array}{l}1,1973 \\
(5,407)^{* * *}\end{array}$ & $\begin{array}{c}0,4761 \\
(3,300)^{* * *}\end{array}$ & $\begin{array}{l}0,71909 \\
(4,556)^{* * *}\end{array}$ \\
\hline$v_{t-1}$ & $\begin{array}{l}-0,4547 \\
(-4,526)^{* * *}\end{array}$ & $\begin{array}{l}-0,0755 \\
(-0,497)\end{array}$ & $\begin{array}{l}-0,4257 \\
(-4,635)^{* * *}\end{array}$ & $\begin{array}{c}0,3685 \\
(4,160)^{* * *}\end{array}$ \\
\hline$p_{t-1}$ & $\begin{array}{c}0,4287 \\
(2,466)^{* *}\end{array}$ & $\begin{array}{c}0,7654 \\
(2,954)^{* * *}\end{array}$ & $\begin{array}{c}0,6932 \\
(4,239)^{* * *}\end{array}$ & $\begin{array}{l}-0,0146 \\
(-0,096)\end{array}$ \\
\hline$a_{t-1}$ & $\begin{array}{c}1,0169 \\
(5,275)^{* * *}\end{array}$ & $\begin{array}{c}0,5313 \\
(1,832)^{*}\end{array}$ & $\begin{array}{c}0,5616 \\
(3,333)^{* * *}\end{array}$ & $\begin{array}{c}-0,0226 \\
(-0,138)\end{array}$ \\
\hline$a_{t}$ & - & - & - & - \\
\hline$s_{t}$ & - & - & $\begin{array}{c}0,0035 \\
(4,295)^{* * *}\end{array}$ & $\begin{array}{c}0,0014 \\
(2,264)^{* *}\end{array}$ \\
\hline$S M_{t}$ & - & $\begin{array}{c}-0,0029 \\
(-1,837)^{*}\end{array}$ & $\begin{array}{l}-0,0010 \\
(-0,824)\end{array}$ & $\begin{array}{c}-0,0023 \\
(-1,489)\end{array}$ \\
\hline$O D_{t}$ & - & $\begin{array}{c}-0,6241 \\
(-1,733)^{*}\end{array}$ & $\begin{array}{c}0,085 \\
(0,304)\end{array}$ & $\begin{array}{l}-0,7412 \\
(-2,131)^{* *}\end{array}$ \\
\hline$T J_{t}$ & - & $\begin{array}{l}-0,0031 \\
(-0,726)\end{array}$ & $\begin{array}{l}-0,0010 \\
(-0,305)\end{array}$ & $\begin{array}{l}-0,0017 \\
(-0,437)\end{array}$ \\
\hline Binária & $\begin{array}{c}0,2270 \\
(1,877)^{*}\end{array}$ & $\begin{array}{c}0,4620 \\
(2,565)^{* *}\end{array}$ & $\begin{array}{c}0,1757 \\
(1,688)^{*}\end{array}$ & $\begin{array}{l}0,2773 \\
(2,778)^{* *}\end{array}$ \\
\hline$R^{2}$ & 0,8153 & 0,8000 & 0,8502 & 0,7595 \\
\hline G.L. & 88 & 85 & 84 & 84 \\
\hline$d w$ & 2,030 & 1,827 & 2,138 & 1,877 \\
\hline
\end{tabular}

a Entre parênteses, estão os valores do teste $t$; os testes " $F$ " são significativos ao nivel de $1 \%$ bos testes de Durbin-Watson (dw), indicaram a rejeição da hipótese de autocorrelação dos residuos *** significativo, a $1 \% ; \quad$ ** significativo, a $5 \%$; $\quad$ * significativo, a $10 \%$;

Fonte: dados da pesquisa. 
Nas tabelas 10, 11, 12 e 13 estão apresentados os multiplicadores, que foram obtidos do produto das matrizes $\mathbf{D}_{1}$ e $\mathbf{D}_{2}$, e que mostram o efeito dinâmico dos custos de comercialização e dos subprodutos.

As matrizes são compostas pelos coeficientes das equações reduzidas de preços e de margem total:

$$
\begin{aligned}
& D_{1}=\left[\begin{array}{cccc}
-0,0756 & 0,7654 & 0,5314 & 0 \\
-0,4257 & 0,6932 & 0,5616 & 0 \\
-0,4548 & 0,4287 & 1,0169 & 0 \\
0,3685 & -0,0146 & -0,0226 & 0
\end{array}\right] \\
& D_{2}=\left[\begin{array}{cccc}
-0,0029 & -0,6241 & -0,0031 & 0 \\
-0,0010 & 0,0850 & -0,0010 & 0,0035 \\
0 & 0 & 0 & 0 \\
-0,0023 & -0,7412 & -0,0018 & 0,0114
\end{array}\right]
\end{aligned}
$$

A primeira linha de cada matriz se refere ao preço ao varejo, a segunda se refere ao preço ao produtor, a terceira se refere ao preço ao atacado e a quarta linha se refere à margem total de comercialização. Na matriz $\mathbf{D}_{1}$, a primeira coluna se refere aos valores defasados do preço ao varejo; a segunda, aos valores defasados do preço ao produtor; a terceira, aos valores defasados do preço ao atacado; e a quarta, aos valores defasados da margem total de comercialização ( que são nulos, pelo fato das equações reduzidas não apresentarem a variável margem defasada). $\mathrm{Na}$ matriz $\mathbf{D}_{2}$, a primeira coluna mostra os impactos imediatos do valor do saláriominimo; a segunda, do óleo diesel; a terceira, da taxa de juros; e a quarta, do valor dos subprodutos. 
O cálculo das raízes características da matriz $\mathbf{D}_{1}$ apresenta os valores: $0 ; 0,4852 ; 0,4852 ;$ e 0,6642 . Como todas essas raízes são menores que 1 , não se rejeita a hipótese de convergência dinâmica do modelo.

A multiplicação consecutiva das matrizes, como explicado no capítulo 4, permitiu que se determinassem os multiplicadores apresentados nas tabelas de 10 a 13.

Iniciando-se pela tabela 10 , que representa os impactos na margem total de comercialização, verifica-se que o salário-mínimo apresenta impacto inicial negativo, contrário ao esperado, mas que se torna positivo a partir do $4^{\circ}$ mês. $\mathrm{O}$ efeito total é negativo. $\mathrm{O}$ óleo diesel também apresenta impacto inicial negativo, contrário ao esperado, tornando-se positivo a partir do $3^{\circ}$ mês, e tendo efeito total negativo. A taxa de juros apresenta impacto inicial negativo e efeito total nulo, que pode ser explicado pelo fato do efeito total dessa variável nos preços ao produtor e ao varejo serem da mesma magnitude, neutralizando seu efeito sobre a margem total. Os subprodutos apresentam resultados de acordo com o previsto, impacto inicial e total positivos, tendo pequena alteração de efeito apenas no $2^{\circ}$ mês. Pode-se dizer que o aumento de $R \$ 1,00$ no preço dos subprodutos leva a aumentos imediatos na margem total de comercialização de $R \$ 0,0014$ e o efeito total é de um aumento de R\$ 0,0041.

A tabela 11, que representa os impactos sobre os preços ao varejo, apresenta o salário-mínimo com impacto inicial negativo, mudando de sinal a partir do $3^{\circ}$ mês, e tendo um efeito total positivo sobre o preço ao varejo.Um aumento de $\mathrm{R} \$ 1,00$ no preço do óleo diesel faz com que o preço ao varejo diminua de $\mathbf{R} \$$ 0,6241 , contrário ao previsto, entretanto, o efeito total causa um aumento de RS 1,7784. A taxa de juros apresenta efeito inicial negativo, contrário ao previsto, porém apresenta efeito total positivo. Os valores dos subprodutos apresentam efeito 
positivo nos primeiros 7 meses que se seguem ao choque, sendo que seu efeito imediato é nulo, e o efeito total é positivo.

Na tabela 12 estão representados os impactos sobre o preço ao produtor; analisando-se primeiramente o salário-mínimo, observa-se que esta variável apresenta impacto inicial negativo, de acordo com o esperado; ou seja, um aumento de $\mathrm{R} \$ 1,00$ no valor do salário-mínimo leva a uma diminuição imediata no preço ao produtor da ordem de $\mathrm{R} \$ 0,0010$; porém o efeito total é positivo. O óleo diesel apresenta impacto inicial e total positivo, contrário ao esperado. a taxa de juros apresenta comportamento semelhante ao salário-mínimo, efeito inicial negativo e efeito total positivo. Os subprodutos apresentam impacto inicial positivo, de acordo com o previsto, tendo efeito total positivo da ordem de 0,0081 .

A tabela 13, que representa os impactos sobre o preço ao atacado, apresenta todos os impactos iniciais nulos de acordo com a expressão 26 . O saláriomínimo apresenta no $2^{\circ}$ mês impacto positivo, mantendo o mesmo sinal até o último mês do estudo. $\mathrm{O}$ óleo diesel apresenta sinal a partir do $2^{\circ}$ mês positivo e o efeito total também positivo; pode-se dizer que o aumento de $\mathrm{R} \$ 1,00$ no preço do óleo diesel leva a aumentos no preço ao atacado, após 12 meses, de $\mathrm{R} \$ 2,1804$. A taxa de juros também apresenta sinal positivo em todos os meses da análise, sendo o primeiro mês nulo. Os subprodutos iniciam sua influência com efeitos positivos, tornando-se nulos a partir do $7^{\circ}$ mês, porém o efeito total dos subprodutos no preço ao atacado é positivo. 
Tabela 10: Efeito dos choques nas variáveis exógenas sobre a margem de total de comercialização da carne bovina - multiplicadores de THEIL.

\begin{tabular}{ccccc}
\hline Meses & $S M_{t}$ & Diesel $_{t}$ & Juros $_{t}$ & Subprod $_{t}$ \\
\hline $\mathbf{0}$ & $-0,0023$ & $-0,7412$ & $-0,0018$ & 0,0014 \\
1 & $-0,0011$ & $-0,2312$ & $-0,0011$ & $-0,0001$ \\
2 & $-0,0002$ & 0,0294 & $-0,0002$ & 0,0009 \\
3 & 0,0003 & 0,1366 & 0,0003 & 0,0009 \\
4 & 0,0005 & 0,1571 & 0,0006 & 0,0006 \\
5 & 0,0005 & 0,1386 & 0,0006 & 0,0003 \\
6 & 0,0005 & 0,1081 & 0,0005 & 0,0001 \\
7 & 0,0003 & 0,0786 & 0,0004 & 0,0000 \\
8 & 0,0003 & 0,0546 & 0,0003 & 0,0000 \\
9 & 0,0002 & 0,0369 & 0,0002 & 0,0000 \\
10 & 0,0001 & 0,0245 & 0,0001 & 0,0000 \\
11 & 0,0001 & 0,0161 & 0,0001 & 0,0000 \\
12 & 0,0001 & 0,0105 & 0,0001 & 0,0000 \\
Total & $-0,0007$ & $-0,1614$ & 0,0000 & 0,0041 \\
\hline
\end{tabular}

Fonte: Dados da pesquisa.

Tabela 11: Efeito dos choques nas variáveis exógenas sobre os preços ao varejo da carne bovina - multiplicadores de THEIL.

\begin{tabular}{ccccc}
\hline Meses & $S M_{t}$ & Diesel $_{t}$ & Juros $_{t}$ & Subprod $_{t}$ \\
\hline 0 & $-0,0029$ & $-0,6241$ & $-0,0031$ & 0,0000 \\
1 & $-0,0005$ & 0,1122 & $-0,0005$ & 0,0027 \\
2 & 0,0009 & 0,4102 & 0,0010 & 0,0025 \\
3 & 0,0015 & 0,4622 & 0,0016 & 0,0016 \\
4 & 0,0015 & 0,4046 & 0,0017 & 0,0008 \\
5 & 0,0013 & 0,3145 & 0,0014 & 0,0004 \\
6 & 0,0010 & 0,2281 & 0,0011 & 0,0001 \\
7 & 0,0007 & 0,1583 & 0,0008 & 0,0000 \\
8 & 0,0005 & 0,1069 & 0,0006 & 0,0000 \\
9 & 0,0004 & 0,0708 & 0,0004 & $-0,0001$ \\
10 & 0,0002 & 0,0465 & 0,0002 & 0,0000 \\
11 & 0,0002 & 0,0304 & 0,0002 & 0,0000 \\
12 & 0,0001 & 0,0198 & 0,0001 & 0,0000 \\
Total & 0,0052 & 1,7784 & 0,0057 & 0,0078 \\
\hline
\end{tabular}

Fonte: Dados da pesquisa. 
Tabela 12: Efeito dos choques nas variáveis exógenas sobre os preços ao produtor da carne bovina - multiplicadores de THEIL.

\begin{tabular}{ccccc}
\hline Meses & $S M_{t}$ & Diese $_{t}$ & Juros $_{t}$ & Subprod $_{t}$ \\
\hline 0 & $-0,0010$ & 0,0850 & $-0,0010$ & 0,0035 \\
1 & 0,0005 & 0,3246 & 0,0006 & 0,0024 \\
2 & 0,0011 & 0,3571 & 0,0012 & 0,0014 \\
3 & 0,0012 & 0,3053 & 0,0012 & 0,0007 \\
4 & 0,0010 & 0,2324 & 0,0010 & 0,0003 \\
5 & 0,0007 & 0,1655 & 0,0008 & 0,0001 \\
6 & 0,0005 & 0,1132 & 0,0006 & 0,0000 \\
7 & 0,0004 & 0,0754 & 0,0004 & 0,0000 \\
8 & 0,0002 & 0,0495 & 0,0003 & 0,0000 \\
9 & 0,0002 & 0,0322 & 0,0002 & 0,0000 \\
10 & 0,0001 & 0,0209 & 0,0001 & 0,0000 \\
11 & 0,0001 & 0,0136 & 0,0001 & 0,0000 \\
12 & 0,0000 & 0,0089 & 0,0000 & 0,0000 \\
Total & 0,0051 & 1,8007 & 0,0057 & 0,0081 \\
\hline
\end{tabular}

Fonte: Dados da pesquisa.

Tabela 13: Efeito dos choques nas variáveis exógenas sobre os preços ao atacado da carne bovina - multiplicadores de THEIL.

\begin{tabular}{ccccc}
\hline Meses & SM $_{t}$ & Diesel $_{t}$ & Juros $_{t}$ & Subprod $_{t}$ \\
\hline 0 & 0,0000 & 0,0000 & 0,0000 & 0,0000 \\
1 & 0,0009 & 0,3203 & 0,0010 & 0,0015 \\
2 & 0,0014 & 0,4138 & 0,0015 & 0,0013 \\
3 & 0,0015 & 0,3873 & 0,0016 & 0,0008 \\
4 & 0,0013 & 0,3146 & 0,0014 & 0,0004 \\
5 & 0,0010 & 0,2355 & 0,0011 & 0,0002 \\
6 & 0,0008 & 0,1674 & 0,0008 & 0,0000 \\
7 & 0,0005 & 0,1150 & 0,0006 & 0,0000 \\
8 & 0,0004 & 0,0773 & 0,0004 & 0,0000 \\
9 & 0,0003 & 0,0512 & 0,0003 & 0,0000 \\
10 & 0,0002 & 0,0336 & 0,0002 & 0,0000 \\
11 & 0,0001 & 0,0220 & 0,0001 & 0,0000 \\
12 & 0,0001 & 0,0144 & 0,0001 & 0,0000 \\
Total & 0,0085 & 2,1804 & 0,0092 & 0,0041 \\
\hline
\end{tabular}

Fonte: Dados da pesquisa. 


\section{CONCLUSÕES}

No presente trabalho analisou-se a formação das margens de comercialização no mercado de carne bovina do Estado de São Paulo, levando em conta os valores dos subprodutos. Especificamente, pretendeu-se detectar a importância dos subprodutos e dos custos de comercialização na formação das margens. Foram considerados três níveis de mercado a saber: produtor, atacado e varejo.

Para realizar a análise foram utilizadas séries mensais de preços da carne bovina aos níveis de produtor, atacado e varejo; preços dos subprodutos obtidos ao atacado; preços dos seguintes insumos de comercialização: óleo diesel, salário-mínimo e taxa de juros. O período considerado foi março de 1986 a junho de 1994, tendo como mês base junho de 1994.

Uma primeira análise da importância dos subprodutos para o mercado de carne bovina foi feita da forma apresentada no capitulo 2 , onde observou-se que quando se considera os subprodutos a participação do setor atacadista na margem de comercialização aumenta consideravelmente (tabelas 6 e B.1). Este fato decorre da importância dos subprodutos na constituição do valor do boi comercializado ao atacado ( tabela 5). Um dos efeitos do aumento da participação dos atacadistas é uma diminuição da participação dos produtores no valor total da venda de carne bovina.

Realizou-se, também, uma análise gráfica dos comportamentos dos preços e das margens nos diversos niveis de mercado. Nesta análise verificou-se que 
os preços dos vários níveis caminham juntos em resposta às mesmas mudanças nas condições de mercado, não havendo tendência explosiva do comportamento dos preços em nenhum dos níveis de mercado. Além disso, percebe-se uma tendência de queda dos preços reais durante o período analisado. Estes resultados podem ser interpretados como uma demonstração de ganho de eficiência por parte do mercado de carne bovina. A margem total absoluta também apresenta uma tendência de queda a partir do início da década de 90.

As margens mensais totais de comercialização da carne bovina foram calculadas em valores absolutos (em valores de junho de 1994) e porcentualmente (em relação ao preço de varejo). O valor médio obtido para a margem total absoluta foi de $\mathrm{R} \$ 1,47 / \mathrm{kg}$ e para a margem total relativa foi obtido $49,95 \%$ (quando não se considera os subprodutos esses valores são $R \$ 1,24 / \mathrm{kg}$ e $42,10 \%$, respectivamente).

O modelo desenvolvido neste trabalho foi baseado no modelo de BARROS (1990), sendo que a principal mudança foi a consideração no modelo dos subprodutos obtidos ao nivel de atacado. A partir desse modelo estrutural foram desenvolvidas todas as equações de preços e de margens utilizadas no estudo. $\mathrm{O}$ modelo dinâmico desenvolvido para o mercado de carne bovina apresentou bom ajustamento.

Os resultados obtidos para as equações de margem total, ao varejo e ao atacado, levam a conclusões bem semelhantes. Os coeficientes das variáveis óleo diesel, taxa de juros e salário-mínimo foram quase sempre não significativos e apresentaram sinais negativos, contrários aos previstos pelo modelo teórico. Isto se explica pelo fato dessas variáveis não serem exclusivamente insumos de comercialização, podendo, também, serem utilizadas como insumos de produção fazendo, assim, parte dos custos de produção.

O sinal negativo do óleo diesel e do salário-mínimo poderia ser explicado pela predominância do efeito desses insumos na produção agrícola, em 
detrimento da comercialização. No caso da taxa de juros pode-se dizer que o impacto dessa variável sobre a venda de estoques, causando queda de preço e margem, tende a superar, numa primeira etapa, seu impacto sobre o custo de comercialização.

Os resultados das estimações mostram que os impactos causados pelos preços dos diferentes níveis de mercado sobre as margens de comercialização predominam sobre os impactos causados pelos insumos de comercialização. Esses resultados sugerem que as variações da margem de comercialização podem ser melhor explicadas por choques na oferta e demanda primária do que por choques nos insumos de comercialização.

Os resultados mostram que os subprodutos devem ser considerados nos estudos de margem de comercialização. A não consideração dos subprodutos poderia resultar em valores enganosos das margens. Apesar da figura 10 mostrar que existe pouca relação entre os preços dos subprodutos e os preços da carne bovina ao varejo, inclusive pelo fato dos subprodutos não comestíveis e da carne não serem comercializados nos mesmos mercados, demostrou-se que as oscilações dos preços dos subprodutos afetarão as margens de comercialização e os preços ao produtor.

As estimativas das equações de preços nos três mercados por mínimos quadrados em dois estágios confirmam que as variáveis utilizadas possuem o efeito duplo de insumos de produção e de comercialização. $O$ preço ao varejo sofreu impacto positivo do óleo diesel e da taxa de juros, de acordo com o previsto, e o preço ao produtor sofreu impacto negativo do salário-mínimo e da taxa de juros, de acordo com o previsto.

Essas estimativas também permitiram a obtenção de alguns parâmetros do modelo estrutural cuja interpretação leva, resumidamente, às seguintes conclusões: 
A cada período os preços observados, tanto ao varejo quanto ao produtor, convergem rapidamente em direção aos seus respectivos "preços-meta".

Os coeficientes técnicos de produção entre os níveis de atacado e varejo e entre os niveis de produtor e atacado permitem que se calcule um rendimento em torno de $64 \%$ entre esses níveis de mercado.

Observa-se também que os subprodutos são considerados ao se determinar o preço ao atacado.

As equações reduzidas dos preços nos três níveis de mercados e a equação de margem total reduzida foram estimadas conjuntamente pelo método SUR, pois o sistema apresentou correlação contemporânea nos erros. Essas estimativas serviram para realizar a análise dos multiplicadores de Theil.

A análise dinâmica pelos multiplicadores de Theil mostrou que a margem de comercialização sofre impacto inicial negativo dos três insumos considerados, sendo que esse impacto muda de sinal a partir do quarto mês, entretanto os impacto totais do salário-mínimo e do óleo diesel foram negativos. A taxa de juros apresentou efeito total nulo, que pode ser explicado pelo fato do efeito total dessa variável nos preços ao produtor e ao varejo serem da mesma magnitude, fazendo com que se neutralize seu efeito sobre a margem total. Os subprodutos apresentam impacto inicial e total positivos como previsto pelo modelo teórico.

Observa-se, também, que mesmo apresentando impacto inicial nulo nos preços ao varejo e ao atacado, o efeito total dos subprodutos sobre esses preços é positivo. O preço ao produtor sofre impactos inicial e total positivos frente uma variação dos preços dos subprodutos. 


\section{BIBLIOGRAFIA}

AGUIAR, D. R. D. Custo, risco e margem de comercialização de arroz e de feijão no estado de São Paulo: análise dinâmica e teste de modelos alternativos.Piracicaba, 1994. 185p. (Doutorado - Escola Superior de Agricultura "Luiz de Queiroz"/USP).

AGUIAR, D. R. D. Formação de preços na indústria Brasileira de soja;1982-1989. Piracicaba, 1990. 140p. (Mestrado - Escola Superior de Agricultura "Luiz de Queiroz"/USP).

BARROS, G. S. A. C. Economia da Comercialização Agrícola. Piracicaba, FEALQ, 1987, 306p.

BARROS, G. S. A. C. Transmissão de preços pela central de abastecimento de São Paulo,Brasil. Revista Brasileira de Economia 44(1):5-20,jan./mar.1990.

BLISKA, F. M. M. Transmissão de preços de carne bovina entre níveis de mercado: uma aplicação do modelo de auto-regressão vetorial. Piracicaba, 1989.209p. (Mestrado - ESALQ/USP).

CANHOS, D. A. L.; DIAS, E. L. Tecnologia de Carne Bovina e Produtos Derivados. São Paulo. Secretaria da Indústria, Comércio, Ciência e Tecnologia. s.d. 440p. 
CANTO, W. L. Sistema Ponderal de Conversões e Determinação de Margens de Comercialização. Campinas, Instituto de Tecnologia de Alimentos, 1986, 55p.

CENSO AGROPECUÁRIO - SÃO PAULO. Rio de Janeiro, FIBGE, n. 21, 1985.

CHIANG, A. Matemática para economistas. São Paulo, EDUSP/McGraw-Hill, 684 p., 1982.

DE ZEN, S. Alguns aspectos do processo de formação de preços da pecuária de corte. In: Curso sobre comercialização de commodities agropecuárias, $3^{\circ}$, Piracicaba, 1994. Anais. Piracicaba, FEALQ, 1994. p.47-56.

ENSMinger, M. E. Produccion Bovina para Carne. Buenos Aires. Centro Regional de Ayuda Tecnica. 1973. 595p.

FERNANDES, S. G. Análise de alternativas de políticas para o setor de carnes no Brasil. Viçosa, 1988. 82p. (Mestrado - UFV).

FGV. Conjuntura Econômica. Fundação Getúlio Vargas, Rio de Janeiro, diversos.

GARDNER, B. L. The farm-retail price spread in a competitive food industry. American Journal of Agricultural Economics, 57: 399-409, 1975.

HADDAD, C. M. A carne bovina da fonte de produção ao consumidor: problemas e propostas de soluções. In: PEIXOTO, A. M.; MOURA, J. C.; FARIA, V. P. Bovinocultura de Corte. 2ed. Piracicaba: FEALQ, 1993. pp.513-531. (Série atualização em zootecnia, 8). 
HEIEN, D. M. Markup pricing in a dynamic model of food industry. American journal of Agricultural Economics, 62: 10-18, 1980.

IEA. Informações Econômicas. Secretaria de Agricultura e Abastecimento, Instituto de Economia Agrícola, São Paulo, diversos.

IGREJA, A. C. M. Evolução da pecuária bovina de corte no estado de São Paulo no período de 1969-1984. Piracicaba, 1987. 197p. (Mestrado - ESALQ/USP).

INTERCARNES, Boletim Informativo, diversos, s. n. t.

JUDGE, G. G. et al. Introduction to the theory and practice of econometrics 2nd ed. New York John Wiley \& Sons, 1988 1024p.

JUNQUEIRA, P. C.; CANTO, W. L. Cesta de mercado- margens totais de comercialização. Agricultura em São Paulo, São Paulo, 18 (9/10): 1-46, set./out. 1971.

KASSOUF, A. L. Previsão de preços na pecuária de corte do Estado de São Paulo. Piracicaba, 1988, 102p. (Mestrado - ESALQ/USP).

KMENTA, J. Elementos de econometria. 2 ed. São Paulo, Atlas. 2v., 694 p., 1988.

MARQUES, P. V.; AGUIAR, D. R. D. Comercialização de Produtos Agrícolas. São Paulo:EDUSP, 1993. 295p. (Coleção Campi, 13). 
MARQUES, P. V. Margens de Comercialização de Produtos Agrícolas. Série Didática $\mathrm{n}^{\circ}$ 81. Dept $^{\circ}$ de Economia e Sociologia Rural, ESALQ/USP, Piracicaba, 1993, 11 p.

MARTINES F ${ }^{\circ}$, J. G. Margens de comercialização e causalidade de preços agrícolas. Piracicaba, 1988. 146p. (Mestrado - Escola Superior de Agricultura "Luiz de Queiroz"/USP).

MORICOCHI, L. et al. Uma reflexão sobre a indústria de carne bovina no brasil. Informações Econômicas, S.P., 25(6), jun.1995.

TAXA DE JUROS NO BRASIL. São Paulo, Nova Análise Editora, 1992.

TEIXEIRA, H. H. L. Modelo de desequilíbrio de margens de comercialização agrícola. Viçosa, 1982. 69p. (M.S.- Universidade Federal de Viçosa).

THEIL, H. Principles of econometrics. New York, John Wiley \& Sons, Inc., 736 p., 1971. 
APÊNDICE A

SUBPRODUTOS DOS BOVINOS NO FRIGORÍFICO 


\section{SUBPRODUTOS DOS BOVINOS NO FRIGORÍFICO}

Baseando-se no trabalho de CANHOS \& DIAS (s.d.) será feita uma discussão das aplicações dos subprodutos gerados ao nível de atacado.

Segundo sua aplicação, os subprodutos podem ser: comestíveis, sendo destinados à alimentação humana, podendo ser consumidos "in natura", semiprocessados ou participando da composição de outros produtos alimentícios; ou não comestíveis, aqueles que não se prestam a consumo direto como alimento, sendo destinados a outras aplicações (farinha para ração animal, produtos farmacêuticos, etrc.).

- SANGUE

Apesar de poder ser utilizado em alimentação humana, o sangue é destinado à produção de plasma e soro, mas em maior quantidade para farinha de sangue ou sangue solúvel.

\section{-FARINHA DE SANGUE}

A maior aplicação da farinha de sangue é como fertilizante, embora possa também ser usada para ração animal. É obtida mediante secagem em sistema de dupla camisa, onde circula vapor seco, que aquece o produto. A seguir é moída por meio de bolas de plástico e ensacada. A farinha de sangue deve conter no mínimo $80 \%$ de proteínas e no máximo $10 \%$ de umidade.

\section{-VISCERAS}

A maior parte das visceras são comestiveis e, dentre elas, estão o coração, figado, rins, que são muito apreciados, sendo excelentes fontes de muitos nutrientes essenciais à dieta humana. 
O figado, um dos subprodutos de maior valor nutritivo é usado tanto para consumo, pelo seu sabor, como pela indústria terapêutica como material no tratamento das anemias, pelo seu teor de ferro e vitamina $\mathrm{A}$.

O coração, pelo seu alto teor em mioglobina, é muito usado em embutidos, fornecendo uma coloração mais atraente aos produtos.

Os rins são muito apreciados para consumo "in natura", sendo usados em diversas preparações culinárias.

- SEBO

O sebo industrial compreende os produtos gordurosos não comestíveis obtidos pela fusão de gorduras, bem como de carcaças, órgãos e vísceras condenadas.

É largamente utilizado pelas indústrias de sabões, tendo como fração importante a glicerina, inclusive na fabricação de explosivos.

-PATAS

As patas de bovinos, sem os tendões e ligamento, podem sofrer processos variados. As canelas podem ser cozidas liberando óleo e gorduras, sendo o óleo usado como lubrificante de máquinas delicadas e principalmente na preparação de couro. Quando submetida a tratamento especial, fornecem uma gelatina especial usada na fabricação de sorvetes, fotografias, etc.

A porção óssea restante é levada para a fabricação de farinha de carne e ossos.

-COURO

A pele dos bovinos constitui cerca de $15 \%$ do peso da carcaça quente, sem descarne e recortes. $O$ método comum de conservação dos couros é a salmoura. 
O tempo de salga é de 20 dias, e juntamente com a salmouragem o total é de 21 dias em contato com o sal. Após este período o couro então é comercializado.

\section{-PELOS}

A extremidade da cauda é destacada na seção de couros e colocada em água a $60^{\circ} \mathrm{C}$, tempo suficiente para que os pelos sejam removidos manualmente. Os pelos das orelhas podem ser destacados com tesoura, ou à mão se tratados em água a $33^{\circ} \mathrm{C}$.

Os pelos são utilizados na indústria de pincéis, além de serem empregados na manufatura de estofados e isolantes.

\section{-OUTROS SUBPRODUTOS}

Os retalhos de carne procedentes da desossa e limpeza dos ossos, também são aproveitados como subprodutos comestíveis. Essas carnes são misturadas, congeladas em blocos e usadas na indústria de carne em conservas e embutidos.

O rabo do boi também é muito apreciado para consumo "in natura", na confecção dos mais variados pratos.

Complementando esses subprodutos, a carne procedente da desossa, bem como retalhos de carne aproveitados de outros setores, constituem a chamada carne industrial. Nela também se incluem o revestimento do tubo do esôfago, a sustentação da bexiga urinária, diafragma e os músculos da mastigação.

Todos esses subprodutos são geralmente misturados, congelados em blocos e enviados à indústria de carnes em conserva e de embutidos. 


\section{APÊNDICE B}


Tabela B.1: Parcelas e margens porcentuais de comercialização de carne bovina. Dados mensais de março de 1986 a dezembro de 1993, em \%.

\begin{tabular}{|c|c|c|c|c|c|c|}
\hline & \multicolumn{3}{|c|}{ Parcelas de Comercialização } & \multicolumn{3}{|c|}{ Margens de Comercialização } \\
\hline Ano e mês & total & varejo & atacado & total & varejo & atacado \\
\hline 1986/Mar. & 43,97 & 32,49 & 11,48 & 50,77 & 32,49 & 18,28 \\
\hline Abr. & 42,95 & 32,75 & 10,20 & 49,18 & 32,75 & 16,42 \\
\hline Maio & 41,36 & 35,00 & 6,36 & 48,47 & 35,00 & 13,47 \\
\hline Jun. & 37,14 & 30,67 & 6,47 & 46,27 & 30,67 & 15,60 \\
\hline Jul. & 31,72 & 11,54 & 20,18 & 41,53 & 11,54 & 29,99 \\
\hline Ago. & 24,71 & 13,19 & 11,52 & 36,56 & 13,19 & 23,37 \\
\hline Set. & 21,43 & 14,46 & 6,97 & 30,51 & 14,46 & 16,05 \\
\hline Out. & 36,86 & 23,08 & 13,77 & 48,75 & 23,08 & 25,66 \\
\hline Nov. & 28,74 & 26,57 & 2,18 & 41,51 & 26,57 & 14,94 \\
\hline Dez. & 33,87 & 31,09 & 2,78 & 42,57 & 31,09 & 11,48 \\
\hline 1987/Jan. & 43,92 & 39,83 & 4,09 & 51,33 & 39,83 & 11,51 \\
\hline Fev. & 46,89 & 38,32 & 8,57 & 53,89 & 38,32 & 15,57 \\
\hline Mar. & 45,13 & 36,60 & 8,53 & 51,04 & 36,60 & 14,44 \\
\hline Abr. & 47,80 & 37,67 & 10,13 & 52,97 & 37,67 & 15,30 \\
\hline Maio & 47,44 & 35,06 & 12,38 & 52,59 & 35,06 & 17,53 \\
\hline Jun. & 46,36 & 34,62 & 11,74 & 52,01 & 34,62 & 17,38 \\
\hline Jul. & 44,84 & 33,62 & 11,22 & 50,13 & 33,62 & 16,50 \\
\hline Ago. & 40,64 & 31,06 & 9,57 & 46,60 & 31,06 & 15,53 \\
\hline Set. & 38,38 & 30,88 & 7.50 & 45,33 & 30,88 & 14,44 \\
\hline Out. & 41,65 & 31,67 & 9,98 & 47,61 & 31,67 & 15,94 \\
\hline Nov. & 40,46 & 32,53 & 7,93 & 46,46 & 32,53 & 13,93 \\
\hline Dez. & 46,81 & 35,85 & 10,97 & 52,64 & 35,85 & 16,80 \\
\hline 1988/Jan. & 48,05 & 37,40 & 10,65 & 54,11 & 37,40 & 16,71 \\
\hline Fev. & 48,06 & 37,27 & 10,79 & 54,88 & 37,27 & 17,61 \\
\hline Mar. & 43,52 & 32,35 & 11,17 & 51,66 & 32,35 & 19,30 \\
\hline Abr. & 42,42 & 32,94 & 9,48 & 51,82 & 32,94 & 18,88 \\
\hline Maio & 44,55 & 37,52 & 7,03 & 53,71 & 37,52 & 16,19 \\
\hline Jun. & 40,30 & 36,00 & 4,30 & 50,16 & 36,00 & 14,17 \\
\hline Jul. & 37,18 & 31,72 & 5,46 & 48,29 & 31,72 & 16,58 \\
\hline Ago. & 41,37 & 33,96 & 7,42 & 50,87 & 33,96 & 16,91 \\
\hline Set. & 41,94 & 33,48 & 8,46 & 50,71 & 33,48 & 17,23 \\
\hline Out. & 38,00 & 34,20 & 3,80 & 48,31 & 34,20 & 14,11 \\
\hline Nov. & 35,83 & 33,11 & 2,72 & 46,02 & 33,11 & 12,91 \\
\hline Dez. & 39.70 & 33,76 & 5,93 & 48,40 & 33,76 & 14,64 \\
\hline 1989/Jan. & 39,83 & 34,90 & 4,93 & 48,91 & 34,90 & 14,01 \\
\hline Fev. & 37,18 & 31,34 & 5,84 & 46,52 & 31,34 & 15,17 \\
\hline Mar. & 33,23 & 28,82 & 4,42 & 42,63 & 28,82 & 13,81 \\
\hline Abr. & 30,44 & 25,20 & 5,23 & 42,07 & 25,20 & 16,86 \\
\hline Maio & 40,09 & 42,68 & $-2,59$ & 50,50 & 42,68 & 7.82 \\
\hline Jun. & 38,60 & 39,42 & $-0,82$ & 51,08 & 39,42 & 11,67 \\
\hline Jul. & 40,97 & 33,65 & 7,31 & 52,36 & 33,65 & 18,71 \\
\hline
\end{tabular}


Tabela B.1: Parcelas e margens porcentuais de comercialização de carne bovina. Dados mensais de março de 1986 a dezembro de 1993, em \%.

\begin{tabular}{|c|c|c|c|c|c|c|}
\hline & \multicolumn{3}{|c|}{ Parcelas de Comercialização } & \multicolumn{3}{|c|}{ Margens de Comercialização } \\
\hline Ano e mês & total & varejo & atacado & total & varejo & atacado \\
\hline Ago. & 38,71 & 36,40 & 2,31 & 48,49 & 36,40 & 12,09 \\
\hline Set. & 41,89 & 36,56 & 5,33 & 50,60 & 36,56 & 14,04 \\
\hline Out. & 42,66 & 35,88 & 6,78 & 50,80 & 35,88 & 14,92 \\
\hline Nov. & 46,36 & 37,18 & 9,17 & 52,32 & 37,18 & 15,13 \\
\hline Dez. & 43,62 & 32,45 & 11,18 & 48,69 & 32,45 & 16,24 \\
\hline 1990/Jan. & 49,00 & 39,88 & 9,12 & 53,81 & 39,88 & 13,93 \\
\hline Fev. & 43,39 & 37,62 & 5,77 & 51,61 & 37,62 & 13,99 \\
\hline Mar. & 60,69 & 34,89 & 25,80 & 66,03 & 34,89 & 31,14 \\
\hline Abr. & 56,45 & 39,09 & 17,36 & 60,52 & 39,09 & 21,43 \\
\hline Maio & 50,25 & 35,85 & 14,40 & 56,98 & 35,85 & 21,12 \\
\hline Jun. & 42,03 & 36.74 & 5,29 & 51,20 & 36,74 & 14,47 \\
\hline Jul. & 46,13 & 33,89 & 12,24 & 53,68 & 33,89 & 19,79 \\
\hline Ago. & 42,21 & 32,19 & 10,01 & 49,63 & 32,19 & 17,43 \\
\hline Set. & 46,54 & 35,62 & 10,92 & 52,37 & 35,62 & 16,75 \\
\hline Out. & 49,02 & 36,94 & 12,08 & 54,55 & 36,94 & 17,60 \\
\hline Nov. & 50,03 & 35,43 & 14,60 & 55,04 & 35,43 & 19,61 \\
\hline Dez. & 52,13 & 36,81 & 15,32 & 56,48 & 36,81 & 19,67 \\
\hline 1991/Jan. & 50,87 & 37,26 & 13,61 & 55,08 & 37,26 & 17,82 \\
\hline Fev. & 43,08 & 30,31 & 12,77 & 48,37 & 30,31 & 18,05 \\
\hline Mar. & 43,03 & 32,06 & 10,97 & 49,22 & 32,06 & 17,16 \\
\hline Abr. & 41,17 & 30,12 & 11,04 & 48,25 & 30,12 & 18,13 \\
\hline Maio & 39,98 & 31,26 & 8,72 & 47,77 & 31,26 & 16,51 \\
\hline Jun. & 39,77 & 28,80 & 10,97 & 46,95 & 28,80 & 18,15 \\
\hline Jul. & 44,01 & 32,75 & 11,27 & 50,77 & 32,75 & 18,02 \\
\hline Ago. & 43,15 & 33,61 & 9,54 & 49,77 & 33,61 & 16,16 \\
\hline Set. & 46,88 & 37,67 & 9,22 & 52,77 & 37,67 & 15,10 \\
\hline Out. & 45,67 & 38,79 & 6,88 & 51,06 & 38,79 & 12,27 \\
\hline Nov. & 47,62 & 39,11 & 8,51 & 52,64 & 39,11 & 13,53 \\
\hline Dez. & 51,03 & 39,13 & 11,90 & 55,67 & 39,13 & 16,54 \\
\hline 1992/Jan. & 49,93 & 35,45 & 14,48 & 54,57 & 35,45 & 19,12 \\
\hline Fev. & 44,99 & 33,29 & 11,70 & 51,74 & 33,29 & 18,45 \\
\hline Mar. & 44,80 & 36,61 & 8,19 & 52,86 & 36,61 & 16,25 \\
\hline Abr. & 42,34 & 35,59 & 6.76 & 50,96 & 35,59 & 15,37 \\
\hline Maio & 42,55 & 37.73 & 4,82 & 51,51 & 37,73 & 13,78 \\
\hline Jun. & 43,15 & 39,25 & 3,90 & 52,10 & 39,25 & 12,85 \\
\hline Jul. & 43,03 & 39,61 & 3,42 & 52,03 & 39,61 & 12,42 \\
\hline Ago. & 45,19 & 37.25 & 7,94 & 52,81 & 37,25 & 15,56 \\
\hline Set. & 40,24 & 34,53 & 5,71 & 47,97 & 34,53 & 13,45 \\
\hline Out. & 43,77 & 39,56 & 4,21 & 51,19 & 39,56 & 11,63 \\
\hline Nov. & 44,14 & 39,42 & 4,73 & 52,35 & 39,42 & 12,94 \\
\hline Dez. & 38,80 & 39,76 & $-0,96$ & 46,76 & 39,76 & 7,00 \\
\hline
\end{tabular}


Tabela B.1: Parcelas e margens porcentuais de comercialização de carne bovina. Dados mensais de março de 1986 a dezembro de 1993, em \%.

\begin{tabular}{c|c|c|c|c|c|c}
\hline & \multicolumn{3}{|c|}{ Parcelas de Comercialização } & \multicolumn{3}{c}{ Margens de Comercialização } \\
\hline Ano e mês & total & varejo & atacado & total & varejo & atacado \\
\hline 1993/Jan. & 42,20 & 38,08 & 4,11 & 49,32 & 38,08 & 11,24 \\
Fev. & 38,18 & 34,24 & 3,95 & 46,96 & 34,24 & 12,72 \\
Mar. & 38,87 & 38,71 & 0,16 & 49,48 & 38,71 & 10,77 \\
Abr. & 38,37 & 41,31 & $-2,94$ & 50,00 & 41,31 & 8,70 \\
Maio & 39,14 & 39,98 & $-0,84$ & 50,57 & 39,98 & 10,59 \\
Jun. & 37,21 & 32,33 & 4,88 & 48,32 & 32,33 & 15,99 \\
Jul. & 38,04 & 35,46 & 2,57 & 47,69 & 35,46 & 12,23 \\
Ago. & 34,40 & 31,85 & 2,56 & 43,19 & 31,85 & 11,35 \\
Set. & 36,96 & 34,39 & 2,57 & 45,60 & 34,39 & 11,21 \\
Out. & 39,82 & 35,84 & 3,99 & 48,07 & 35,84 & 12,23 \\
Nov. & 40,74 & 39,41 & 1,33 & 49,50 & 39,41 & 10,09 \\
Dez. & 39,21 & 37,93 & 1,29 & 47,01 & 37,93 & 9,08 \\
\hline
\end{tabular}

FONTE: CANTO (1986), IEA e INTERCARNES; elaboração do autor. 